Prepared for the U.S. Department of Energy

under Contract DE-AC05-76RL01830

\title{
Strong-Sludge Gas Retention and Release Mechanisms in Clay Simulants
}

PA Gauglitz

WC Buchmiller

SG Probert

AT Owen

FJ Brockman

February 2012

\section{Pacific Northwest}

NATIONAL LABORATORY

Proudly Operated by Battelle Since 1965 


\title{
DISCLAIMER
}

This report was prepared as an account of work sponsored by an agency of the United States Government. Neither the United States Government nor any agency thereof, nor Battelle Memorial Institute, nor any of their employees, makes any warranty, express or implied, or assumes any legal liability or responsibility for the accuracy, completeness, or usefulness of any information, apparatus, product, or process diselosed, or represents that its use would not infringe privately owned rights. Reference herein to any specific commercial product, process, or service by trade name, trademark, manufacturer, or otherwise does not necessarily constitute or imply its endorsement, recommendation, or favoring by the United States Government or any agency thereof, or Battelle Memorial Institute. The views and opinions of authors expressed herein do not necessarily state or reflect those of the United States Government or any agency thereof.

\author{
PACIFIC NORTHWEST NATIONAL LABORATORY \\ operated by \\ BATTELLE \\ for the \\ UNITED STATES DEPARTMENT OF ENERGY \\ under Contract DE-AC05-76RL01830
}

Printed in the United States of America

Available to DOE and DOE contractors from the

Office of Scientific and Technical Information,

P.O. Box 62, Oak Ridge, TN 37831-0062;

ph: (865) 576-8401

fax: $(865) 576-5728$

email: reports@adonis.osti.gov

\author{
Available to the public from the National Technical Information Service, \\ U.S. Department of Commerce, 5285 Port Royal Rd., Springfield, VA 22161 \\ ph: (800) 553-6847 \\ fax: (703) 605-6900 \\ email: orders@ntis.fedworld.gov \\ online ordering: http://www.ntis.gov/ordering.htm
}

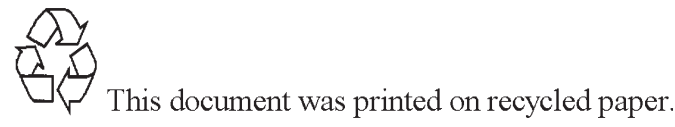

(9/2003) 


\section{Strong-Sludge Gas Retention and Release Mechanisms in Clay Simulants}

PA Gauglitz

WC Buchmiller

SG Probert

AT Owen

FJ Brockman

February 2012

Prepared for

the U.S. Department of Energy

under Contract DE-AC05-76RL01830

Pacific Northwest National Laboratory

Richland, Washington 99352 



\section{Executive Summary}

The Hanford Site has 28 double-shell tanks (DSTs) and 149 single-shell tanks (SSTs) containing radioactive wastes that are complex mixes of radioactive and chemical products. The mission of the Department of Energy's River Protection Project is to retrieve and treat the Hanford tank waste for disposal and close the tank farms. A key aspect of the mission is to retrieve and transfer waste from the SSTs, which are at greater risk for leaking, into DSTs for interim storage until the waste is transferred to and treated in the Hanford Waste Treatment and Immobilization Plant. There is, however, limited space in the existing DSTs to accept waste transfers from the SSTs, and approaches to overcoming the limited DST space will benefit the overall mission.

The current safety basis for managing the waste in the tank farms provides controls to prevent spontaneous buoyant-displacement gas release events (BDGREs) and provide for ongoing safe storage of the waste. The current mission plan for future waste transfers assumes a relaxed set of BDGRE controls for selected wastes and DSTs based on a new experimental finding that shows relatively low gas retention for sediment materials that are sufficiently strong (shear strengths greater than about $1000 \mathrm{~Pa}$ ). Based on these relaxed controls, waste from additional SSTs could be retrieved and transferred to DSTs while still avoiding the potential for BDGREs.

The purpose of this study is to summarize and analyze the key previous experiment that forms the basis for the relaxed controls and to summarize progress and results on new experiments focused on understanding the conditions that result in low gas retention. The previous large-scale test used about $50 \mathrm{~m}^{3}$ of sediment, which would be unwieldy for doing multiple parametric experiments. Accordingly, experiments began with smaller-scale tests to determine whether the desired mechanisms can be studied without the difficulty of conducting very large experiments.

The previous large-scale gas retention test was conducted in a $3.5 \mathrm{~m}$ diameter test vessel with a sediment layer about $5 \mathrm{~m}$ deep. The average retained-gas volume fraction grew over a 25 day period to a peak value of about $7 \%$ and then decreased to about $5 \%$. This is much lower than in previous small-scale tests.

A key objective for the current gas-retention tests is to conduct tests that have slower gas generation rates and are larger than the previous small-scale tests. In the current study, small-scale tests were conducted with various mixtures of kaolin clay and Min-U-Sil $30^{\circledR 1}$, which is finely ground silica with a median diameter of about 8 microns, in primarily $12.7 \mathrm{~cm}$ diameter test vessels with gas generation provided either by the decomposition of hydrogen peroxide to form oxygen bubbles or by the corrosion of iron to form hydrogen bubbles. The gas generation rates varied and resulted in gas retention that peaked after about 1 to 10 days. The volumes of retained gas and total generated gas were measured over time to determine the retained-gas fraction. Tests were conducted in transparent vessels to allow observations of the bubbles, and the structure of retained bubbles was also characterized in selected experiments using an $\mathrm{x}$-ray microfocus computed tomography (XMT) instrument. These tests were about five-fold larger in diameter and had gas generation rates at least 20 -fold slower than the previous small-scale tests. Tests were also conducted in the $12.7 \mathrm{~cm}$ diameter vessels with initial simulant layer depths that ranged from 0.1 to $1.50 \mathrm{~m}$. In general, for tests with $0.1 \mathrm{~m}$ initial layer depths and with gas generated from hydrogen

\footnotetext{
${ }^{1}$ Min-U-Sil 30 is a registered trademark of U.S. Silica Company.
} 
peroxide, the peak gas retention was about $20-30 \%$. A lower peak gas retention was observed when gas was generated from the iron particles than when it was generated from hydrogen peroxide. The retained bubbles were visibly different between the two methods of gas generation, but experiments to determine the mechanisms that gave different bubble shapes and thus different retention were not conducted. One larger test was conducted with kaolin clay in a $58.4 \mathrm{~cm}$ diameter vessel with gas generated by the corrosion of iron particles.

The most significant results from the current experiments are that progressively lower gas retention occurs in tests with progressively deeper sediment layers and that the method of gas generation also affects the maximum retention. Based on the results of this study, it is plausible that relatively low gas retention could occur in sufficiently deep tank waste in DSTs. The current studies and previous work, however, have not explored how gas retention and release will behave when two or more layers with different properties are present.

The other main conclusion from this study is that there was no apparent role of vessel diameter on bubble retention for the $12.7 \mathrm{~cm}$ and $58.4 \mathrm{~cm}$ diameter vessels used in this study. For tests with layers only $0.1 \mathrm{~m}$ deep, there was no apparent role of simulant strength on the peak retention for strengths between 260 and $1800 \mathrm{~Pa}$. Tests investigating the effect of strength with deeper layers were not conducted.

Current and previous studies have focused on the gas retention behavior in single layers that have relatively uniform properties. The gas retention behavior when multiple layers are present that have different strengths and/or different gas generation rates may be quite different. The overall understanding of the mechanisms resulting in low gas retention would be improved if test results were obtained for representative scenarios of layered systems. Current and previous experimental studies have also not quantified how accurately gas retention behavior can be determined from measurements when the system pressure is changed through changes in the hydrostatic pressure of an overlying liquid layer. In addition to the general confirmation of expected gas expansion and compression, the gas retention behavior of layered systems may be affected by the interaction of adjacent layers, resulting in uncertainty in interpreting the gas retention behavior. Again, the overall understanding of low gas retention behavior would be improved with testing that demonstrates the behavior of single and multiple gas-retaining layers with changes in hydrostatic pressure. 


\section{Acknowledgments}

The authors would like to acknowledge Joe Meacham of Washington River Projection Solutions for providing English translations of a number of the original Dutch-language reports on the large-scale gas retention test with lake-bottom sludge from Ketelmeer, for showing us where to find the original data in the daily logs for this experiment, and for a range of technical discussions associated with the topic of gas retention in strong-sludge materials. The authors also would like to thank Beric Wells and Nick Kirch for helpful technical discussions related to this study, Lenna Mahoney for help on correlating the kaolin/ Min-U-Sil 30 shear strength data and for a thoughtful review of a preliminary version of this report, Mart Oostrom for his help in translating a technical report from Dutch, Mike Truex for suggesting the use of colloidal iron particles for generating gas bubbles, Jim Fort and Dave Pfund for a careful review of this final report, and Maura Zimmerschied for her technical editing contributions. 



\section{Acronyms and Abbreviations}

\begin{tabular}{ll} 
BDGRE & buoyant displacement gas-release event \\
$\mathrm{cm}$ & centimeters \\
$\mathrm{CT}$ & computed tomography \\
$\mathrm{D}$ & dimensional \\
DI & deionized \\
DST & double-shell tank \\
EPK & Edgar plastic kaolin, from Edgar Minerals division of The Feldspar Corporation \\
$\mathrm{g}$ & grams \\
ID & inside diameter \\
in & inch \\
$\mathrm{kV}$ & kilovolt \\
LUM & unit of measure for luminosity \\
$\mathrm{m}$ & meter \\
$\mathrm{mA}$ & milliampere \\
min & minutes \\
mm & millimeter \\
OD & outside diameter \\
Pa & Pascal \\
SST & single-shell tank \\
XMT & x-ray microfocus computed tomography \\
& \\
\hline &
\end{tabular}





\section{Contents}

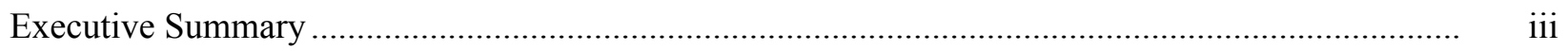

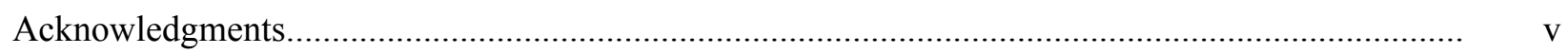

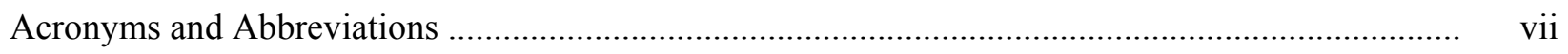

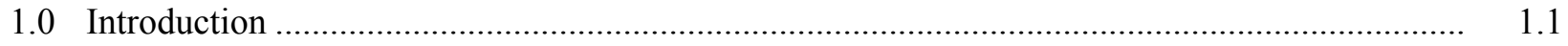

1.1 Previous Large-Scale Studies of Bubble Retention in Strong Sediment............................ 1.2

1.2 Previous Small-Scale Studies of Bubble Retention ...................................................... 1.6

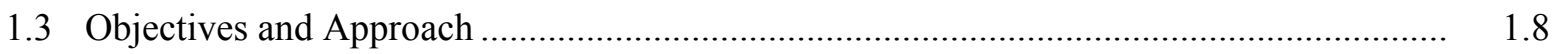

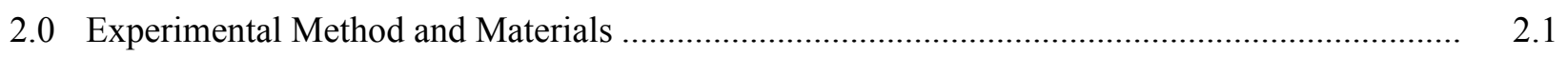

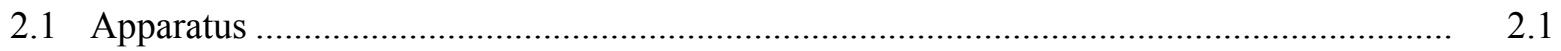

2.2 Simulants and Gas Generation Methods ..................................................................... 2.4

2.2.1 Test Methods for Bubble Growth................................................................ 2.10

2.3 X-Ray Microfocus Computed Tomography.............................................................. 2.12

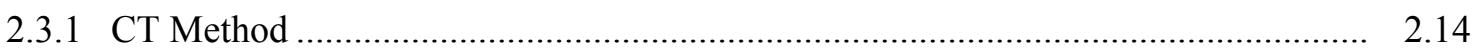

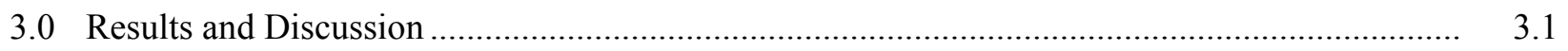

3.1 Role of Gas Generation Rate and Method on Gas Retention........................................... 3.1

3.2 Effect of Simulant Strength on Gas Retention ............................................................. 3.4

3.3 Effect of Initial Depth of Simulant Layer and Vessel Diameter ..................................... 3.8

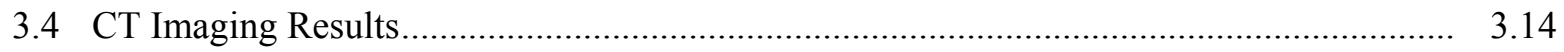

4.0 Alternate Scenarios and Potential Behavior .................................................................... 4.1

5.0 Conclusions and Recommendations for Future Work ..................................................... 5.1

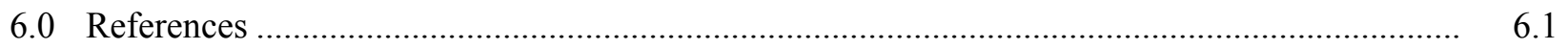

Appendix - Approach for Slow Biological Gas Production ........................................................ A.1 


\section{Figures}

1.1 Schematic of the Large-Column Gas Retention Test using Ketelmeer Sludge with the Water Removal System.

1.2 Retained Gas Volume and Ketelmeer Sediment Volume from the Data in Cornelisse (1997)...

1.3 Cumulative Released Gas and Retained Gas from the Data in Cornelisse (1997)

1.4 Gas Void Fraction in the Ketelmeer Sediment from the Data in Cornelisse (1997) ................. 1.6

1.5 Particle-Displacing Bubble and a Bubble that Fingers between Particles .............................. 1.7

1.6 Retained Bubbles in Bentonite Clay Simulants with a Range of Shear Strengths .................... 1.7

1.7 Previous Results for the Maximum Gas Fraction in Simulant and Actual SST Waste.............. 1.8

2.148 in. and 12 in. Acrylic Test Vessels and Schematic of a 12 in. Vessel................................. 2.2

2.2 Schematic of Apparatus for Measuring Volume of Displaced Gas ........................................... 2.2

2.3 "Head" Plate Position in 12 in. Vessel .................................................................................. 2.3

2.4 "Head" Plate Construction ............................................................................................... 2.4

2.5 Schematic of 12 in. Thin-Gap Test Vessel........................................................................ 2.5

2.6 Assembled 12 in. Thin-Gap Test Vessel with Kaolin Clay .................................................... 2.6

2.7 Schematic of 48 in. Thin-Gap Test Vessel ....................................................................... 2.7

2.8 Assembled 48 in. Thin-Gap Test Vessel ....................................................................... 2.8

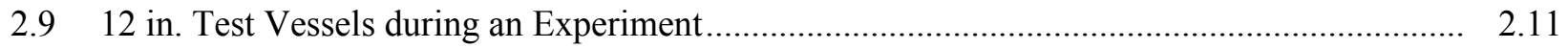

2.1048 in. Test Vessel during an Experiment ............................................................................ 2.12

2.11 X-Ray Micro-Focus Tomography System ................................................................. 2.13

3.1 Gas Volume Generated for a Range of Hydrogen Peroxide Concentrations in $55 \mathrm{wt} \%$

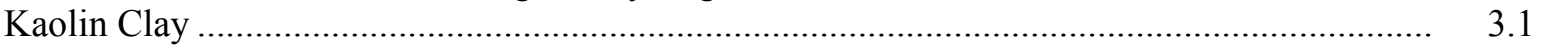

3.2 Growth in Gas Void Fraction for a Range of Hydrogen Peroxide Concentrations in $55 \mathrm{wt} \%$ Kaolin Clay

3.3 Growth in Gas Void Fraction as a Function of Gas Volume Collected for a Range of Hydrogen Peroxide Concentrations in $55 \mathrm{wt} \%$ Kaolin

3.4 Gas Volume Generated for a Range of Iron Concentrations in $55 \mathrm{wt} \%$ Kaolin Clay and a Comparison to Gas Generated from $0.41 \mathrm{wt} \%$ Hydrogen Peroxide

3.5 Growth in Gas Void Fraction as a Function of Gas Volume Collected for a Range of Iron Concentrations in $55 \mathrm{wt} \%$ Kaolin and a Comparison to Gas Retention from $0.41 \mathrm{wt} \%$ Hydrogen Peroxide.

3.6 Gas Volume Generated for Simulants with a Range of Kaolin Concentrations with Shear Strength Ranging from about 15 to $1800 \mathrm{~Pa}$.

3.7 Growth in Gas Void Fraction as a Function of Gas Volume Generated using Hydrogen Peroxide for a Range of Simulant Strengths

3.8 Gas Volume Generated for Mixtures of Kaolin and Min-U-Sil 30 that Span a ShearStrength Range of 31 to $1300 \mathrm{~Pa}$.

3.9 Growth in Gas Void Fraction as a Function of Gas Volume Generated for Kaolin and Min-U-Sil 30 Mixtures having Shear Strengths Ranging from 31 to $1300 \mathrm{~Pa}$ 
3.10 Effect of Initial Clay-Layer Depth on Gas Void Fraction in Tests using $55 \mathrm{wt} \%$ Kaolin Simulants with $0.41 \mathrm{wt} \%$ Hydrogen Peroxide for Gas Generation.

3.11 Effect of Initial Layer Depth on Gas Void Fraction using $55 \mathrm{wt} \%$ Kaolin Simulants with $0.25 \mathrm{wt} \%$ Iron for Gas Generation

3.12 Comparison of Gas Retention in Vessels of Different Diameters and with Gas Generated by Hydrogen Peroxide or Iron Particles.

3.13 Images of Bubbles from Tests with $80 \mathrm{~cm}$ Initial Kaolin Layers using Hydrogen Peroxide and Iron Particles for Gas Generation.

3.14 Measured Gas Void Fraction as a Function of Elevation at the Conclusion of the $80 \mathrm{~cm}$ Depth Test with $55 \mathrm{wt} \%$ Kaolin Clay. The line shows a linear best fit of the data.

3.15 Gas Retention and One of the Gas Release Pathways in the Large-Scale Test with Iron Particles for Gas Generation in $55 \mathrm{wt} \%$ Kaolin Clay Starting at an Initial Depth of $80 \mathrm{~cm}$

3.16 Extrapolation to Larger Scale of Maximum Gas Void Fraction Results from Column Tests ....

3.17 Bubbles Retained in the Thin-Gap Apparatus for Different Strength Kaolin Slurries.

3.18 Cross-sections of the Weaker $45 \mathrm{wt} \%$ Kaolin and the Stronger $55 \mathrm{wt} \%$ Kaolin at $\sim 0 \mathrm{hr}, 6$ $\mathrm{hr}, 24 \mathrm{hr}$, and $48 \mathrm{hr}$ after the Beginning of Bubble Growth

3.19 CT Cross-Sections at Four Elevations and a Side View for a Kaolin Simulant with a Shear Strength of about $680 \mathrm{~Pa}$

3.20 CT Cross-Sections at Four Elevations and the Side View for a Kaolin Clay Simulant with a Shear Strength of about $38 \mathrm{~Pa}$

3.21 2-D Shapes of Bubble Cross-Sections from the Top-to-Bottom and Front-to-Back of a Bubble.....

\section{Tables}

2.1 Kaolin Simulants and Estimated Shear Strength and Density ........................................... 2.8

2.2 Kaolin/Min-U-Sil 30 Simulants and Estimated Shear Strength and Density .......................... 2.9

2.3 Parameters used during XMT Characterization ................................................................. 2.14 



\subsection{Introduction}

The Hanford Site has 28 double-shell tanks (DSTs) and 149 single-shell tanks (SSTs) containing radioactive wastes that are complex mixes of radioactive and chemical products. The U.S. Department of Energy Office of River Projection manages the River Protection Project, which has the mission to retrieve and treat the Hanford tank waste for disposal and close the tank farms. A key aspect of the mission is to retrieve and transfer waste from the SSTs, which are more leak-prone, into DSTs for interim storage until the waste is transferred to and treated in the Hanford Waste Treatment and Immobilization Plant (Certa et al. 2011). There is, however, limited space in the existing DSTs to accept waste transfers from the SSTs; approaches to overcoming the limited DST space will benefit the overall mission.

The current safety basis for managing the waste in the tank farms provides criteria and limits to provide ongoing safe storage of the waste. The potential for hydrogen gas retention and release in DSTs creates a safety hazard that must be managed. For underground storage tanks at Hanford, the safety basis for the tanks mitigates the potential for exceeding the lower flammability limit in tank headspace by grouping the tanks by their retained-gas and headspace volume and their propensity to have spontaneous buoyant displacement gas release events (BDGREs) (Weber 2009). To prevent BDGREs, this approach restricts the depth (or volume) of settled waste solids or sediment that may be stored in each tank as well as the ratio of the densities of the supernatant liquid and sediment, which limits the ability to reduce waste volume by evaporating and concentrating the supernatant. The current plan for completing the mission (Certa and Wells 2009) assumes a relaxed set of BDGRE controls for selected wastes and DSTs based on a new experimental finding that shows relatively low gas retention for certain sediment properties. Based on these relaxed controls, waste from additional SSTs can be retrieved and transferred to DSTs while still avoiding BDGREs. Meacham (2010) discusses this new approach and the new experimental evidence of relatively low gas retention.

The new experimental finding of low gas retention, and a description and model of the mechanisms involved, was recently reported for a large-scale experiment of gas retention with lake-bottom sediment from Ketelmeer in the Netherlands (Van Kessel and Van Kesteren 2002; Winterwerp and Van Kesteren 2004). In the large-scale experiment, which is discussed in more detail below in Section 1.1, the retained-gas volume fraction peaked at about $7 \%$ and then decreased to about $5 \%$. This large-scale test was conducted in a $3.5 \mathrm{~m}$ diameter vessel with about $50 \mathrm{~m}^{3}$ of sediment. The retained-gas volume fraction measured in this experiment was substantially lower than what had been observed previously in small-scale laboratory experiments, typically one-inch-diameter vessels, where gas retention peaked at about $40 \%$ gas in many samples; the small-scale results are reviewed in more detail in Section 1.2 below.

The new finding of low retention and the mechanisms leading to it have been summarized by Van Kessel and Van Kesteren (2002) and Winterwerp and Van Kesteren (2004) and they cite a number of studies with additional details. A key aspect of the new mechanism is that as bubbles grow via gas generation, they form continuous channels to the top of the sediment. The channels become partially filled with the overlying liquid and remain open rather than being filled entirely with the gas that initially created the channel. Winterwerp and Van Kesteren (2004) commented that laboratory experiments need to be large, on the order of meters, for these gas release channels to be present. Van Kessel and Van Kesteren (2002) have developed a model for these channels and have noted that the sediment strength needs to be high enough to keep these channels open to allow gas transport. Because this 
mechanism is associated with stronger sediments (of order $1000 \mathrm{~Pa}$ shear strength), this mechanism will be generally referred to as a strong-sludge mechanism.

While the large-scale test was carefully monitored and reported, it is a single test. In particular, systematic experiments have not been conducted to define when channel formation does and does not occur as a function of sediment parameters (such as shear strength and other mechanical properties) and whether low gas retention will always occur for a specific range of parameters. Accordingly, a need exists to obtain experimental results that quantify the range of key parameters for when low gas retention occurs.

If the newly identified mechanism occurs in DSTs with sufficiently strong settled waste, the maximum gas fraction may be low enough to make BDGREs physically impossible. Determining conditions in which BDGREs do not occur will greatly benefit the management of the waste inventory in the DSTs by removing or reducing current restrictions, allowing an increase in the sludge storage capacity and supernatant density in DSTs, which will allow partially filled DSTs to be filled until they are essentially completely full. It is anticipated that SST retrieval will be delayed by a lack of DST capacity in approximately 2018 (Certa et al. 2011) unless the current restrictions on waste volume and supernatant density are relaxed. Tank farm planners estimate that, by implementing relaxed constraints based on the strong-sludge bubble retention and release mechanism, they will be able to use 2 million gallons of previously unusable tank space, and potentially as much as 3 million gallons. It is difficult to estimate the cost and schedule savings, but the ability to store an extra 1 million gallons of waste would avoid the need to build one new DST at a cost of roughly $\$ 88 \mathrm{M}$ per DST in a farm of four DSTs (Willis and Ahrendt 2009).

The purpose of this report is to summarize and analyze the key previous work that forms the basis of the technical approach for understanding low gas retention in strong sludge and to conduct and summarize new experiments focused on understanding the mechanisms of low gas retention. The previous large-scale test used about $50 \mathrm{~m}^{3}$ of sediment, which would be unwieldy for doing multiple parametric experiments. Accordingly, experiments will begin with smaller-scale tests to determine whether the desired mechanisms can be studied without the difficulty of conducting very large experiments. In the following subsections, we analyze data from the previous large-scale tests and compare these results with previous small-scale laboratory studies, and then summarize the specific approach being taken for quantifying when low gas retention occurs. Section 2 discusses the experimental method and materials, followed by a discussion of the results in Section 3. Section 4 gives a brief discussion of potential scenarios that may have different gas retention behavior but were not studied, and conclusions and recommendations for further work are provided in Section 5.

\subsection{Previous Large-Scale Studies of Bubble Retention in Strong Sediment}

As mentioned in the previous section, Van Kessel and Van Kesteren (2002) have summarized the results of a single large-scale test of bubble retention in lake-bottom sediment taken from Ketelmeer in the Netherlands. They also provide references to a series of technical summaries associated with various aspects of this test and data evaluation. The report by Cornelisse (1997) provides a daily log of the test data for the experiment, which was conducted over a period of about 100 days. Figure 1.1 shows a simplified schematic of the experiment described by Cornelisse (1997). Lake-bottom sludge from 
Ketelmeer was loaded into a $3.5 \mathrm{~m}$ diameter vessel to an approximate depth of $5 \mathrm{~m}$. Bacterial decomposition of organic material in the sludge generated gas, with methane being the primary insoluble component (Van Kessel and Van Kesteren 2002). Some of the gas was retained in bubbles, which displaced the sediment and water, and some of the gas was released. A layer of water above the sludge was kept at a nearly constant level of $6.75 \mathrm{~m}$ from the bottom of the tank by removing or adding water from a water measurement tank. The weight of the water removed or added to the test vessel was measured with a force meter on the water measurement tank. The quantity of displaced water can be used to determine the volume of gas retained in the sediment.

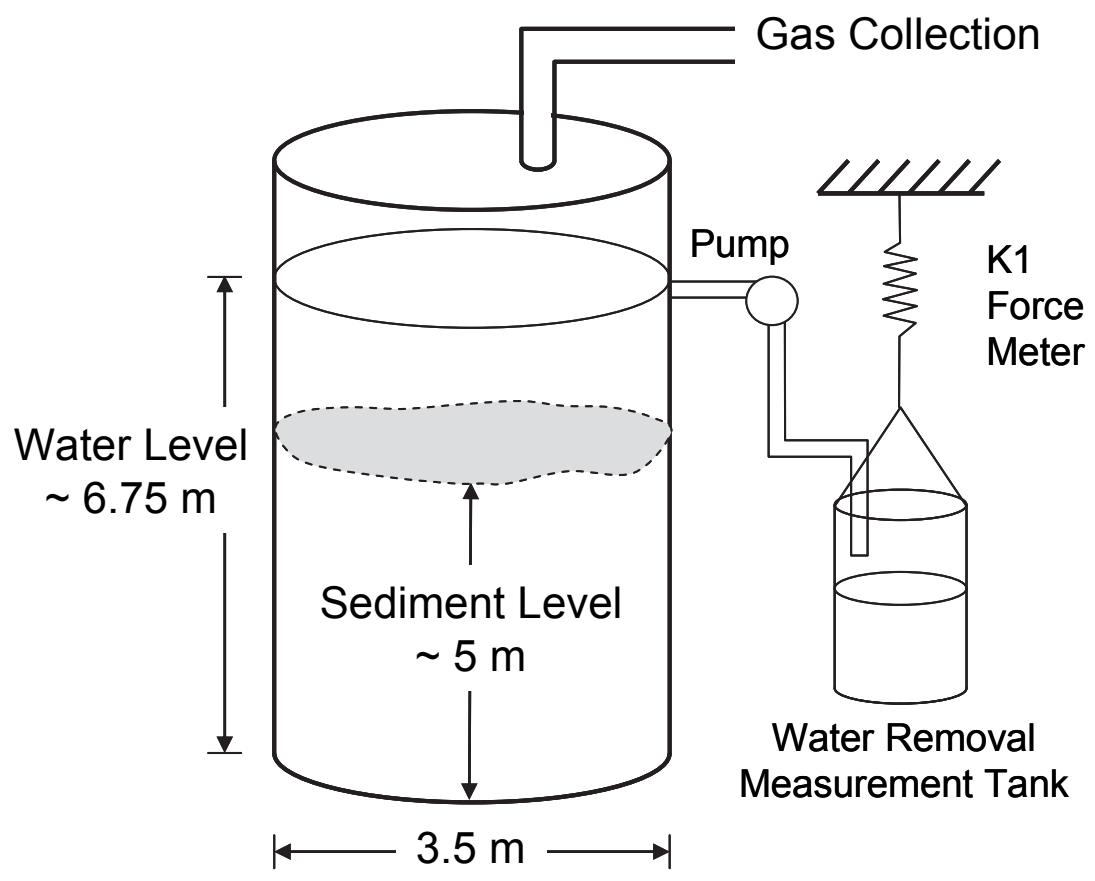

Figure 1.1. Schematic of the Large-Column Gas Retention Test using Ketelmeer Sludge with the Water Removal System (Cornelisse 1997; Van Kessel and Van Kesteren 2002)

Van Kessel and Van Kesteren (2002) noted that the final retained average gas fraction in this experiment was about $5 \%$ and the peak average gas volume fraction was about $8 \%$. They also show gas fraction as a function of time, though not the average values discussed here (see Figure 1 of Van Kessel and Van Kesteren 2002). The average gas volume fraction in the sediment (the total retained gas volume divided by the total sediment volume) as a function of time is a test result specifically important for gas retention in DSTs. The data in the daily logs given in Cornelisse (1997) are sufficient to calculate the average retained gas volume fraction during the experiment; these data are discussed below. ${ }^{1}$

The sediment used in the large-scale test came from Ketelmeer, The Netherlands. Van Kessel (1998) gives pore size distributions from a mercury intrusion method (Winterwerp and Van Kesteren 2004) for two samples of Ketelmeer sediment, though the samples were not taken from the specific material used in the large-scale test. For the two samples, the median pore diameter was about 2 microns. In Van Kessel (1998), bubble retention was also studied in a kaolin slurry; for comparison, the median pore diameter for

\footnotetext{
${ }^{1}$ JE Meacham of Washington River Protection Solutions has previously used the data in the daily logs to calculate the average gas void fraction, and showed us where to locate the original data in Cornelisse (1997).
} 
the kaolin slurry was slightly smaller at about 1 micron. Typically, the pore-entry diameters from a mercury intrusion measurement are on the order of about half the grain diameter for an unconsolidated material (Dullien 1992). For the large-scale test, Verhoeven (1998) measured in-situ shear strength using a vane at a number of elevations from the top to the bottom of the sediment in the test vessel. The shear strength ranged from $1000 \mathrm{~Pa}$ near the top of the sediment to $8600 \mathrm{~Pa}$ near the bottom, with an average value of $3600 \mathrm{~Pa}$ for the nine measurements (see Figure 2 of Verhoeven 1998).

The daily logs given in Cornelisse (1997) provide data from the force meter on the water removal measurement tank shown in Figure 1.1, the amount of water removed from the water measurement tank when it occasionally became full, the water level and sediment level in the test vessel, and the volumetric flow of gas released into the headspace of the vessel. The water level in the test vessel varied by only a couple of centimeters throughout the test, but a centimeter of level change represents a significant volume of retained gas. The total volume of retained gas is equal to the cumulative amount of water removed to the measurement tank together with adjustments made for changes in the water level. The total volume of the sediment can be estimated from the sediment level in the daily logs by assuming the vessel is a cylinder (a schematic of the test vessel in Cornelisse (1997) shows a curved bottom, but there is no discussion of the exact shape). Cornelisse (1997) provides a plot of the force data on the water measurement tank that accounts for the occasional removal of water from the tank. Our evaluation of the daily log data was compared with the data in the graph; one apparent error in the daily log (on December $7,1996)$ was corrected to make the data from the daily log match the final figure in Cornelisse (1997). The cumulative released gas can be determined from the daily logs of the net gas flow leaving the test vessel. Note that because the water level is held essentially constant, the measured net gas leaving the test vessel is the gas that releases from the sediment. Gas that is retained by the sediment and displaces the sediment only causes water to be removed into the water measurement tank. Finally, the gas void fraction in the Ketelmeer sediment can be calculated from the ratio of the retained gas volume to the sediment volume at a given time.

Figure 1.2 shows the results of our evaluation of the Cornelisse daily log data for retained gas volume and sediment volume during the duration of the test. The retained gas volume increases with time, reaches a peak value of about $3.5 \mathrm{~m}^{3}$, and then decreases. The sediment volume begins at about $45 \mathrm{~m}^{3}$ and increases together with the increasing retained gas, but then decreases to below the initial volume. As described in Van Kessel and Van Kesteren (2002), the overall settling and compaction of the Ketelmeer sediment is occurring concurrently with the gas generation and retention and is the reason the sediment volume decreases. Figure 1.3 shows the cumulative gas released from the sediment based on data on gas flow from the gas collection system. An important aspect of these data is that a large volume of gas continued to be released from the sediment well after the peak in retained gas volume.

Figure 1.4 shows the average retained gas void fraction in the large-scale test with the Ketelmeer sediment. The average void fraction peaks at about $7 \%$ and then decreases to about $5 \%$, which are the average gas void fractions reported by Van Kessel and Van Kesteren (2002). This is strikingly low gas retention in comparison with smaller-scale tests of bubble retention reported by Van Kesteren (see Figure 11.5 of Winterwerp and Van Kesteren 2004), Van Kessel (1998), and similar studies focused on bubble retention in actual waste and simulants for Hanford waste (Gauglitz et al. 1996; Rassat et al. 1998). 


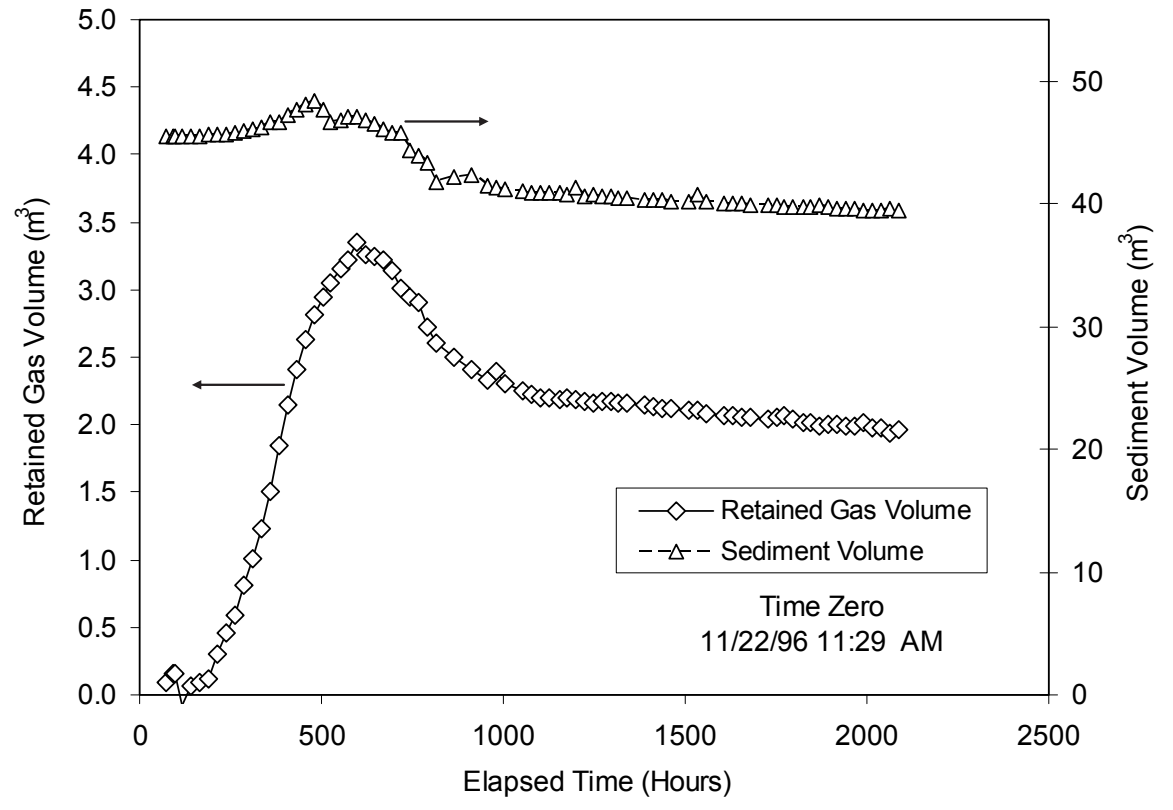

Figure 1.2. Retained Gas Volume and Ketelmeer Sediment Volume from the Data in Cornelisse (1997)

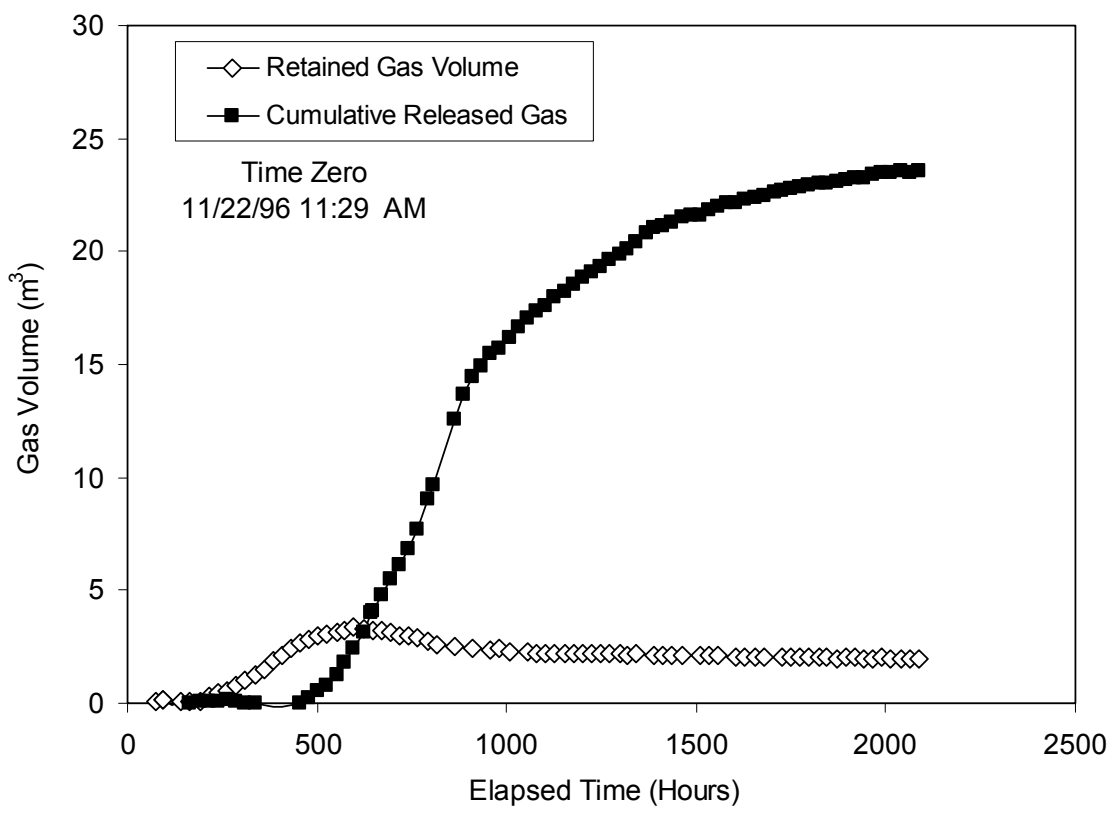

Figure 1.3. Cumulative Released Gas and Retained Gas from the Data in Cornelisse (1997) 


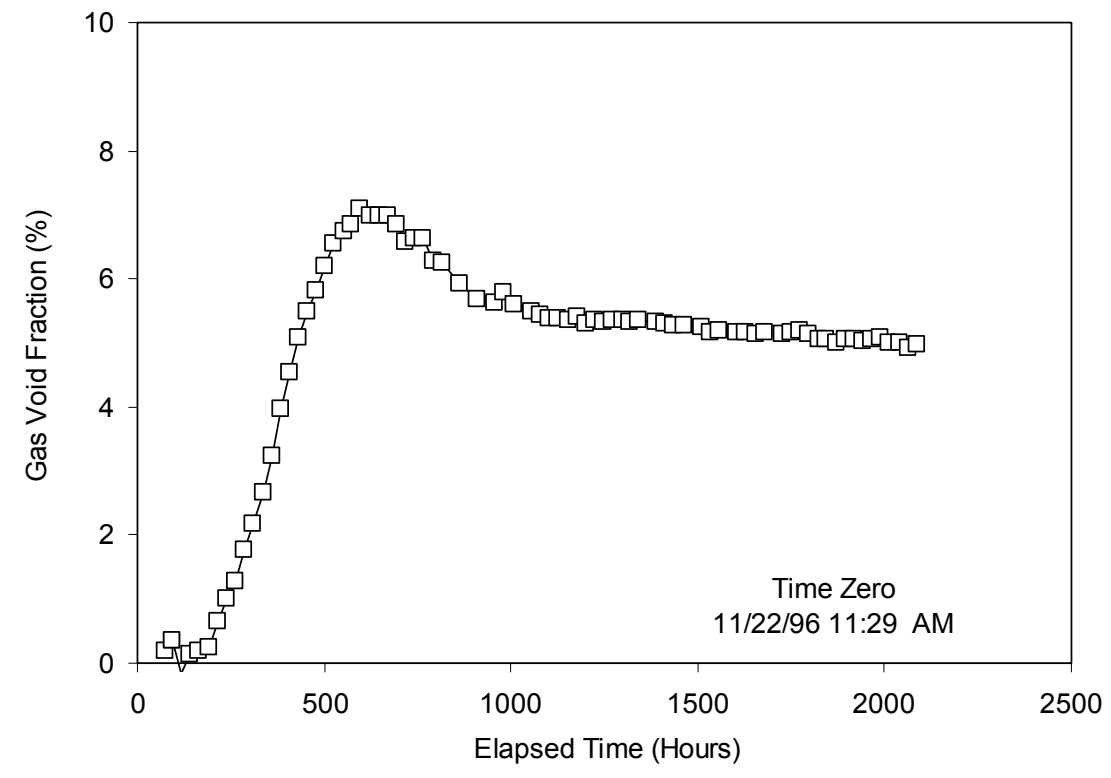

Figure 1.4. Gas Void Fraction in the Ketelmeer Sediment from the Data in Cornelisse (1997)

\subsection{Previous Small-Scale Studies of Bubble Retention}

Retention of bubbles is known to occur in a variety of materials, ranging from yield-stress fluids and pastes (Chhabra 1993) to ocean sediments (Wheeler 1990). Small-scale studies have been conducted to develop an understanding of bubble behavior in support of both the large-scale test discussed above and bubble retention in Hanford waste. While the applications are different, there are significant similarities among all of the small-scale studies.

Van Kessel (1998) and Winterwerp and Van Kesteren (2004) conducted a number of small-scale experiments in association with the large-scale test discussed above, and provide summaries of the experiments and images of retained bubbles. These small-scale studies showed either slit-shaped or round bubbles, depending on the experiment, and both these studies have examples of gas retention exceeding $50 \%$ by volume. Van Kessel and Van Kesteren (2002) and Winterwerp and Van Kesteren (2004) have discussed and modeled a number of interacting mechanisms based on their observations of their large-scale and small-scale tests. Winterwerp and Van Kesteren (2004) specifically noted that laboratory tests need to be on the order of $1 \mathrm{~m}$ in size to observe gas-induced channel formation, which is an important mechanism. With only one large-scale test, it is hard to do model validation of all the interacting mechanisms.

The small-scale studies on the mechanisms of gas retention and bubble behavior in tank waste have been the subject of a number of studies (see for example, Gauglitz et al. 1994, 1995, 1996, 2001, 2009; Stewart et al. 1996; Rassat et al. 1997, 1998, 1999; Bredt et al. 1995; Bredt and Tingey 1996; and Walker et al. 1994). Gauglitz et al. (2009) have recently summarized these studies. When the waste particles are much smaller than the bubbles, the bubbles displace the waste and are retained by the strength of the waste, which is equivalent to the description given by Winterwerp and Van Kesteren (2004) for this scenario. Figure 1.5 depicts two scenarios: in one scenario, a bubble displaces particles and is retained by the strength of the surrounding material; in the second scenario a bubble fingers between the particles. 


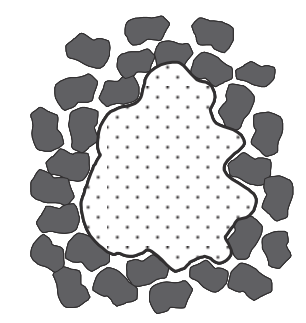

Bubble displacing particles and held by waste strength

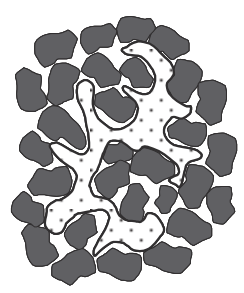

Bubble held within pores by capillary forces

Figure 1.5. Particle-Displacing Bubble and a Bubble that Fingers between Particles

Figure 1.6 shows images of bubbles retained in bentonite clay simulant with a range of strengths (Gauglitz et al. 1996) in which the bubbles have displaced the much smaller micron-size clay particles. The image of the distorted slit-shaped bubble for the $1040 \mathrm{~Pa}$ bentonite and the larger-scale image in Gauglitz et al. (1996) of this material look quite similar to the image of retained bubbles in kaolin presented in Van Kessel (1998).

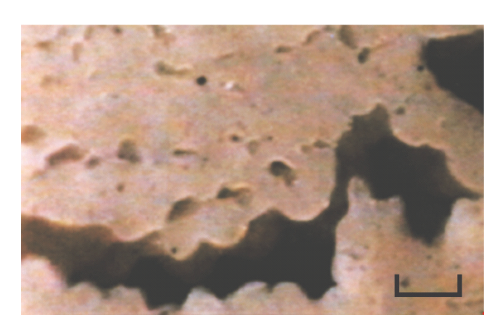

$1040 \mathrm{~Pa}$

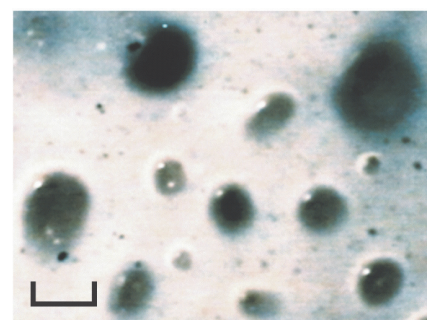

$67 \mathrm{~Pa}$

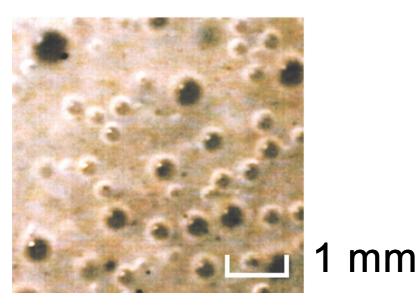

$6 \mathrm{~Pa}$

Figure 1.6. Retained Bubbles in Bentonite Clay Simulants with a Range of Shear Strengths (from Gauglitz et al. 1996; the length-scale bar is $1 \mathrm{~mm}$ in each image)

The previous small-scale studies of gas-bubble retention in Hanford waste generally used vessels of about $2.5 \mathrm{~cm}$ diameter (Gauglitz et al. 1994, 1995, 1996, 2001; Rassat et al. 1997, 1998, 1999; Bredt et al. 1995; Bredt and Tingey 1996), though a few tests were conducted in vessels with diameters up to $91 \mathrm{~cm}$ (Gauglitz et al. 1996). Typically, the depth of the material being studied was about $10-30 \mathrm{~cm}$. Although the test conditions and methods of generating gas bubbles varied, tests with clay simulant would typically be fast enough to obtain a peak value in gas retention within about an hour. Some of these tests had an overlying liquid layer, though most of the tests just used the sediment layer in the experiments. These previous tests were typically analyzed to determine the maximum, or peak, retained-gas fraction and results were compared based on the shear strength of the material. Figure 1.7 reproduces a summary of many of these tests provided by Rassat et al. (1998). In comparison with the large-scale test discussed above, the maximum gas fraction is substantially higher in small-scale tests. While gas retention decreases with increasing shear strength beyond a peak value at about $50 \mathrm{~Pa}$, the gas fraction is still about $25 \%$ for a shear strength of a few thousand $\mathrm{Pa}$, which is roughly the shear strength measured in the largescale Ketelmeer sludge test. 


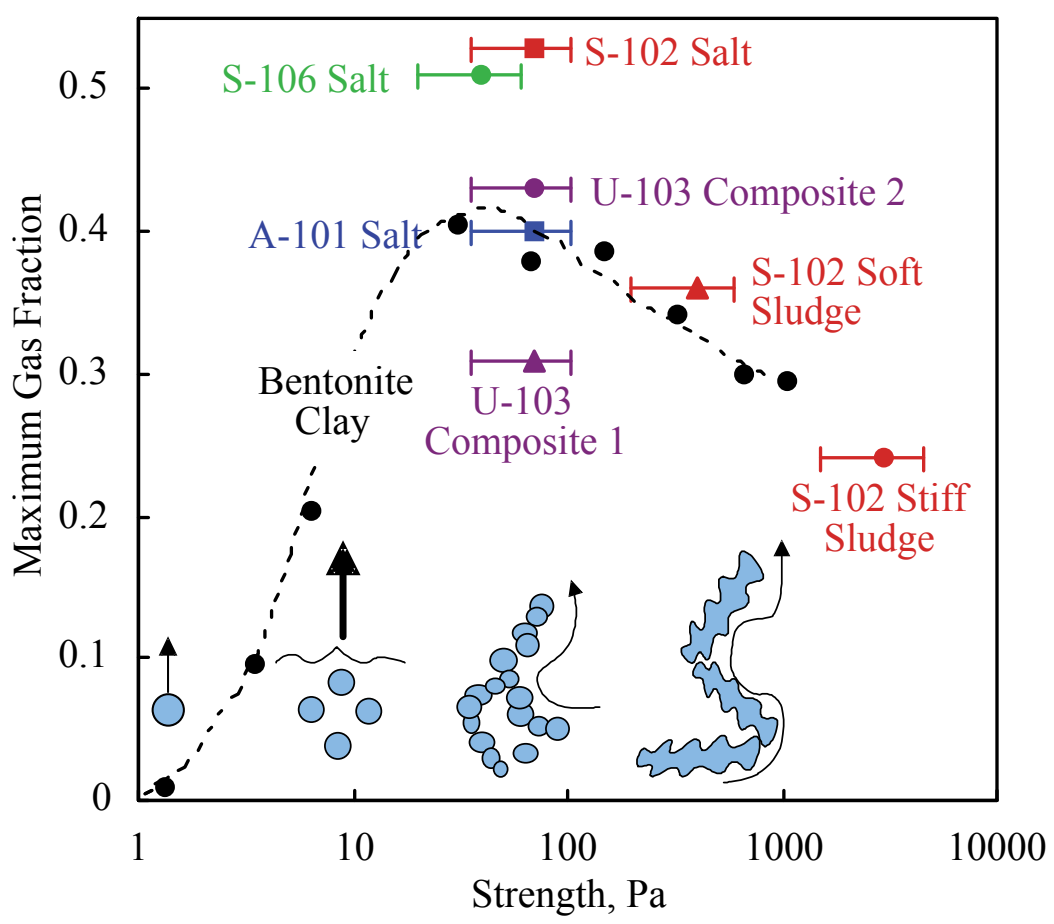

Figure 1.7. Previous Results for the Maximum Gas Fraction in Simulant and Actual SST Waste (from Figure 5.1 of Rassat et al. 1998)

Understanding the mechanisms causing the low retained-gas fraction in the large Ketelmeer sludge experiment and reproducing this behavior is the overall objective of the current study. In general, the large-scale test discussed above differs from the previous small-scale tests in six significant aspects:

- larger scale

- slower gas generation

- overlying liquid layer

- sedimentation and compaction during gas generation

- biogenic gas generation

- different sediment material.

The following section discusses the initial approach to addressing these differences and understanding the mechanisms giving low retained gas.

\subsection{Objectives and Approach}

The overall objectives of this study are to understand the mechanisms that result in low gas retention and to determine the range of experimental parameters when this behavior occurs. Previous small-scale tests differed from the large-scale Ketelmeer test in several ways, and the overall approach in this study is to conduct experiments that move closer to the parameter range for the Ketelmeer test. In particular, we will seek simulants, gas generation rates, and test geometries in which low gas retention can be observed and quantified. 
In previous small-scale tests, bubbles grew for about an hour and typically did not have an overlying liquid layer. Accordingly, initial tests in the present study focused on simulants in which gas was generated at about one-tenth the rate of previous studies and the tests included an overlying liquid layer. In the previous small-scale tests, the technique used to generate retained bubbles was the addition of a small amount of hydrogen peroxide that decomposed to give oxygen bubbles. The current testing will generate retained bubbles using either hydrogen peroxide or the addition of small quantities of micronsize iron particles that corrode over days to give hydrogen bubbles.

Previous small-scale studies also primarily measured gas retention in $2.54 \mathrm{~cm}$ (1 in.) diameter vessels with depths of about $10 \mathrm{~cm}$, so the tests in this study used larger vessels (five and 23 times that diameter) and used progressively taller columns (up to $150 \mathrm{~cm}$ ).

Tests were conducted to determine the volume of retained gas, and thus the gas void fraction, in various simulants with a range of strengths and in various size vessels. The rate of gas generation was also measured. Selected experiments also used computed tomography (CT) imaging to characterize the shapes of retained bubbles with different simulants. In all of these experiments, visual observations of the bubbles were made to determine whether gas release channels similar to what was observed in the Ketelmeer test could be observed. 



\subsection{Experimental Method and Materials}

Bubble retention and release tests were conducted using various test vessels, slurries, and reactants to generate, retain, and release gas in a manner that mimics conditions for bubble retention in Hanford DSTs. Test vessels were constructed in two basic configurations. The first was an enclosed transparent acrylic cylinder fitted with connections to allow collection of gas that was displaced from the vessel. The second consisted of two parallel acrylic plates fastened together to view gas generation and retention characteristics in a slurry confined within a thin gap between the plates. One test was conducted in a larger diameter acrylic cylinder and this test did not include gas collection. The primary simulants used in the experiments were water slurries containing kaolin clay or mixtures of kaolin and Min-U-Sil 30 (U.S. Silica Company). Some scoping tests were also conducted with Laponite ${ }^{\circledR 1}$ and silica sand. In some of the experiments, gas generation was accomplished by adding various amounts of a $3 \%$ hydrogenperoxide solution that would decompose to generate oxygen gas. Differing gas generation rates and gas retention conditions were evaluated by varying the composition of the slurry, the amount of hydrogen peroxide, and the slurry depth. A second method of generating gas within the slurry was to add a small amount of colloidal iron particles that would corrode slowly to generate hydrogen gas. Details on the test apparatuses and simulants are given below. Two experiments were also conducted with the test vessel placed inside an x-ray microfocus CT scanner to image bubbles during the bubble growth experiments. A description of the CT scanner and imaging is given below.

\subsection{Apparatus}

The cylindrical growth columns were fabricated from $15.24 \mathrm{~cm}$ (6 in.) outside diameter (OD), $12.7 \mathrm{~cm}$ (5 in.) inside diameter (ID) cast acrylic tubing with two different nominal heights. Each cylindrical vessel typically consisted of a $1 / 2$ " acrylic plate base, a cast acrylic tube body with one or more sections, and a screw-on acrylic cap. Figure 2.1 shows the 12 in. and $48 \mathrm{in}$. vessels and the basic construction dimensions for the base section. The 48 in. tall vessel is segmented with two threaded extensions that attach to a common base. Six of the $12 \mathrm{in}$. vessels were fabricated to allow multiple experiments to be conducted concurrently. All acrylic caps were drilled and tapped to accommodate a $1 / 8$ " tube $\times 5 / 16-24$ straight-thread connector. A centimeter scale was taped to the side of each vessel to help measure the heights of the slurry and the cover liquid during experiments.

A key aspect of conducting gas retention-and-release experiments is measuring the total (combined) volume of gas that is released or retained in the simulant, which corresponds to the amount of gas displaced from the test vessel. To measure the displaced gas, a gas collection system portrayed in Figure 2.2 was used. For the $12 \mathrm{in}$. vessels, displaced gas was collected in an inverted $500 \mathrm{~mL}$ graduated cylinder that was filled with water and placed in a $4 \mathrm{~L}$ water bath. The total volume of gas, which is the combination of released gas and the retained gas bubbles that expand the volume of the clay, was measured using the cylinder graduations. Periodically, the graduated cylinder was refilled with water to continue gas collection. Tests with the $48 \mathrm{in}$. vessel used a $2 \mathrm{~L}$ graduated cylinder and a $10 \mathrm{~L}$ water bath. Both systems used 1/8" OD tubing and assorted Swagelok ${ }^{\circledR}$ fittings to transport the gas from the acrylic test vessel to the inverted graduated cylinder.

\footnotetext{
${ }^{1}$ Laponite is a registered trademark of Rockwood Additives Limited.
} 


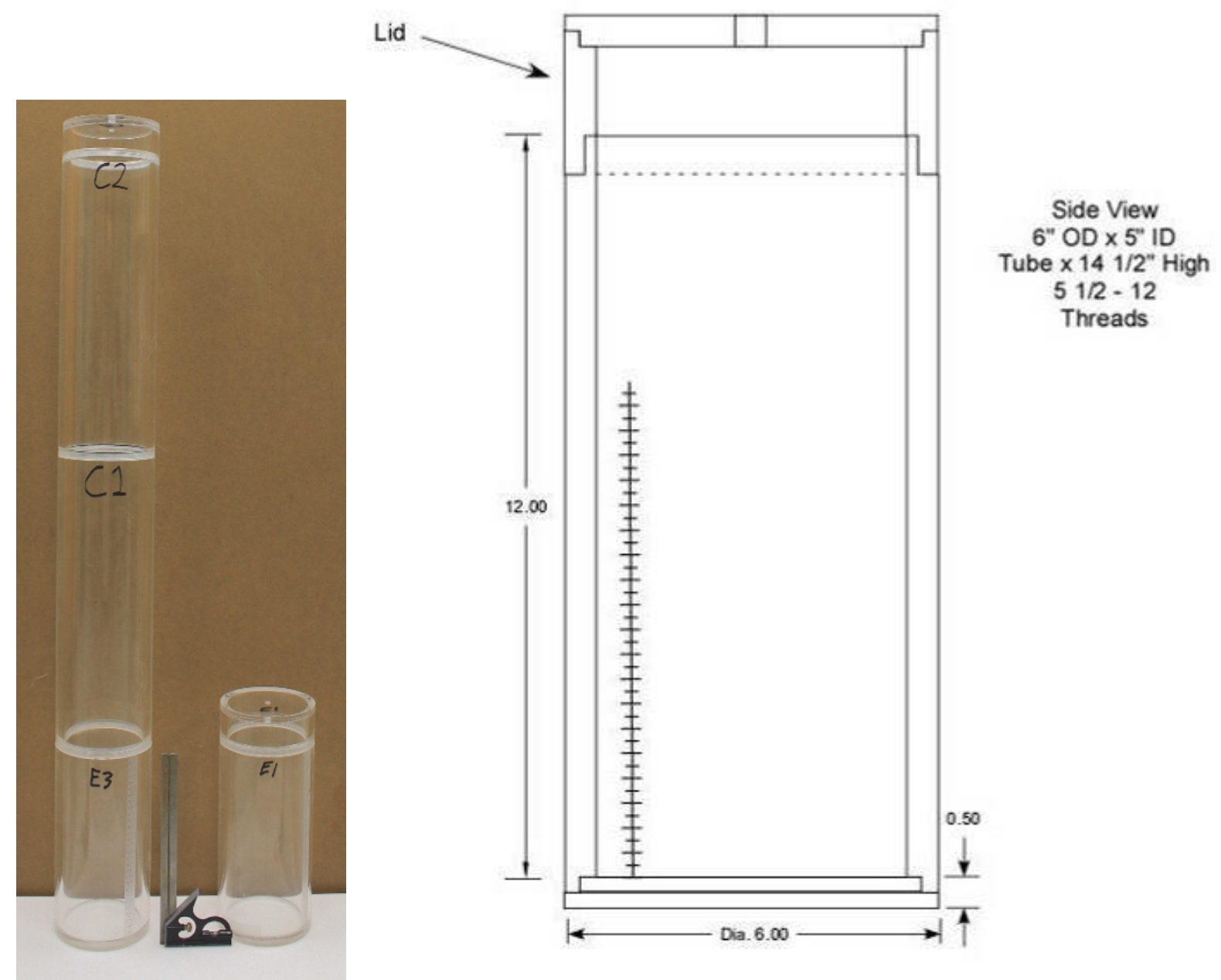

Figure 2.1. 48 in. and 12 in. Acrylic Test Vessels and Schematic of a 12 in. Vessel

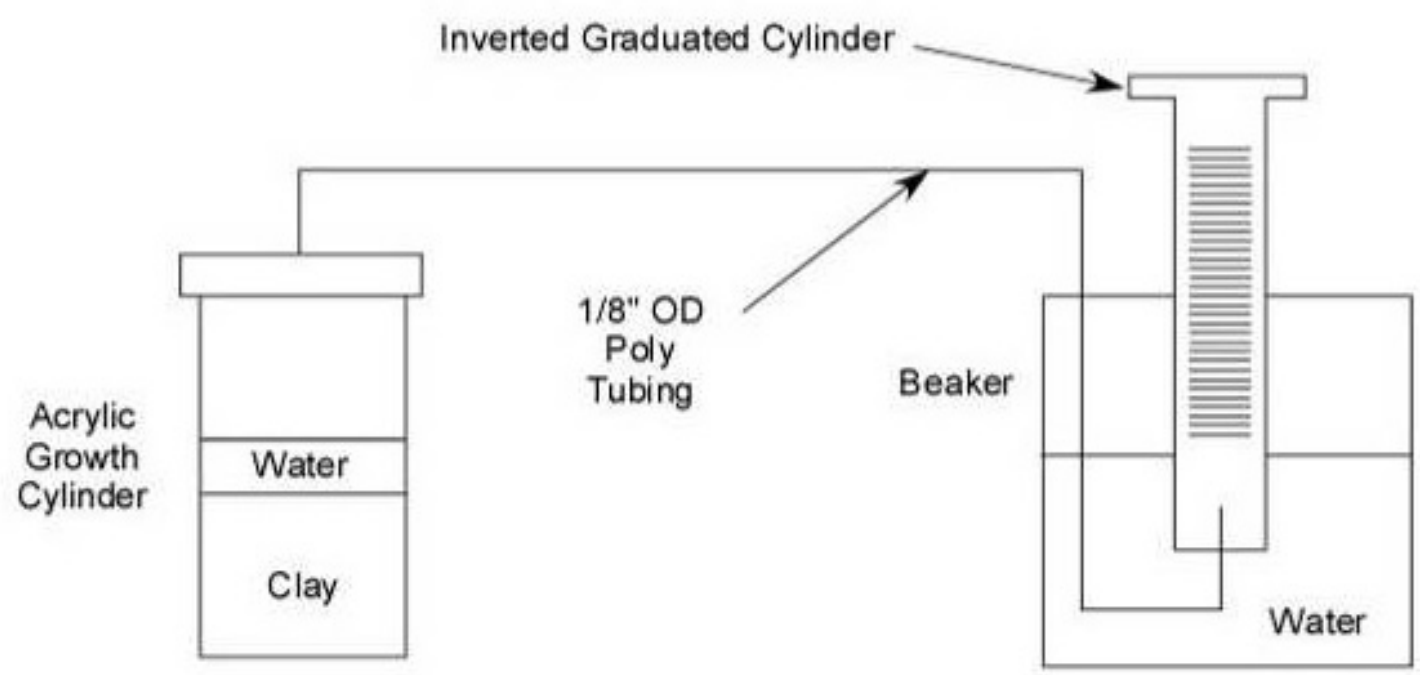

Figure 2.2. Schematic of Apparatus for Measuring Volume of Displaced Gas 
A parameter that is expected to be important for bubble retention is the depth of the simulant, which provides a gravitational load, or self-weight, that may affect the shape and vertical connectivity of the bubbles. One way of varying the gravitational load is to conduct experiments with progressively deeper sediment layers, which was done using the 48 in. test vessel. An alternate method of adding additional weight to the sediment was also tested: a combination of a circular perforated plate and a number of $1 / 4$ in thick circular stainless steel plates (for weight) were placed on top of the clay simulants. Figure 2.3 shows how the plates were positioned on top of the clay in the 12 in. test vessel, and Figure 2.4 documents the construction specifications for these plates. The same set of plates was also used in the 48 in. test vessel. For the tests performed, 20 plates were used and together with the perforated plate had a mass of $7.392 \mathrm{~kg}$. For a $55 \mathrm{wt} \%$ kaolin clay with the slurry density given in Table 2.1, this mass is equivalent to a $38.4 \mathrm{~cm}$ tall column of clay.

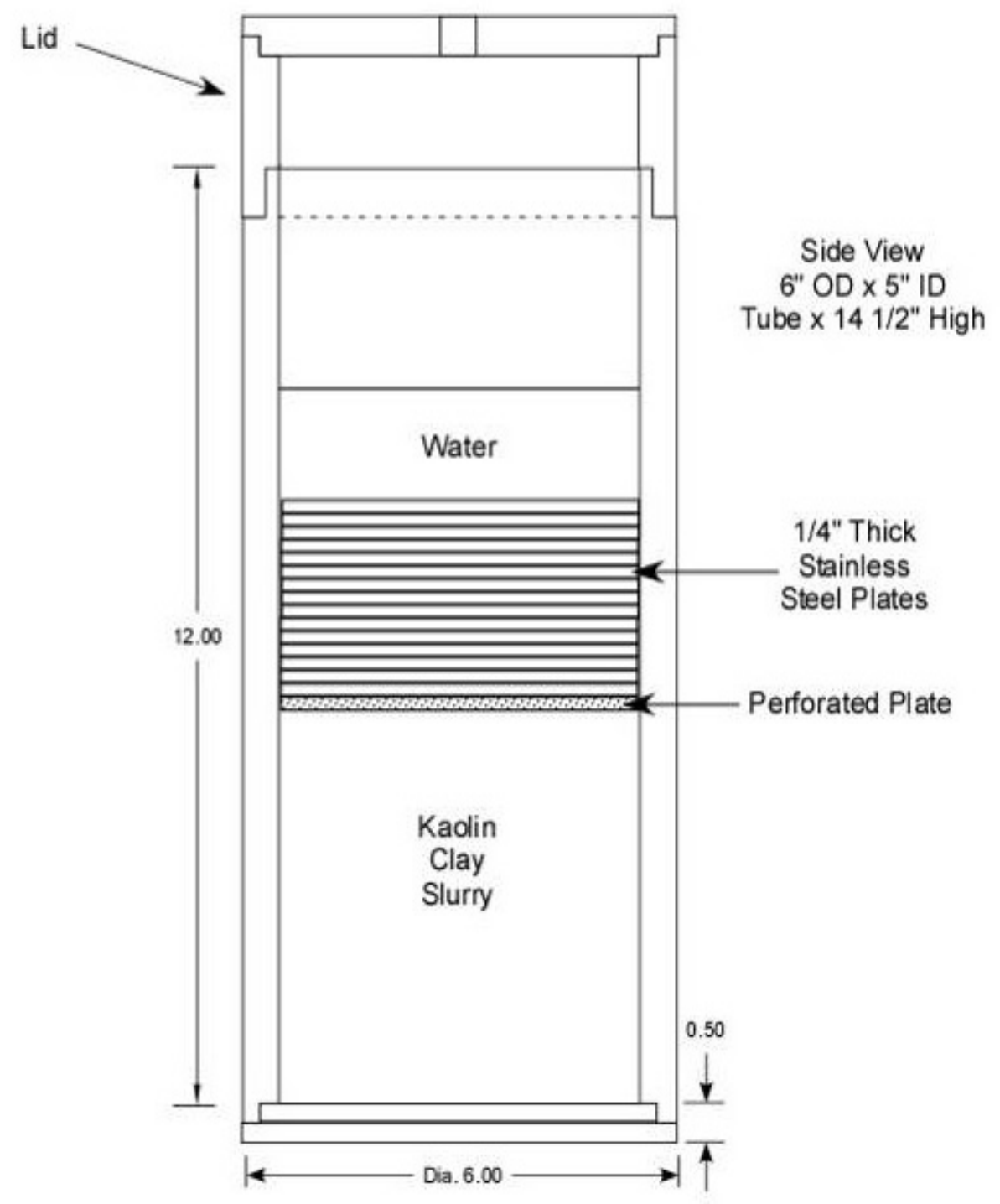

Figure 2.3. "Head" Plate Position in 12 in. Vessel 


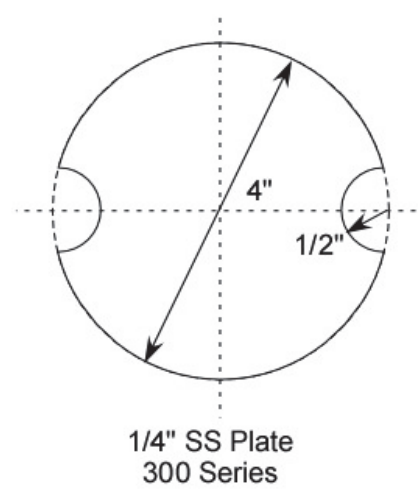

300 Series

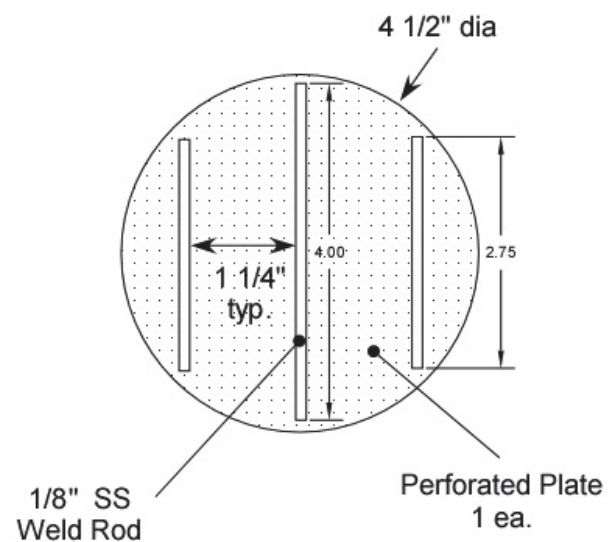

Figure 2.4. "Head" Plate Construction

Two thin-gap test vessels, with heights to roughly match those of the $12 \mathrm{in.}$ and $48 \mathrm{in}$. cylindrical vessels, were also fabricated to study bubble behavior. With the bubbles and sediment confined to a thin gap, it is easier to obtain visual images of bubbles and perhaps identify the formation of gas release channels as described in Section 1. The apparatus was constructed with parallel $1 / 2$ in. thick acrylic plates separated by a thin gap. Figure 2.5 shows a schematic of the dimensions for the shorter of the two vessels, and Figure 2.6 shows the apparatus assembled with a kaolin clay layer in the bottom portion. The gap thickness is set by the thickness of a U-shaped Teflon ${ }^{\circledR}$ gasket, and the thickness is adjustable by using any combination of the $1 / 16,1 / 8,3 / 16$, and 1/4 in. thick gaskets shown in Figure 2.5. Figure 2.7 shows the dimensions of the taller thin-gap test vessel and Figure 2.8 shows the assembled apparatus.

\subsection{Simulants and Gas Generation Methods}

Testing was conducted with simulants that are slurries of deionized (DI) water and EPK kaolin (Edgar Minerals Inc., Edgar, Florida), or combinations of EPK kaolin and Min-U-Sil 30 (U.S. Silica Company, Berkeley Springs, West Virginia), which is fine-ground silica with a median diameter of about 8 microns. For smaller-scale tests, typical preparation of the simulants involved the use of a KitchenAid ${ }^{\circledR} 4 \mathrm{~L}$ stainless steel bowl mixer. Varying amounts of pre-measured solids were transferred into the mixer bowl with various amounts of water. After the solids had been mixed sufficiently to obtain a uniform mixture based on visual observation of the absence of clay clumps, (typically more than $5 \mathrm{~min}$ ), hydrogen peroxide or small iron particles were added and mixing continued for about a minute. The hydrogen peroxide is used because it decomposes into water and oxygen, which then becomes gas bubbles (Gauglitz et al. 1996) and the corrosion of iron particles is known to generate hydrogen gas (Reardon 1995). Upon completion of the mixing, the slurry was transferred to the test vessel. Wooden spoons and plastic spatulas were typically used to aid in transfer of the slurry. Once the slurry was transferred and its mass quantified, an effort was made to remove artificial air voids to the extent possible. Air voids were often removed by tapping the container and slurry on a rubber mat placed on a hard surface. Once a reasonable effort had been made to remove the voids, a measurement of slurry height in the test vessel was taken and recorded. The slurry level (hence volume) could be used to estimate the initial retained-gas void fraction from the density and mass of the slurry in the vessel. When simulant volumes in excess of 2-3 L were required, multiple small batches were prepared and combined, or a large batch was mixed in a five-gallon poly bucket. The larger batches prepared in the poly bucket required an appropriately sized overhead mixer. 

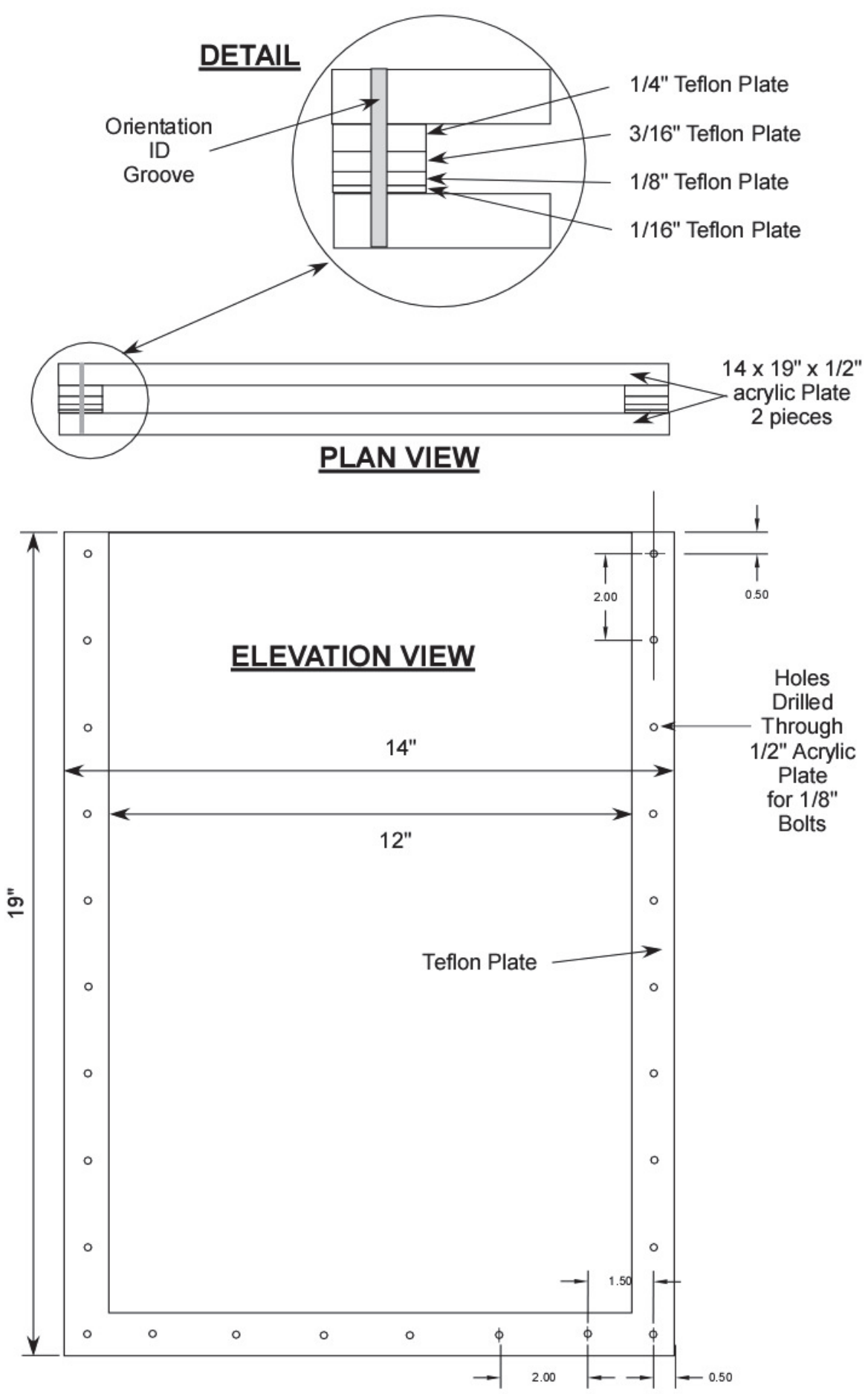

Figure 2.5. Schematic of 12 in. Thin-Gap Test Vessel 


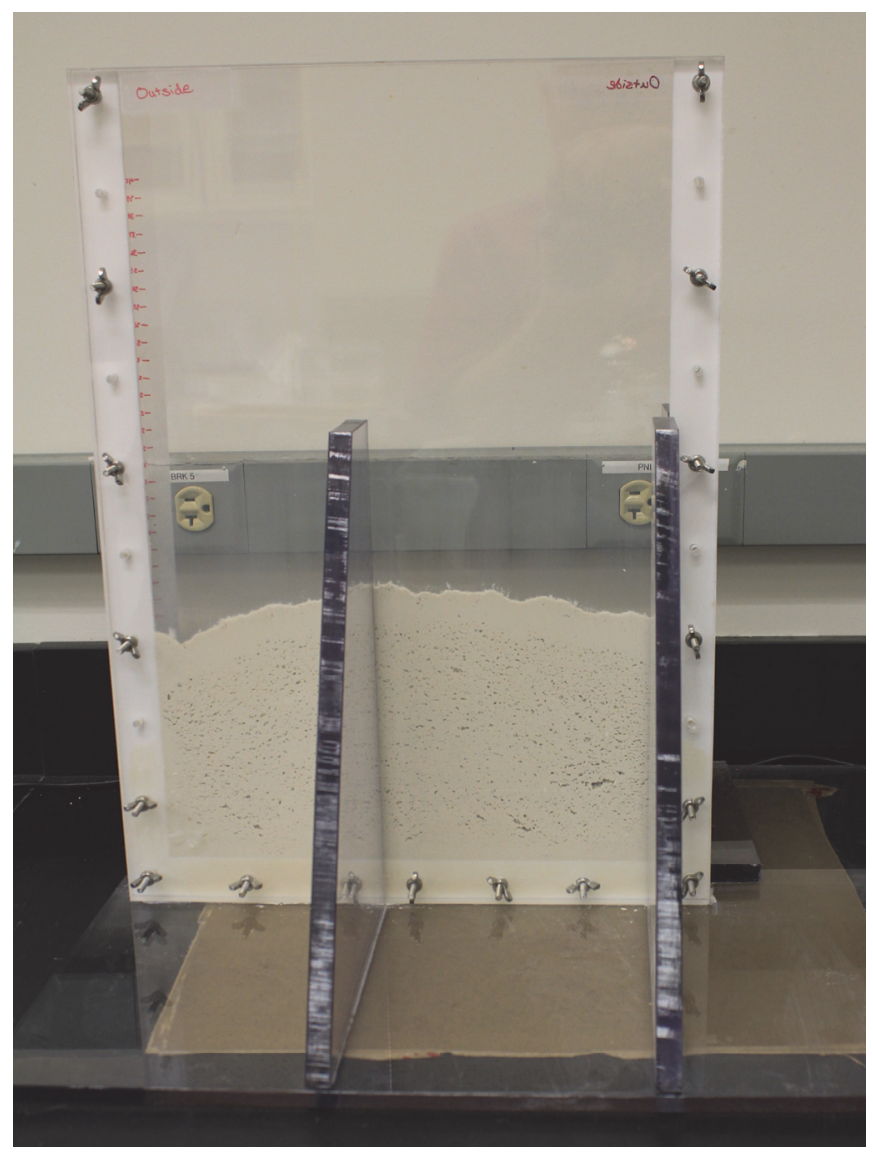

Figure 2.6. Assembled 12 in. Thin-Gap Test Vessel with Kaolin Clay

Table 2.1 summarizes the shear strengths and densities for the kaolin simulants used in the bubble retention tests. The shear strength was estimated using the following correlation given in Gauglitz et al. (2010) for the same EPK kaolin clay as used in this study:

$$
\tau_{\mathrm{s}}=0.018 * \exp [0.1915 *(\mathrm{wt} \% \text { kaolin })]
$$

The density of the mixture was calculated assuming that neither the kaolin nor the water contain a significant amount of entrained air or other gas. The density, $\rho_{\mathrm{s}}$, of the kaolin simulant is then

$$
\rho_{\mathrm{s}}=\frac{1}{\left(1-\mathrm{x}_{\mathrm{k}}\right) / \rho_{\mathrm{w}}+\mathrm{x}_{\mathrm{k}} / \rho_{\mathrm{k}}}
$$

where $\mathrm{x}_{\mathrm{k}}$ is the mass fraction of kaolin, and $\rho_{\mathrm{w}}\left(998 \mathrm{~kg} / \mathrm{m}^{3}\right)$ and $\rho_{\mathrm{k}}\left(2650 \mathrm{~kg} / \mathrm{m}^{3}\right)$ are, respectively, the intrinsic densities of the water and kaolin components of the mixture (Gauglitz et al. 2010). 


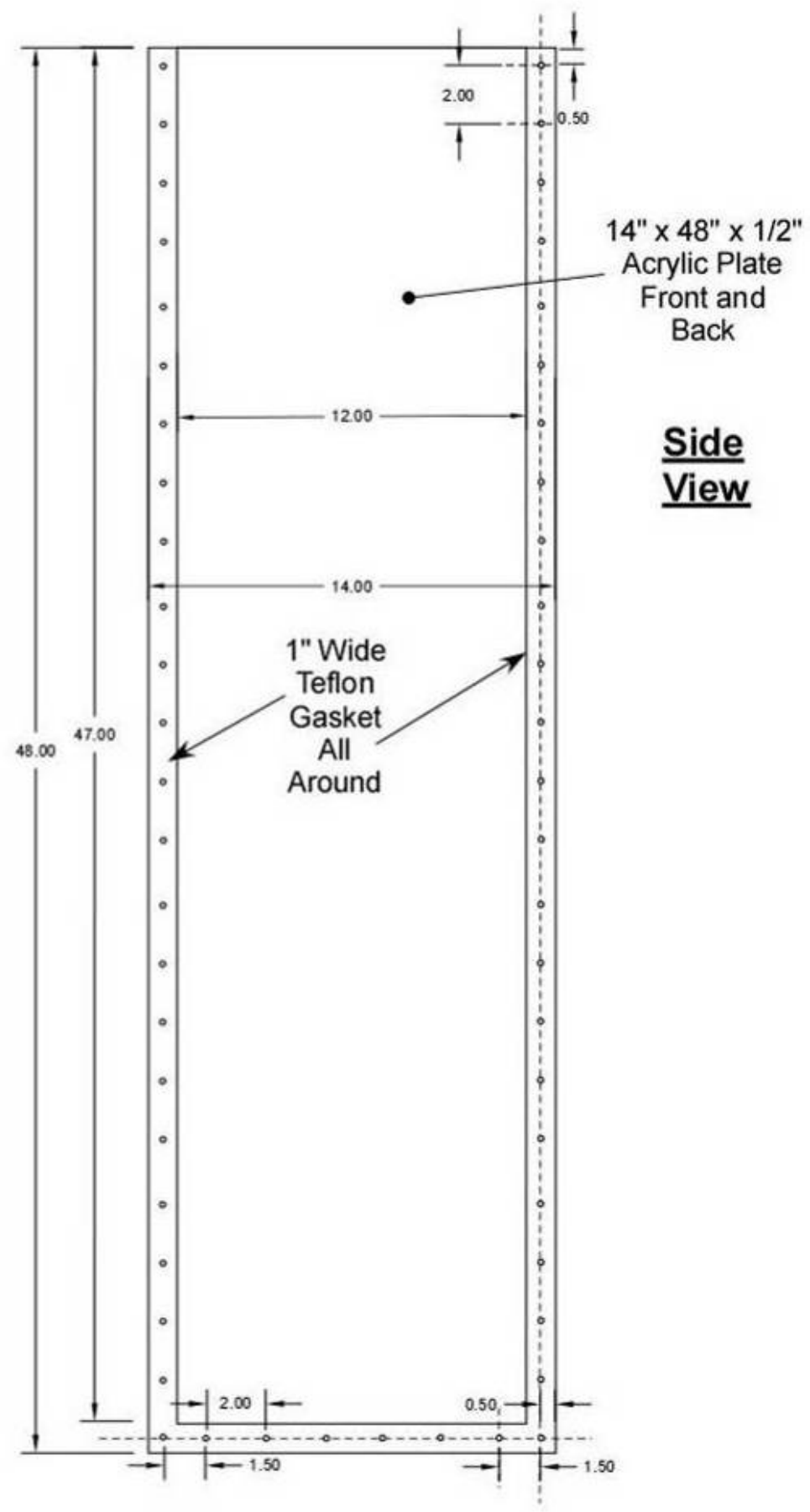

Figure 2.7. Schematic of 48 in. Thin-Gap Test Vessel 

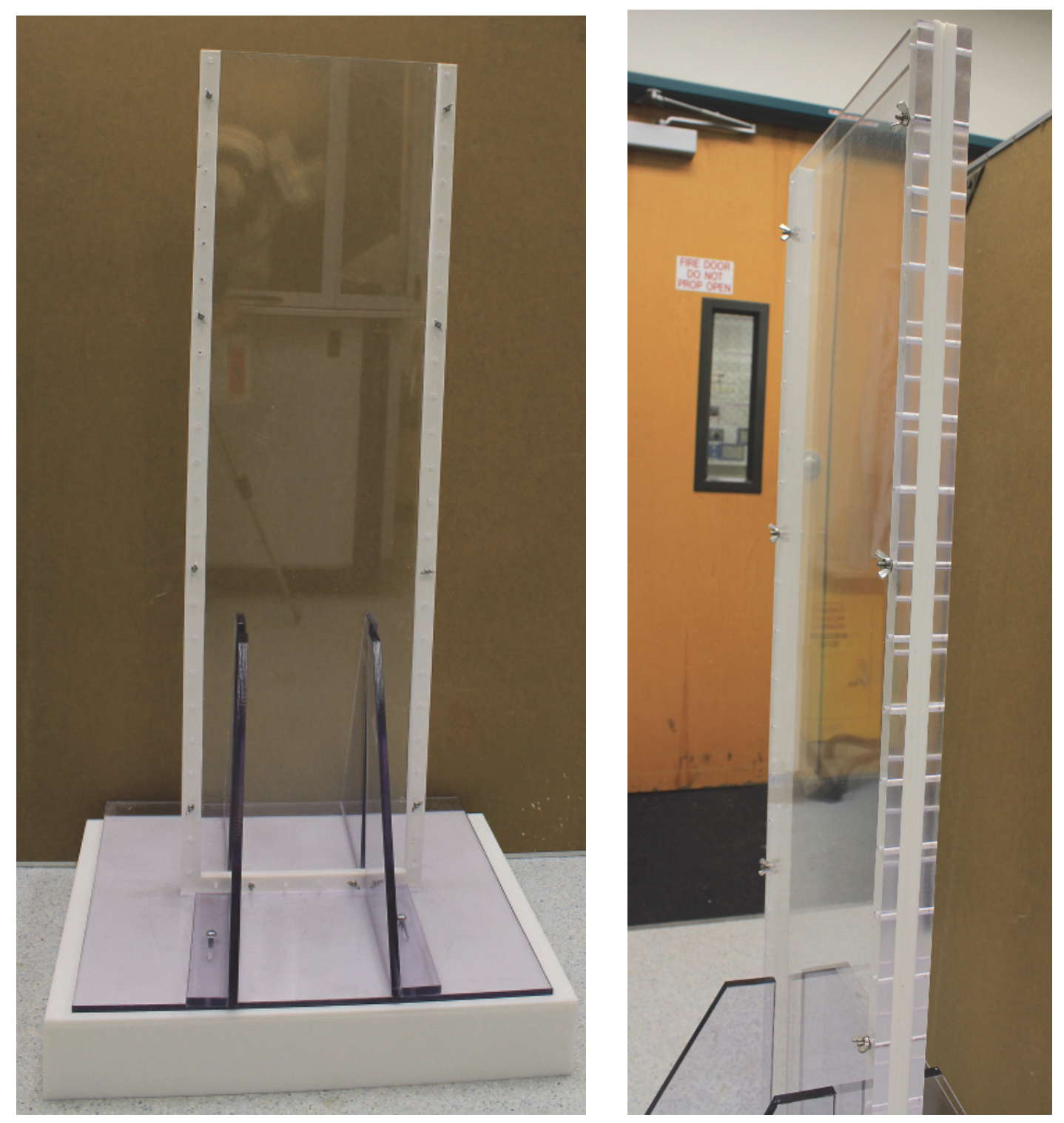

Figure 2.8. Assembled 48 in. Thin-Gap Test Vessel

Table 2.1. Kaolin Simulants and Estimated Shear Strength and Density

\begin{tabular}{ccc}
\hline $\begin{array}{c}\text { Kaolin } \\
(\mathrm{wt} \%)\end{array}$ & $\begin{array}{c}\text { Shear } \\
\text { Strength } \\
(\mathrm{Pa})\end{array}$ & $\begin{array}{c}\text { Density } \\
\left(\mathrm{kg} / \mathrm{m}^{3}\right)\end{array}$ \\
\hline 35 & 15 & 1277 \\
40 & 38 & 1330 \\
45 & 99 & 1387 \\
50 & 260 & 1450 \\
55 & 680 & 1519 \\
60 & 1800 & 1594 \\
\hline
\end{tabular}


Table 2.2 summarizes the estimated shear strengths and densities of the kaolin/Min-U-Sil 30 simulants used in the bubble retention tests. To estimate the shear strengths of various combinations of kaolin and Min-U-Sil 30, the data in Gauglitz et al. (2010) was fit to an exponential equation similar to Equation 2.1 using a least-squares method, resulting in the following:

$$
\tau_{\mathrm{s}}=0.0003189 * \exp [0.265 *(\mathrm{wt} \% \text { kaolin })] * \exp [0.177 *(\mathrm{wt} \% \text { Min }-\mathrm{U}-\mathrm{Sil} 30)]
$$

The density of the mixture, $\rho_{\mathrm{s}}$, can be described similarly to Equation 2.2 by the following, where $\mathrm{x}_{\mathrm{k}}$ and $\mathrm{x}_{\mathrm{M}}$ are the mass fractions of kaolin and Min-U-Sil 30, respectively (Gauglitz et al 2010):

$$
\rho_{\mathrm{s}}=\frac{1}{\left(1-\mathrm{x}_{\mathrm{k}}-\mathrm{x}_{\mathrm{M}}\right) / \rho_{\mathrm{w}}+\mathrm{x}_{\mathrm{k}} / \rho_{\mathrm{k}}+\mathrm{x}_{\mathrm{M}} / \rho_{\mathrm{M}}}
$$

The intrinsic densities of the water, kaolin, and Min-U-Sil 30 components of the mixture are $\rho_{\mathrm{w}}\left(998 \mathrm{~kg} / \mathrm{m}^{3}\right), \rho_{\mathrm{k}}\left(2650 \mathrm{~kg} / \mathrm{m}^{3}\right)$, and $\rho_{\mathrm{M}}\left(2650 \mathrm{~kg} / \mathrm{m}^{3}\right)$.

Table 2.2. Kaolin/Min-U-Sil 30 Simulants and Estimated Shear Strength and Density

\begin{tabular}{cccc}
\hline $\begin{array}{c}\text { Kaolin } \\
(\text { wt\% })\end{array}$ & $\begin{array}{c}\text { Min-U-Sil 30 } \\
(\text { wt } \%)\end{array}$ & $\begin{array}{c}\text { Shear } \\
\text { Strength } \\
(\mathrm{Pa})\end{array}$ & $\begin{array}{c}\text { Density } \\
\left(\mathrm{kg} / \mathrm{m}^{3}\right)\end{array}$ \\
\hline 40 & 5 & 31 & 1387 \\
35 & 24 & 240 & 1579 \\
33 & 33 & 690 & 1696 \\
30 & 41 & 1300 & 1790 \\
\hline
\end{tabular}

The quantity and rate of gas generation from the addition of hydrogen peroxide depend on the quantity of hydrogen peroxide added to the clay simulants as well as the proportions of kaolin and Min-U-Sil 30. The experiments were conducted by adding various amounts of a 3-wt\% solution of hydrogen peroxide in water (Sigma Aldrich ${ }^{\circledR}$ ) to the simulants. The wt $\%$ of solids in a slurry are calculated by making the approximation that the mass of added hydrogen peroxide is the mass of the same amount of water. In general, the rate of gas generation increases with increasing concentration of hydrogen peroxide and increasing wt $\%$ of kaolin. The mixtures of kaolin and Min-U-Sil 30 in Table 2.2, with decreasing kaolin but increasing Min-U-Sil 30, were selected to have roughly the same gas generation rate over the range of shear strengths. A second method of generating retained gas bubbles was to mix iron particles with the kaolin slurries and allow the iron to corrode and form hydrogen bubbles. The iron particles used in this study were S-3700 MICROPOWDER ${ }^{\circledR}$ iron (International Specialty Products), which have a median particle size of about two microns based on vendor literature. The corrosion of iron for yielding hydrogen gas proceeds in a series of steps (Reardon 1995) that can be summarized as follows:

$$
\mathrm{Fe}+2 \mathrm{H}_{2} \mathrm{O} \rightarrow \mathrm{Fe}^{2+}+2 \mathrm{OH}^{-}+\mathrm{H}_{2}(\mathrm{~g}) \rightarrow \frac{1}{3} \mathrm{Fe}_{3} \mathrm{O}_{4}(\mathrm{~s})+\frac{4}{3} \mathrm{H}_{2}(\mathrm{~g})+\frac{2}{3} \mathrm{H}_{2} \mathrm{O}
$$


Depending on the chemistry and temperature of the simulant, the reaction will proceed to only the intermediate step or completely to form magnetite $\left(\mathrm{Fe}_{3} \mathrm{O}_{4}\right)$, and the moles of hydrogen gas generated per mole of iron also depends on the extent of the reaction. Experiments were conducted with iron concentrations ranging from 0.125 to $0.5 \mathrm{wt} \%$ iron particles in kaolin slurries. Initially, experiments used S-3700 MICROPOWDER that came from material that had been in the laboratory for a period of time. For a final large-scale experiment, a new batch of material was obtained. With the new batch of iron particles, the generation of hydrogen proceeded more quickly (see Section 3). It is suspected that the older material that had been in the laboratory probably had a surface layer of corrosion that delayed the onset of additional corrosion and hydrogen generation. Studies of hydrogen generation from corroding uranium metal show similar delays in onset of gas generation (Delegard and Schmidt 2009). During the initial studies with the iron particles, it appeared that there was some biological activity in the clay and a small amount of biocide (100 ppm of Mt. Hood 480) was added to the clay for the final large-scale experiment.

The large-scale test of bubble retention in lake-bottom sediment taken from Ketelmeer, which was discussed in Section 1.1, used a biogenic method to generate retained gas bubbles (Van Kessel and Van Kesteren 2002). With this method, gas generation occurred over about an 80 day period. An alternate method for the biogenic generation of gas was considered for this study, but not tested in the laboratory. The Appendix gives a summary of this method.

\subsubsection{Test Methods for Bubble Growth}

Prior to testing, a 12 in. tall cylindrical test vessel was weighed empty and then filled with DI water to a level of $10 \mathrm{~cm}$ and weighed again. Using the density of water, the volume at the $10 \mathrm{~cm}$ mark was calculated from the mass of DI water. The measured volume was compared with the volume calculated assuming a $10 \mathrm{~cm}$ tall cylinder for the $5 \mathrm{in}$. ID $(12.7 \mathrm{~cm})$ acrylic tube, and the difference was found to be quite small. At the start of testing, each test vessel was loaded with slurry to a target depth of $10 \mathrm{~cm}$ and weighed; the mass of slurry in each vessel was then determined by subtracting the mass of the empty vessel. Using the slurry densities given in Table 2.1 and Table 2.2, the initial void fraction of the slurry can be calculated. The initial void fraction varied in each test, but was typically about $5 \%$. The results presented in Section 4 for gas void fraction are for the growth in retained gas above this initial amount.

Once the initial mass measurements were taken, a layer of DI water was placed on top of the test slurry. Occasionally, it was necessary to add more DI water during testing to keep the clay layer submerged. The capped test vessel was then connected to the gas collection system using $1 / 8$ " OD tubing. The gas collection system consisted of an inverted $500 \mathrm{~mL}$ graduated cylinder held in a $4 \mathrm{~L}$ polycarbonate beaker filled with water. The gas displaced from the test cylinder was directed to bubble into the graduated cylinder, and the volume of collected gas was recorded as a function of time. Periodically, the graduated cylinder was refilled with water to continue gas collection. Figure 2.9 shows multiple 12 in. test vessels during an experiment. During the course of an experiment, the levels of the water and sediment were recorded. An increase in the water level in a test vessel corresponds to an increase in volume due to retained gas. Sometimes the sediment would increase in height more than the water level, and this was due to formation of water-filled cracks. The gas volume fraction due to bubble growth is simply the increase in the water level divided by the sediment height. 
The preparation of the 48 in. and taller cylindrical test vessels was essentially the same as for the 12 in. cylindrical vessels, except on a larger scale. Loading the column typically took longer than for the 12 in. vessel tests, so more bubble growth occurred in the time between when the peroxide was added to the clay and when the column was filled. The taller vessels were bounced on a rubber mat to help release trapped gas voids. After the clay was loaded and bubbles released to the extent possible, a layer of DI water was added and then the top column segment and cap were attached and connected to the gas collection system. Figure 2.10 shows the assembled apparatus for the 48 in. system.

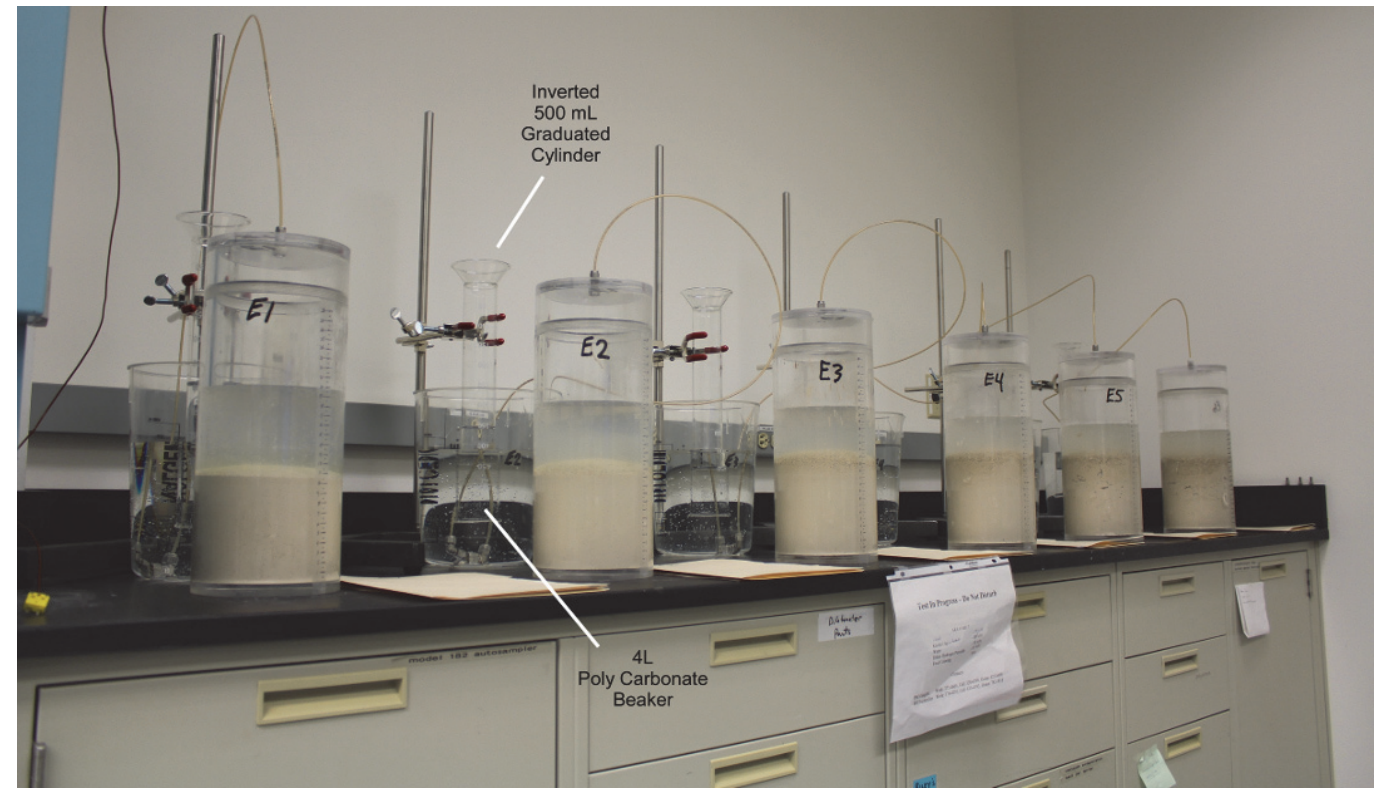

Figure 2.9. 12 in. Test Vessels during an Experiment

As with the test method for the 12 in. vessels, masses, slurry heights, and DI-water layer heights were documented. It should be noted that in loading both assemblies, a plate (plastic weighing boat or similar) was held above the slurry when the DI water cover layer was being added to break the fall of the water as it was poured onto the clay. A clear layer of cover water was essential to observe the initial slurry surface deformation caused by gas generation. As the bubble release occurred, the water became cloudy as fines became suspended by the motion of the releasing gas bubbles. For one of the $48 \mathrm{in}$. vessel tests with $55 \mathrm{wt} \%$ kaolin clay, when the bubble growth experiment had been completed, the weight of the column was measured after removing the clay in $10 \mathrm{~cm}$ increments. With the mass of each increment and the volume calculated from the vessel diameter and increment height, the bulk density with gas voids was calculated for each increment. Using an estimate for the gas-free clay density (Table 2.1 gives a density of $1,519 \mathrm{~kg} / \mathrm{m}^{3}$ for the $55 \mathrm{wt} \%$ clay), the following relationship gives the gas void fraction of each increment:

$$
\text { void fraction }=1-\frac{\rho_{\text {bulk }}}{\rho_{\mathrm{s}}}
$$

where $\rho_{\text {bulk }}$ is the measured bulk density with retained gas bubbles and $\rho_{\mathrm{s}}$ is the gas-free density of the clay. These measurements then give gas void fraction as a function of depth in the sediment layer at the end of the experiment. 


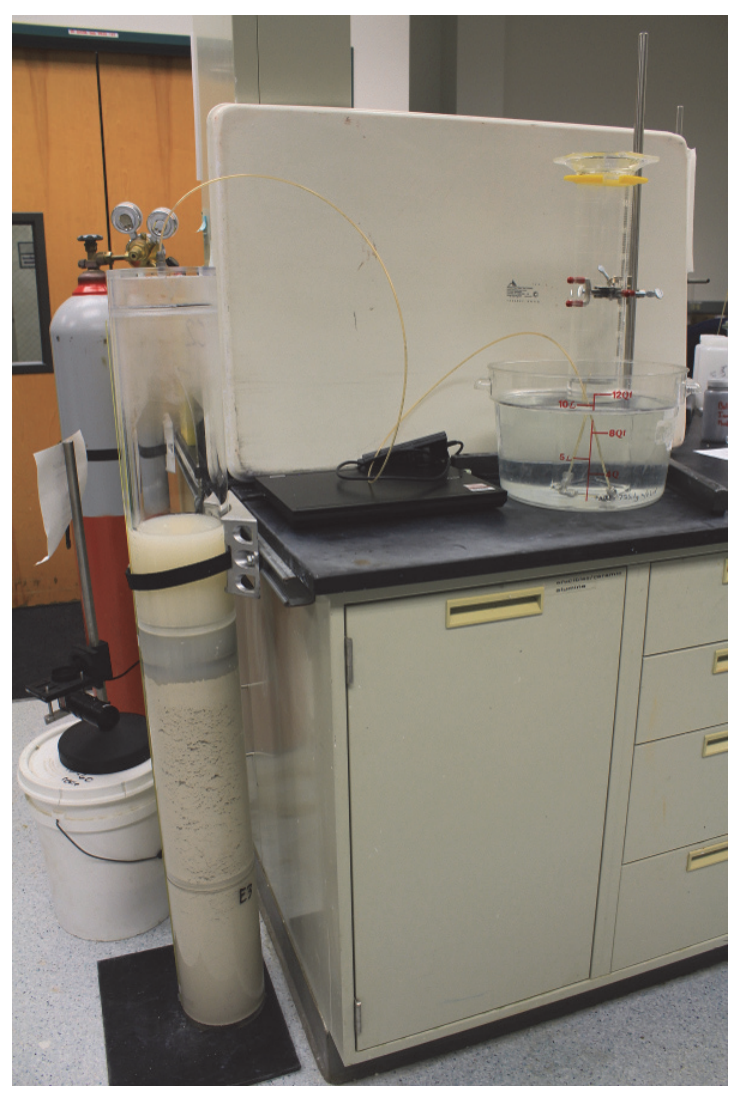

Figure 2.10. 48 in. Test Vessel during an Experiment

At this initial stage of this study, only a few tests were conducted with the 12 in. thin-gap test vessel. These experiments were conducted with 40, 50, and $55 \mathrm{wt} \%$ kaolin clay mixed with $3 \mathrm{wt} \%$ hydrogen peroxide solution. For these tests, the simulant was mixed and then a small amount was poured onto one of the acrylic plates that had been placed on a horizontal surface with the gasket correctly positioned. The second plate was lowered onto the bottom plate, causing the simulant to spread and fill a portion of the vessel. After the holes in the two plates were aligned, the two plates were held together with screws and wing nuts. Once assembled, the apparatus was turned upright and held vertically with a stand, and a layer of DI water was placed on top of the clay. The levels of the water and clay were recorded and shapes of bubbles observed as functions of time. Figure 2.6 shows a clay layer during an experiment in the 12 in. thin-gap vessel.

\subsection{X-Ray Microfocus Computed Tomography}

$\mathrm{X}$-ray microfocus $\mathrm{CT}$, which is more commonly known as $\mathrm{CT}$, is a non-destructive imaging technique used to examine internal structures of natural and man-made materials. Various forms of this imaging technique have been utilized by the medical industry since 1972 and CT imaging is currently an essential part of patient diagnostics (Kalender 2000). In recent years, scientists have used these systems to investigate geologic materials, with the technology rapidly becoming a part of routine sample characterization (Ketcham and Carlson 2001). For example, imaging with x-rays was used to support studies in site remediation for heavy-metal contaminants and in the evaluation of bulk vitrification processing of low-level tank waste (Wellman et al. 2005; McGrail et al. 2003). 
Major components of the CT system include a flat-panel detector, a rotating stage, and an x-ray tube capable of high resolution and high magnification. Initially, two-dimensional (2-D) cross-sectional images of an object are generated based on density variations. For example, water- and gas-filled voids (low density) are easily distinguished within geologic sediment or sludges (high density). As the object is continuously rotated $360^{\circ}$ in the $\mathrm{x}$-ray beam, a designated number of images are collected for each degree of rotation. Each sequential image collected contains a detailed map of the interior features of the object. After images are acquired, the data is reconstructed using software designed for high-performance image processing. By applying image correction tools, real-time volume rendering and three-dimensional (3-D) visualizations are obtained.

The CT system is an NSI X-View Digital X-ray Imaging and Microfocus Computed Tomography system manufactured by North Star Imaging, Inc. (Rogers, Minnesota). The system, shown in Figure 2.11, is housed in an 8,000 pound lead-lined near-zero-emission enclosure and mounted on a leveling table. X-rays are generated by a microfocus X-ray source (COMET Feinfocus Model 160.48 $160 \mathrm{kV}$ ) and images are collected by a PaxScan ${ }^{\circledR} 2520 \mathrm{~V}$ flat panel digital x-ray detector (with a pixel pitch of 127 microns and a total active imaging area of $8 \times 10$ inches). The sample stage is equipped with a $150 \mathrm{~mm}$ diameter turntable $\left(360^{\circ}\right.$ continuous rotation) and is capable of $150 \mathrm{~mm}$ vertical travel; it can be positioned between the detector and x-ray source to optimize the field of view. Depending on instrument parameters, the system is capable of achieving a spatial resolution of $>6$ microns (in the focal plane) on an object $6.75 \mathrm{~mm}$ in diameter. For the larger samples studied here using the $5 \mathrm{in}$. test vessels described in Section 2, the resolution is lower. Data acquisition and image reconstruction are achieved using commercially available software (X-View IW). The software includes a comprehensive set of image analysis tools capable of high performance image processing and measurement functions common to XMT systems (2-D slice reconstruction and 3-D volume and surface rendering).

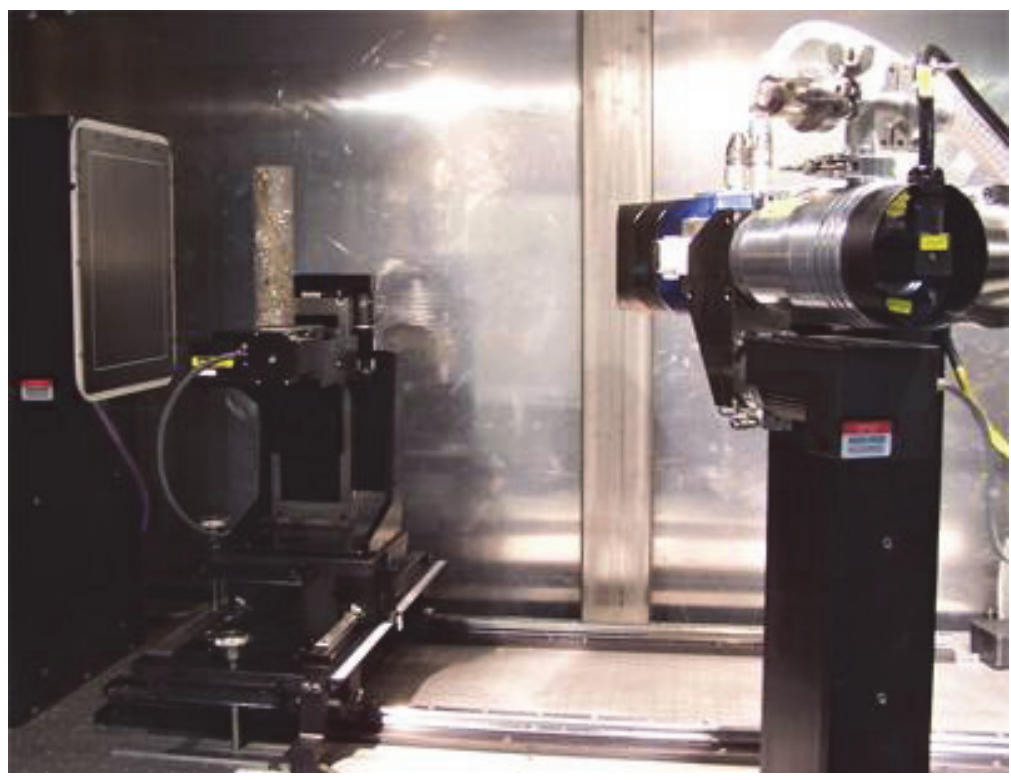

Figure 2.11. X-Ray Micro-Focus Tomography System 


\subsubsection{CT Method}

CT images of bubbles in two kaolin clay simulants were collected to observe the difference between bubbles retained in a weak material $(40 \mathrm{wt} \%, 38 \mathrm{~Pa})$ and a strong material $(55 \mathrm{wt} \%, 680 \mathrm{~Pa})$. These experiments were conducted using the 12 in. cylindrical test vessels and followed the methods described previously in Section 2. For these tests, $6 \mathrm{~g}$ of hydrogen peroxide ( $200 \mathrm{~g}$ of the $3 \mathrm{wt} \%$ solution) was added to each simulant, though different quantities of each simulant were mixed so the hydrogen peroxide concentration varied slightly $(0.24 \mathrm{wt} \%$ for the $38 \mathrm{~Pa}$ kaolin and $0.29 \mathrm{wt} \%$ for the $680 \mathrm{~Pa}$ kaolin).

The 12 in. tall test vessels have a 6 in. OD. This diameter is the largest vessel that can fit on the sample stage and rotate. To maximize the field of view for these samples, the stage was positioned so that the central axis of rotation was $829 \mathrm{~mm}$ from the detector, allowing the total active imaging area of the detector to be used. Prior to acquiring images, each simulant-filled cylinder was placed on the sample stage and centered. Height measurements were recorded for the clay and water. Typically, x-ray tube settings were obtained by adjusting the voltage and current to obtain the highest image contrast, which corresponded to luminosity values between 3000 and 6000 LUM. Table 2.3 shows the parameters used for these tests. To optimize the detector, dark- and light-field calibrations were performed. These calibrations created a uniform background response similar to that of the cylinder when scanned. This took an average of 10-15 min. Each cylinder was then centered on the sampling stage and imaged using 2 frames per second with a total of 721 projections collected over 360 degrees. Relative distances between the detector, cylinder, and x-ray tube were determined using a vendor-supplied calibration tool and imaging procedure (NSI Procedure REV 05-05-V2).

Table 2.3. Parameters used during XMT Characterization

\begin{tabular}{lc}
\hline \multicolumn{1}{c}{ Parameter } & Setting \\
\hline Voltage, $\mathrm{kV}$ & 110 \\
Current, $\mathrm{mA}$ & $807-1294$ \\
Luminosity & $2600-7000$ \\
Frames per Second & 2 \\
Views & 721 \\
\hline
\end{tabular}




\subsection{Results and Discussion}

Experiments were conducted to quantify the role of a number of parameters related to gas retention and the corresponding bubble behavior, with the overall objective of identifying mechanisms that lead to low gas retention. The test focused on varying the gas generation rate, the method of generating the gas, and simulant shear strength; CT bubble-imaging experiments were also conducted to observe the bubble structure in both a weak and a strong simulant. Experiments were then conducted in vessels with deeper simulant layers to determine the effect of the overlying weight of the simulant on the maximum retainedgas fraction. To further explore the role of the weight of a simulant layer affecting bubble retention, two experiments were conducted in which weights were placed on the top of the simulants to mimic the weight of additional overlying material. Finally, one larger-diameter test was conducted to determine whether the diameter of the vessel has a significant effect. The results of these experiments are discussed below.

\subsection{Role of Gas Generation Rate and Method on Gas Retention}

In the gas retention experiments, the cumulative volume of generated gas, the cumulative volume of gas retained as indicated by the rise in the liquid level, and the clay volume as indicated by the clay level, were all measured as a function of time. Figure 3.1 shows the cumulative gas collected, which is the total gas volume generated, from a series of tests in the $12 \mathrm{in}$. cylindrical test vessels with a $55 \mathrm{wt} \%(680 \mathrm{~Pa})$ kaolin simulant in which the concentration of hydrogen peroxide was varied to give different gas generation rates and different total volumes of generated gas. These experiments started with an initial clay layer of about $10 \mathrm{~cm}$, which in a vessel with a $5 \mathrm{in}$. ID corresponds to an initial volume of $1270 \mathrm{~mL}$. For this volume of initial sediment, generating $1000 \mathrm{~mL}$ of gas should be sufficient to have gas generation and release continue after reaching a peak in gas retention. The results show that gas is generated more rapidly with higher hydrogen peroxide concentration, and for this variation in concentration the rate of generation varied by a factor of almost ten. For all the hydrogen peroxide concentrations (shown as wt $\%$ of the slurry mass), the rate of gas generation declines with time, and for the lower hydrogen peroxide concentrations gas generation eventually ceases after a majority of the hydrogen peroxide decomposes.

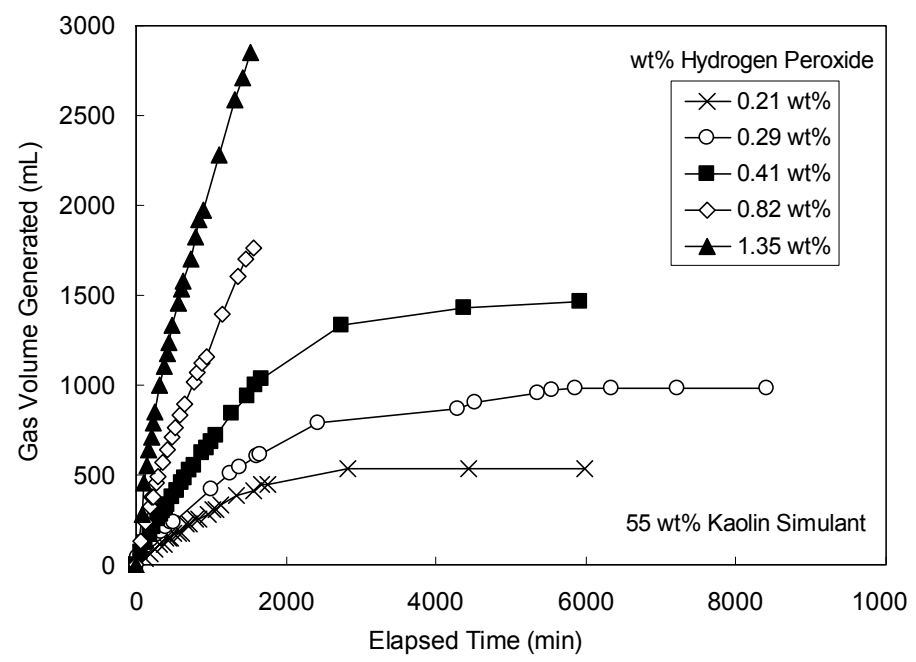

Figure 3.1. Gas Volume Generated for a Range of Hydrogen Peroxide Concentrations in $55 \mathrm{wt} \%$ (680 Pa) Kaolin Clay 
For $0.41 \mathrm{wt} \%$ hydrogen peroxide, approximately a liter of gas was generated in $1500 \mathrm{~min}$. In previous studies with bentonite clay simulants, the bentonite clay would decompose the hydrogen peroxide within about $1 / 10^{\text {th }}$ of this time period, or about ten times faster (Gauglitz et al. 1996). One of the objectives of this study was to identify a simulant and method of gas generation that gives slower gas generation than previous studies, and kaolin/hydrogen peroxide simulant meets this objective. Further reduction in gas generation rate is still needed to match the large-scale test of Van Kessel and Van Kesteren (2002) that was discussed in Section 1.1. As shown in Figure 1.2, sufficient gas generation to reach a peak in gas retention occurred over a period of about $600 \mathrm{hr}$.

Figure 3.2 shows the growth in gas void fraction during the bubble retention experiment with a range of hydrogen peroxide concentrations. There is always some initial trapped air in the kaolin when loading the test cylinder, but the results presented here are for the growth in voids, so all of the test results begin at zero fraction of generated void. The initial volume of trapped voids can be determined from measurements of the initial volume and mass of the clay in the vessel together with the density of the clay simulant. Typically, the initial gas was between $1 \%$ and $5 \%$ for all of the bubble retention experiments reported here. For all of the tests, the gas retention increased with time but at different rates because the gas generation rate was different in each test. For the higher concentrations of hydrogen peroxide, the gas void fraction reached a peak value of just under $30 \%$ gas and then remained at this gas fraction or decreased somewhat with time. For the lowest two concentrations of hydrogen peroxide, gas retention stopped increasing, but at lower values. For these tests, there was insufficient gas generated to reach a peak in retention in the $55 \mathrm{wt} \%(680 \mathrm{~Pa})$ kaolin. Gas retention reaching a peak value and then holding steady or decreasing slightly with continued gas generation is equivalent to observations made in previous studies with similar strength bentonite simulants (Gauglitz et al. 1996).

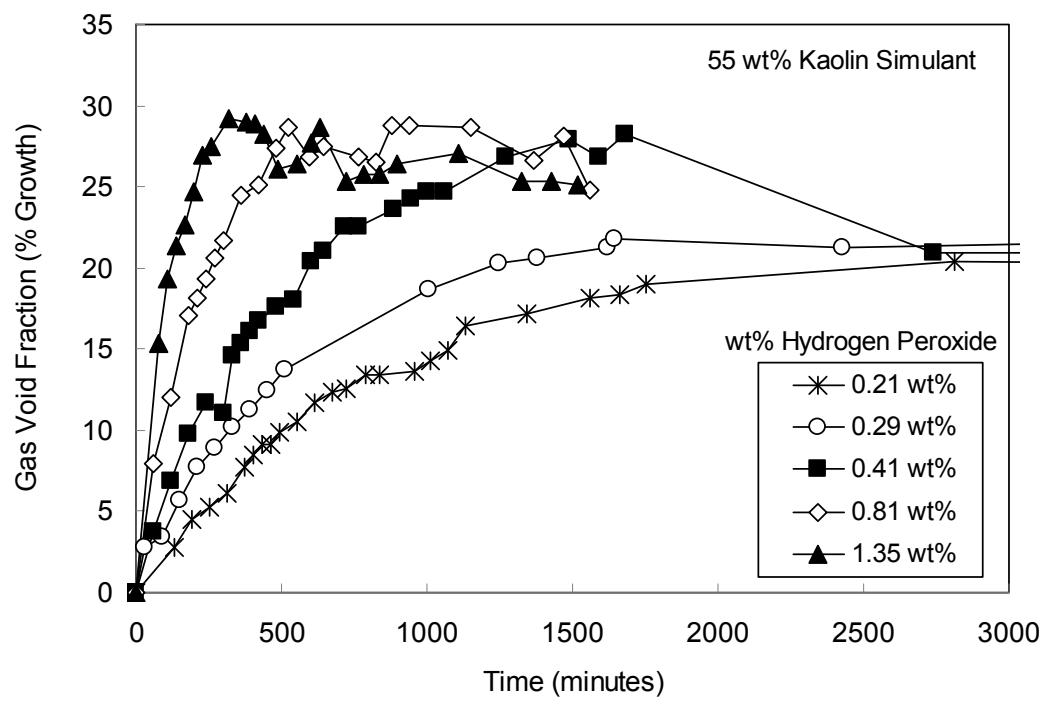

Figure 3.2. Growth in Gas Void Fraction for a Range of Hydrogen Peroxide Concentrations in $55 \mathrm{wt} \%$ (680 Pa) Kaolin Clay

To determine whether the gas generation rate has an effect on gas retention, the gas retention results that were shown as a function of time in Figure 3.2 can instead be shown as a function of gas volume collected. The role of the gas generation rate can be evaluated by comparing gas retention as a function of generated gas volume at the same volume of generated gas. Figure 3.3 shows the gas retention results 
as a function of generated gas volume for the range of hydrogen peroxide concentrations tested. All of the data collapse to essentially a single curve except toward the very end of each test. For the three highest concentrations, the gas retention peaks at just under 30\% and holds constant or decreases somewhat. For the lowest hydrogen peroxide concentration of $0.21 \mathrm{wt} \%$, only about $500 \mathrm{~mL}$ of gas was generated and this only allowed the retained gas to reach about $20 \%$, but the retention results for this test follow the same initial behavior as all of the other tests. For the $0.29 \mathrm{wt} \%$ and $0.41 \mathrm{wt} \%$ hydrogen peroxide data, the initial growth in gas retention follows all of the other tests until the end of these tests where the gas retention either decreases or holds constant at a lower value of about $20 \%$ gas. The single test at $0.29 \mathrm{wt} \%$ hydrogen peroxide shows a lower peak retention of about $22 \%$ gas with continued gas generation between 600 and $1000 \mathrm{~mL}$ of generated gas. As shown in Figure 3.1, the rate of gas generation between 600 and $1000 \mathrm{~mL}$ of generated gas is slower than the gas generation rate earlier in this test. Overall, these data show that the initial growth in gas retention does not depend on gas generation rate, for the range tested, but the data do suggest that peak gas retention may decrease with slower gas generation rates.

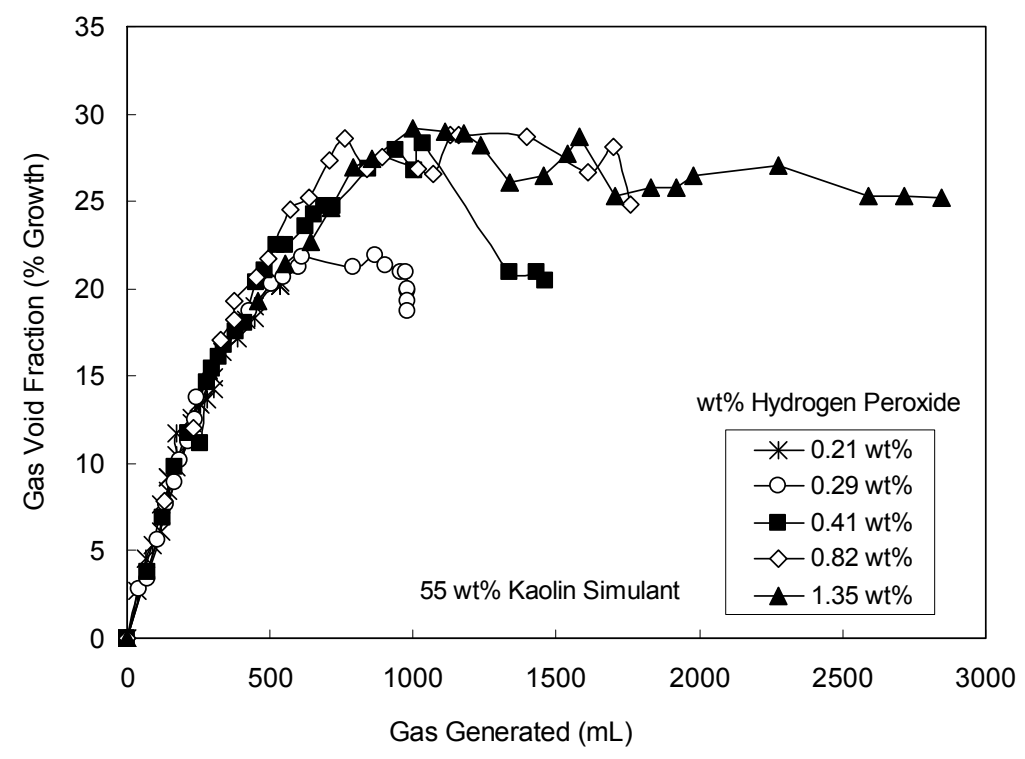

Figure 3.3. Growth in Gas Void Fraction as a Function of Gas Volume Collected for a Range of Hydrogen Peroxide Concentrations in $55 \mathrm{wt} \%$ (680 Pa) Kaolin

Figure 3.4 shows the gas generation behavior after small iron particles were added to the slurry that corroded over time to give hydrogen gas. The gas generation behavior with $0.41 \mathrm{wt} \%$ hydrogen peroxide $\left(\mathrm{H}_{2} \mathrm{O}_{2}\right)$ is also shown for comparison. With the iron particles, there was an initial delay of about five days (7000 $\mathrm{min}$ ) before gas generation began. This initial delay is possibly due to a surface corrosion layer on the iron particles. Similar delays in gas generation have been observed during the corrosion of uranium metal (Delegard and Schmidt 2009). Once gas generation began, the volume of generated gas was larger with progressively higher concentrations of iron. In comparison to gas generation by hydrogen peroxide, the generation rate with iron, once the generation rate began, is comparable. In particular, the total gas volume generated with $0.25 \mathrm{wt} \%$ iron is similar to that from the test with $0.41 \mathrm{wt} \%$ hydrogen peroxide. Because these generated gas volumes are similar and also sufficient to generate more gas than is needed to reach the peak retention, subsequent tests with simulant layers of different depths and vessels of different diameters will use these concentrations of hydrogen peroxide and iron particles. 


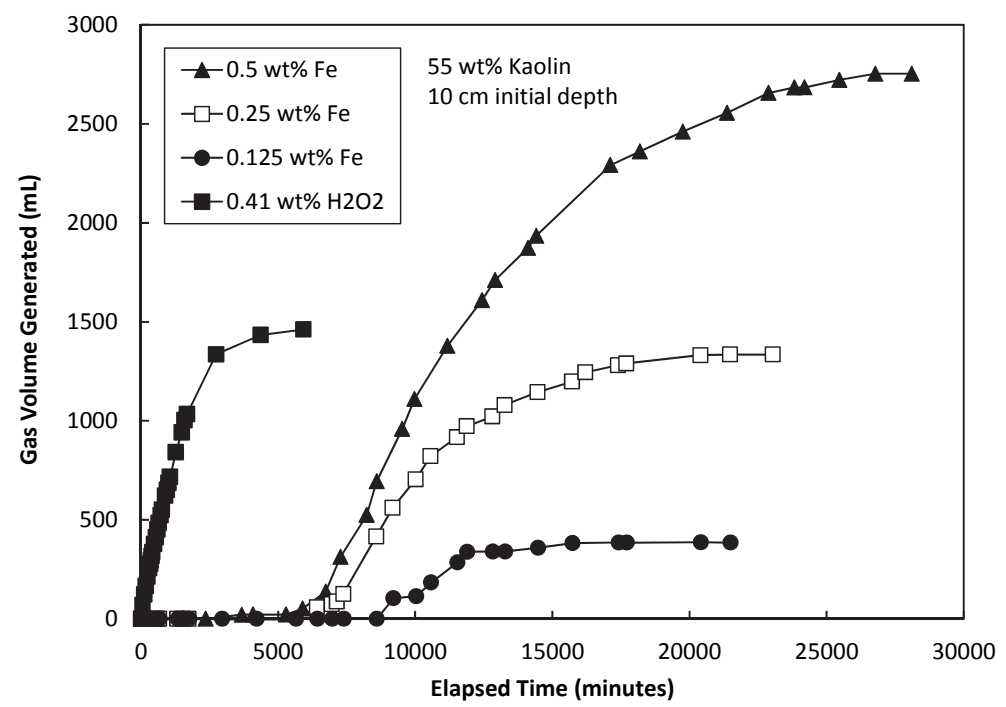

Figure 3.4. Gas Volume Generated for a Range of Iron Concentrations in $55 \mathrm{wt} \%$ (680 Pa) Kaolin Clay and a Comparison to Gas Generated from $0.41 \mathrm{wt} \%$ Hydrogen Peroxide

Figure 3.5 shows the retained gas fraction as a function of the generated gas volume for the three different concentrations of iron and also shows the result when $0.41 \mathrm{wt} \%$ hydrogen peroxide was used for gas generation. In general, while the initial increases in gas fraction behave essentially the same, the maximum gas fraction increases with increasing iron concentration. The difference in peak gas retention between tests with $0.25 \mathrm{wt} \%$ and $0.5 \mathrm{wt} \%$ iron is larger than the difference between $0.41 \mathrm{wt} \%$ and $0.82 \mathrm{wt} \%$ hydrogen peroxide shown in Figure 3.3. Comparing the tests with $0.25 \mathrm{wt} \%$ iron and $0.41 \mathrm{wt} \%$ hydrogen peroxide, which gave similar total gas generation, a lower peak gas retention was observed when gas was generated from the iron particles in comparison to being generated from hydrogen peroxide. The retained bubbles from the two methods of gas generation were visibly different in shape and size (see Figure 3.13), but experiments to determine the mechanisms that gave different bubble shapes and different retention were not conducted.

\subsection{Effect of Simulant Strength on Gas Retention}

A series of gas retention tests were conducted to determine the effect of simulant strength on gas retention behavior. These tests used kaolin simulants ranging from $35 \mathrm{wt} \%$ to $60 \mathrm{wt} \%$, which spanned a range of shear strengths of 15 to $1800 \mathrm{~Pa}$ as given in Table 2.1, beneath a liquid layer. Figure 3.6 shows the gas volume collected for each of these experiments as a function of time. For these tests, $6 \mathrm{~g}$ of hydrogen peroxide ( $200 \mathrm{~g}$ of the $3 \mathrm{wt} \%$ solution) was added to each simulant, though different quantities of each simulant were mixed so the hydrogen peroxide concentration varied as shown in the legend. As shown in Figure 3.6, these experiments did not have the same rate of gas generation, which would have been better for evaluating the role of simulant strength. The results in Figure 3.1 suggest that the small variation in hydrogen peroxide concentration for these tests does not account for all the difference in gas generation rate. Accordingly, it is apparent that gas generation rate increases with increasing concentration of kaolin in the slurry. In additional tests described below in this subsection, simulants composed of different mixtures of kaolin and Min-U-Sil 30 were used; the gas generation rate was nearly constant for a similar range of shear strengths. 


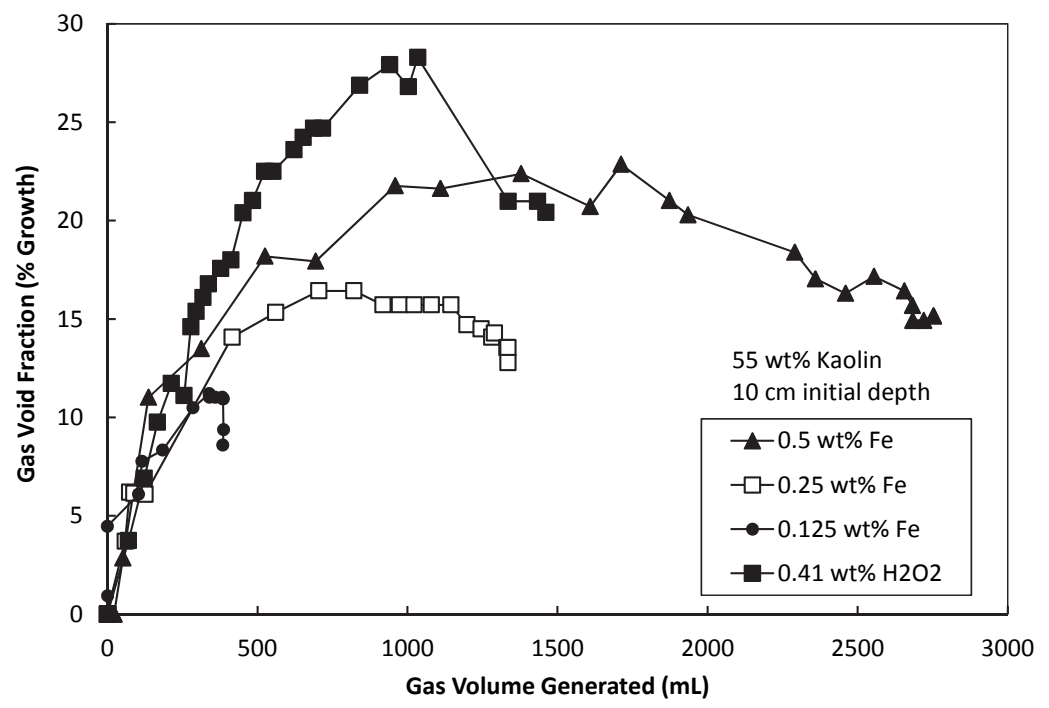

Figure 3.5. Growth in Gas Void Fraction as a Function of Gas Volume Collected for a Range of Iron Concentrations in $55 \mathrm{wt} \%(680 \mathrm{~Pa})$ Kaolin and a Comparison to Gas Retention from $0.41 \mathrm{wt} \%$ Hydrogen Peroxide

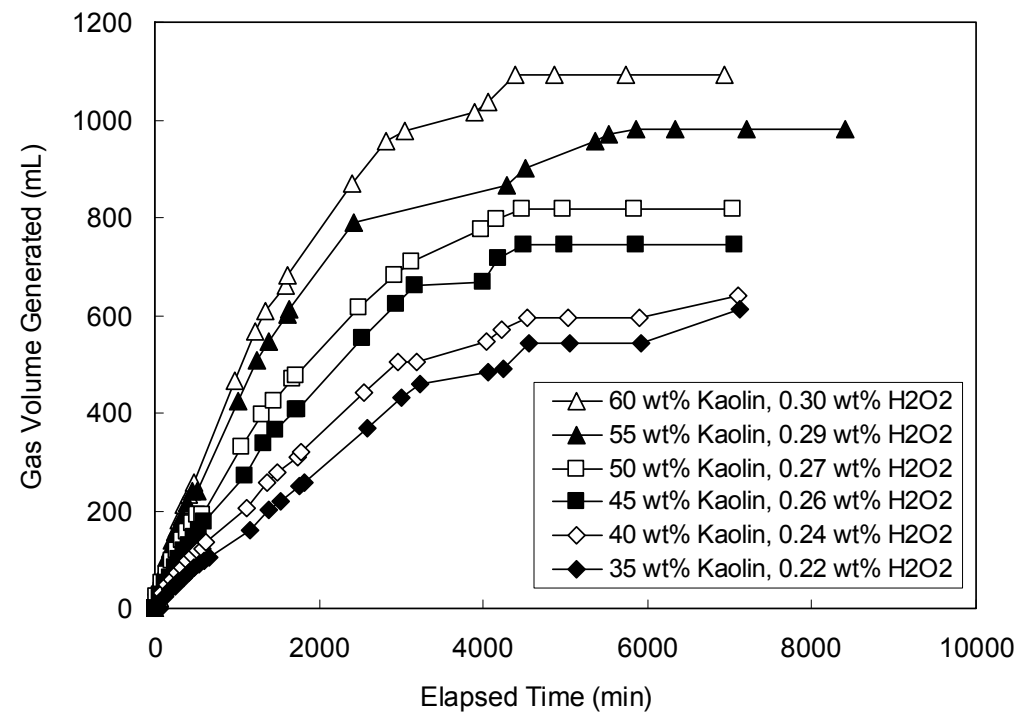

Figure 3.6. Gas Volume Generated for Simulants with a Range of Kaolin Concentrations with Shear Strength Ranging from about 15 to $1800 \mathrm{~Pa}$

Figure 3.7 shows the growth in gas void fraction as a function of the generated gas volume for this range of kaolin simulants. For the three weakest simulants with kaolin concentrations ranging from 35 to $45 \mathrm{wt} \%$ kaolin (15 to $99 \mathrm{~Pa}$ ), the gas fraction increases and then drops dramatically because of significant gas release events. For simulants with 50,55, and $60 \mathrm{wt} \%$ kaolin, corresponding to shear strengths of 260,680 , and $1800 \mathrm{~Pa}$, the gas void fraction grows to just above $20 \%$ and then decreases slightly with continued gas generation. Among these three relatively strong simulants, there is no apparent difference in the peak gas retention. 


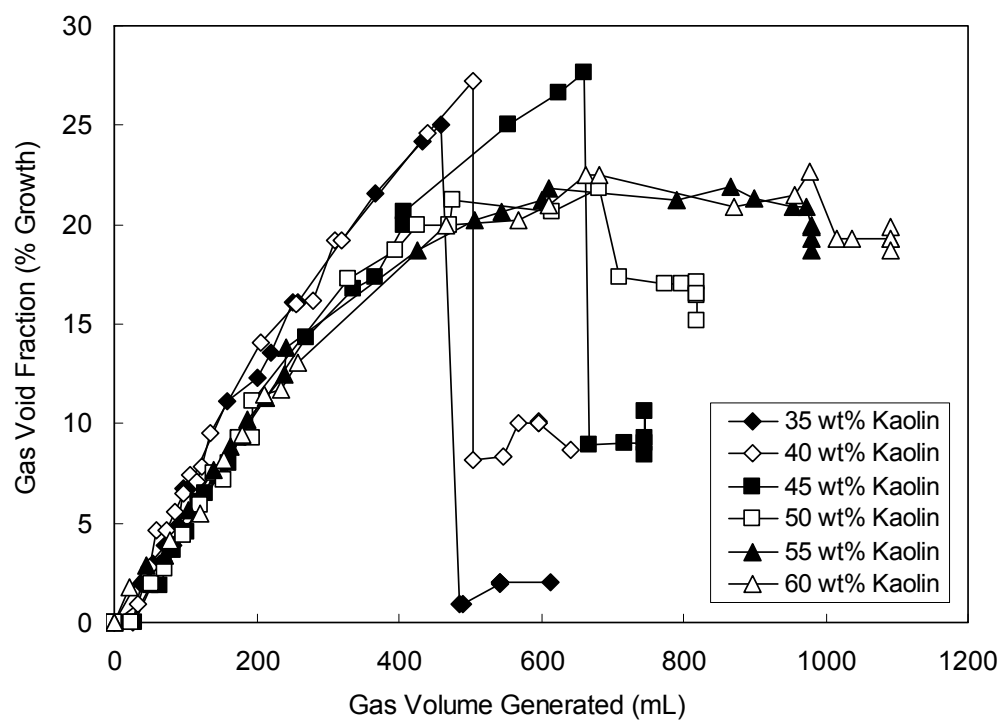

Figure 3.7. Growth in Gas Void Fraction as a Function of Gas Volume Generated using Hydrogen Peroxide for a Range of Simulant Strengths

Because the gas generation rate was not constant for the tests spanning a range of kaolin concentrations and shear strengths, there may still be an effect of simulant strength that was obscured by the increase in generation rate with increasing kaolin concentration and strength. Accordingly, a simulant was selected that would have nearly constant gas generation rate for an interesting range of shear strengths. This simulant selected was mixtures of kaolin and Min-U-Sil 30 as described in Section 2. For these simulants, essentially the same mass of both kaolin and hydrogen peroxide was added to each mixture, and the amounts of Min-U-Sil 30 and water were adjusted to obtain the desired range of shear strengths. As shown in Table 2.2, the estimated shear strength for these simulants varied from 31 to $1300 \mathrm{~Pa}$.

Figure 3.8 shows the gas volume generated as a function of time for the four kaolin/Min-U-Sil 30 mixtures tested. The range of gas generation rates for the kaolin/Min-U-Sil 30 mixtures is much smaller than the range for the kaolin results in Figure 3.6. Figure 3.9 shows the growth in gas void fraction as a function of the generated gas volume for these simulants having a range of shear strengths but nearly constant gas generation rate. For the weakest simulant (31 Pa), the gas fraction increases to almost 30\% and then drops dramatically due to a gas release event, similar to what was observed with the weaker kaolin simulants. For the strongest three kaolin/Min-U-Sil 30 simulants with shear strengths of 240, 690, and $1300 \mathrm{~Pa}$, the gas void fraction reaches a peak near $25 \%$ and then decreases slightly with continued gas generation. For these three strong simulants, there is no apparent difference in the maximum growth in gas retention. 


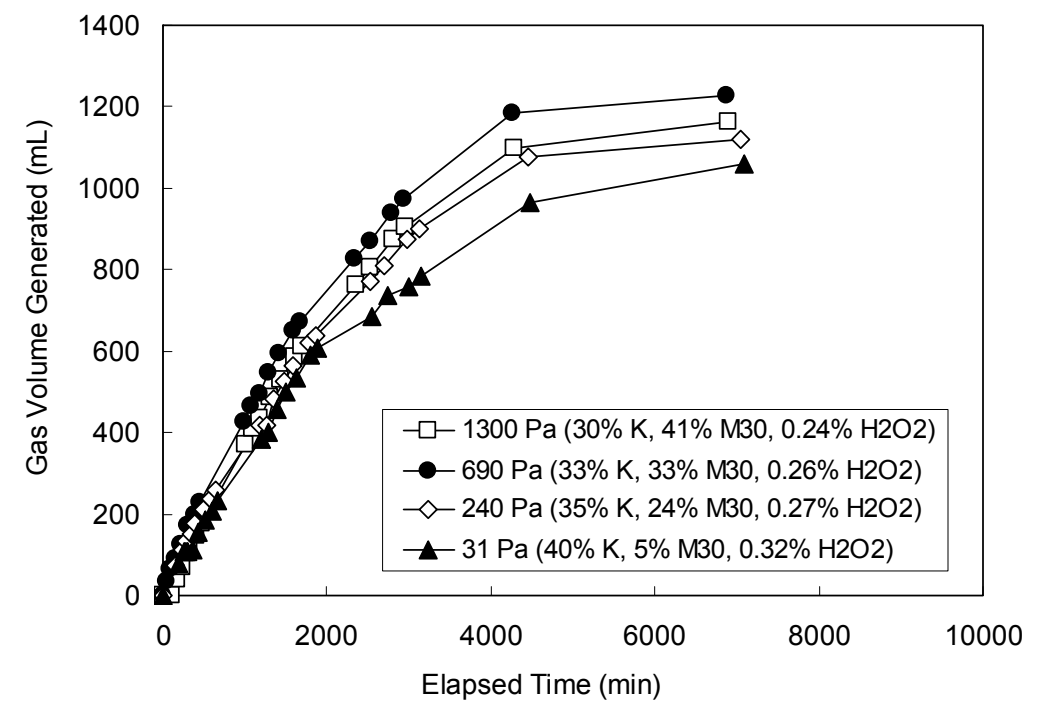

Figure 3.8. Gas Volume Generated for Mixtures of Kaolin and Min-U-Sil 30 that Span a Shear-Strength Range of 31 to $1300 \mathrm{~Pa}$

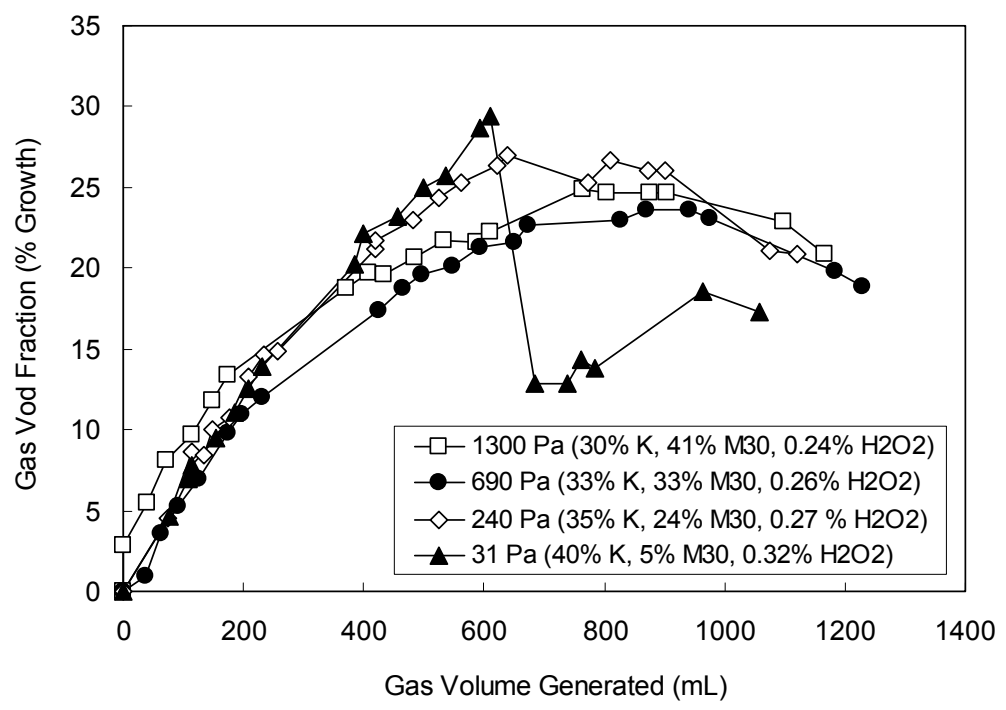

Figure 3.9. Growth in Gas Void Fraction as a Function of Gas Volume Generated for Kaolin and Min-U-Sil 30 Mixtures having Shear Strengths Ranging from 31 to $1300 \mathrm{~Pa}$

One interesting behavior that was observed in bubble retention tests with kaolin was that the kaolin would crack during bubble generation and the clay level would rise faster than the water level. This happened when water from the overlying layer filled the cracks in the clay. This behavior became more apparent as the shear strength of the kaolin sample increased. Initially, it was thought that this might be an important behavior for when low gas retention might occur, but this behavior was not observed in any of the larger tests discussed below in Section 3.3, so based on these limited results it appears to be an artifact of small-scale testing. 


\subsection{Effect of Initial Depth of Simulant Layer and Vessel Diameter}

Tests were conducted to determine the effect of the initial depth of the clay layer on gas retention. Based on previous work, it is expected that channel formation and low gas retention are more likely in stronger materials, so these tests were conducted with $55 \mathrm{wt} \%(680 \mathrm{~Pa})$ kaolin simulants, which had the second-highest kaolin strength. Figure 3.10 shows results for the growth in gas fraction for tests conducted with initial clay-layer depths of 10,50 , and $80 \mathrm{~cm}$ using $0.41 \mathrm{wt} \%$ hydrogen peroxide to generate gas. The most significant observation from these tests is that the peak in gas retention becomes smaller as the depth of the initial layer increases. The data in Figure 3.10 identified as " $50 \mathrm{~cm}$ with weights" are results from a test that was equivalent to the other $50 \mathrm{~cm}$ depth tests but with weights added to the top of the clay to mimic the weight of an additional $38 \mathrm{~cm}$ of clay (see Section 2 for details on the weights). In comparing the two $50 \mathrm{~cm}$ depth tests, the addition of the weights clearly resulted in lower gas retention. If the primary role of bed height is associated with the longer distance through which gas in the lower region of the column must migrate before it can be released, then adding weight to the top of the sediment will have little effect. Because gas retention decreased with the additional weight on the sediment at the same depth of clay, this suggests that the self-weight of the sediment affects bubble retention. For all of these experiments, the $5 \mathrm{in}$. diameter test vessels were used and $0.41 \mathrm{wt} \%$ hydrogen peroxide was added to the clay to generate gas, and this was sufficient to generate gas well beyond the point at which the peak retention was reached.

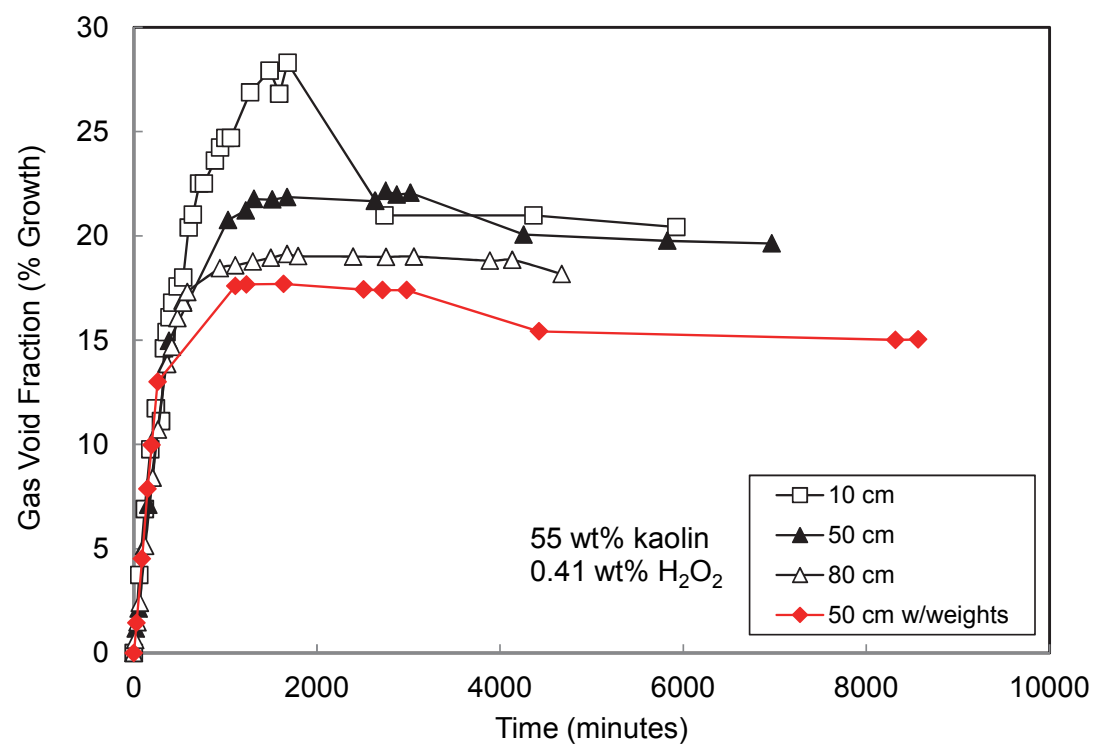

Figure 3.10. Effect of Initial Clay-Layer Depth on Gas Void Fraction in Tests using $55 \mathrm{wt} \%$ Kaolin (680 Pa) Simulants with $0.41 \mathrm{wt} \%$ Hydrogen Peroxide for Gas Generation

Figure 3.11 shows the results from a similar series of tests to determine effect of the initial layer depth on the gas retention when iron particles were used to generate the gas. Tests with different initial layer depths were conducted using the 5 in. diameter $(12.7 \mathrm{~cm})$ vessels; one additional test used a 23 in. diameter $(58.4 \mathrm{~cm})$ vessel to compare results for a change in only the vessel diameter. The results show a similar trend of decrease in peak gas retention with increasing depth of the simulant layer. Figure 3.11 also shows similar peak gas retention values for the vessels with different diameters, but the time scale for the increase in gas retention was quite different. All of the tests in $12.7 \mathrm{~cm}$ diameter vessels used iron particles from an available supply that had been in the laboratory for a period of time, while the 
large-scale test in the $58.4 \mathrm{~cm}$ diameter vessel used a newly purchased batch of iron particles. The older batch of iron probably had a surface layer of corrosion that delayed the onset of additional corrosion of the iron and gas generation.

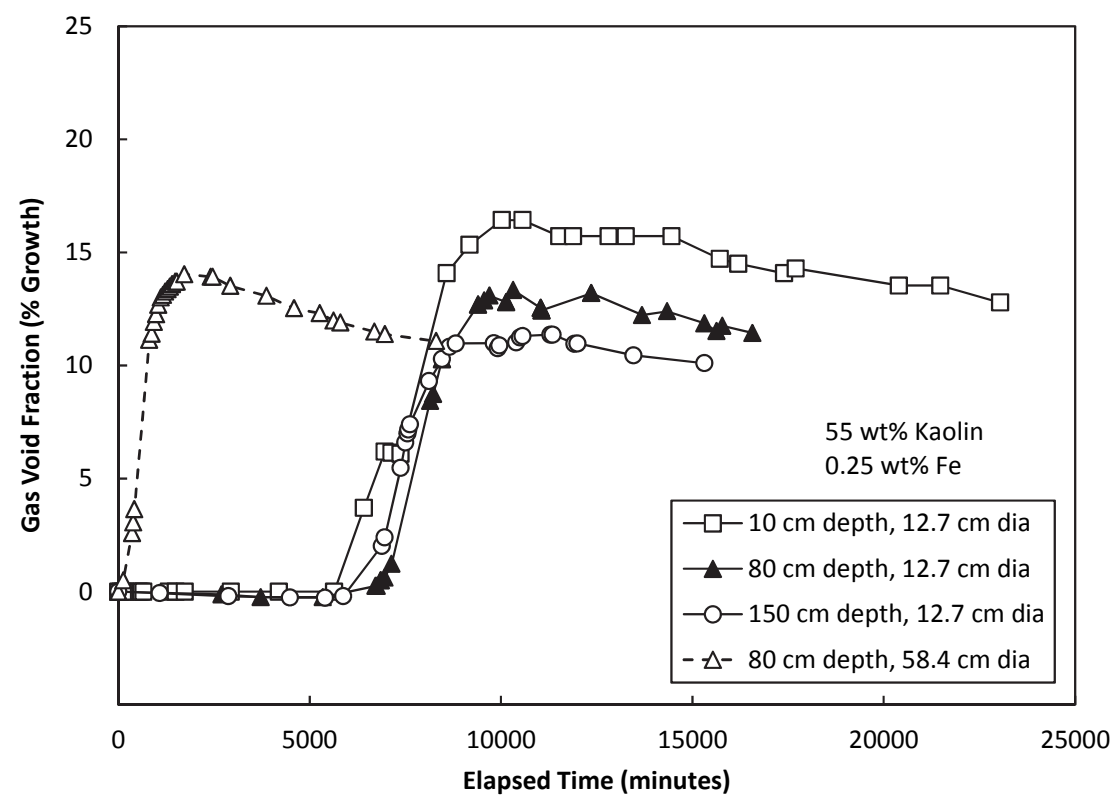

Figure 3.11. Effect of Initial Layer Depth on Gas Void Fraction using $55 \mathrm{wt} \%$ Kaolin $(680 \mathrm{~Pa})$ Simulants with $0.25 \mathrm{wt} \%$ Iron for Gas Generation

Figure 3.12 shows the gas retention behavior with the times shifted so the onsets of gas generation and retention occur at the same time. The results also compare the retention behavior for gas being generated with iron particles and with hydrogen peroxide. The comparison shows no apparent role of vessel diameter on the peak retention for these vessel sizes. Similar to the results discussed in Section 3.1, the peak retention is certainly less when iron particles generated the gas than when the gas was generated from hydrogen peroxide.

The bubble structure was noticeably different when gas was generated with hydrogen peroxide than when it was generated by iron particles. With hydrogen peroxide, the bubbles at the bottom of the column also appeared different from those throughout the majority of the column. The left-hand images in Figure 3.13 show bubbles after 2400 min of gas generation using hydrogen peroxide when the gas void fraction (growth) was steady at the peak retention of about 19\%. Toward the top and in the middle of the column, the bubbles were slit-shaped and looked very similar to those in previous observations (see Figure 1.6). Near the bottom at a height of $20 \mathrm{~cm}$, the bubbles appear smaller and more closely spaced. The right-hand images show bubbles after 9420 min of gas generation with iron particles when the gas void fraction (growth) was $12.7 \%$ and essentially at the peak retention for this test. The bubbles generated with the iron particles were longer and larger slits and there were fewer smaller bubbles between these slits than between the bubbles generated with hydrogen peroxide. 


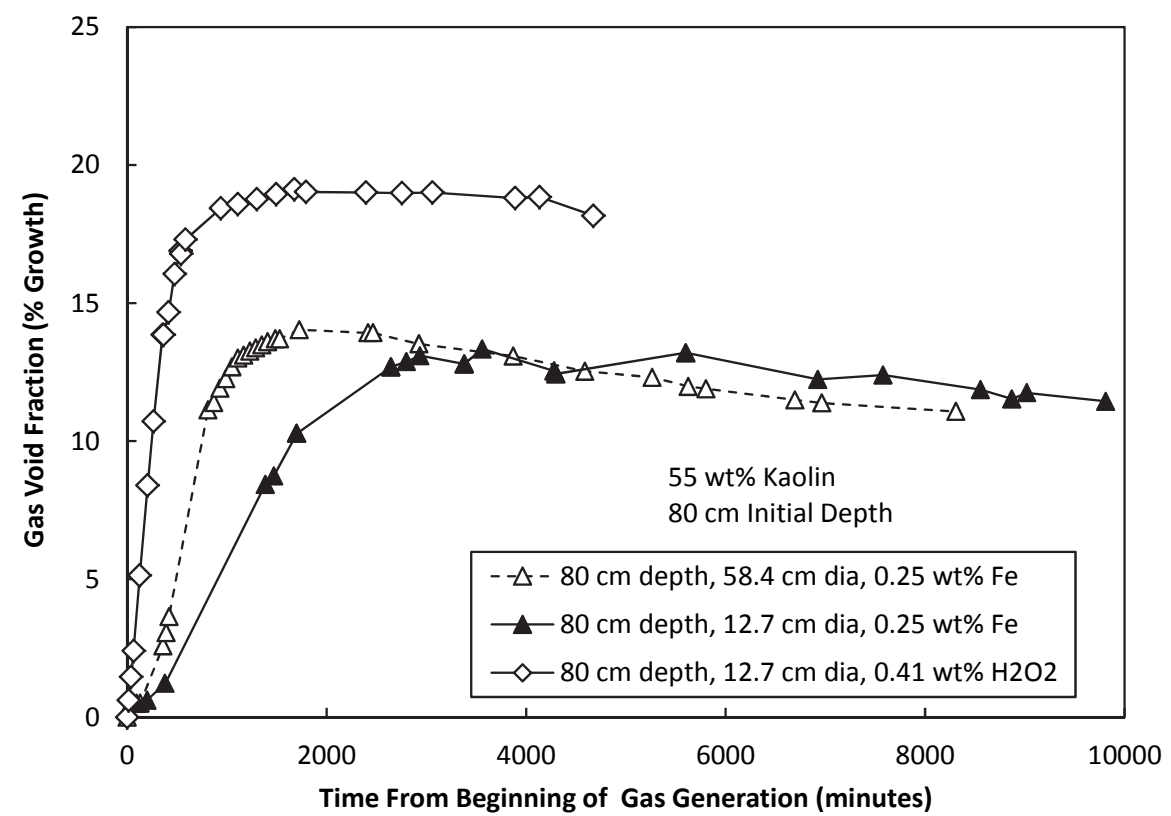

Figure 3.12. Comparison of Gas Retention in Vessels of Different Diameters and with Gas Generated by Hydrogen Peroxide or Iron Particles

After the conclusion (at about $6000 \mathrm{~min}$ ) of the $80 \mathrm{~cm}$ depth test with hydrogen peroxide shown in Figure 3.13, the bulk density of the clay with gas voids was measured by removing $10 \mathrm{~cm}$ segments of clay and weighing the column after each segment was removed. The gas void fraction was then calculated using Equation 2.5 as discussed in Section 2. Figure 3.14 shows the results for the void fraction as a function of depth. The void fraction is about $22 \%$ on average and is nearly constant with depth. Note that this average void fraction includes the initial voids so is a few percent higher than the peak value of about 19\% for the void fraction (growth) shown in Figure 3.10.

Figure 3.15 shows gas retention for the $58.4 \mathrm{~cm}$ diameter test using iron particles for gas generation in $55 \mathrm{wt} \%$ kaolin Clay (680 Pa). As gas bubbles were generated and the void fraction increased, pathways for gas release must have been established, because gas releases were visually obvious as bubbling in the liquid layer above the clay well beyond the time when the peak in gas retention occurred. For tests in the $12.7 \mathrm{~cm}$ diameter columns, gas movement within the bed was never visually obvious though gas releases were again easily recognized as bubbling in the liquid layer. In the $58.4 \mathrm{~cm}$ diameter vessel, gas movement within the clay layer was visually obvious in a few apparent gas release pathways. The gas movement could be identified when a small quantity of liquid was present in the gas pathway and would periodically move when gas flow occurred through that pathway. For the visually observable gas pathways, the liquid would be momentarily displaced and then return. Gas movement may have occurred through many more pathways, but a pathway without liquid present would not visually show gas movement. This movement of gas in established pathways is similar to descriptions given by Van Kessel and Van Kesteren (2002) and Winterwerp and Van Kesteren (2004). 


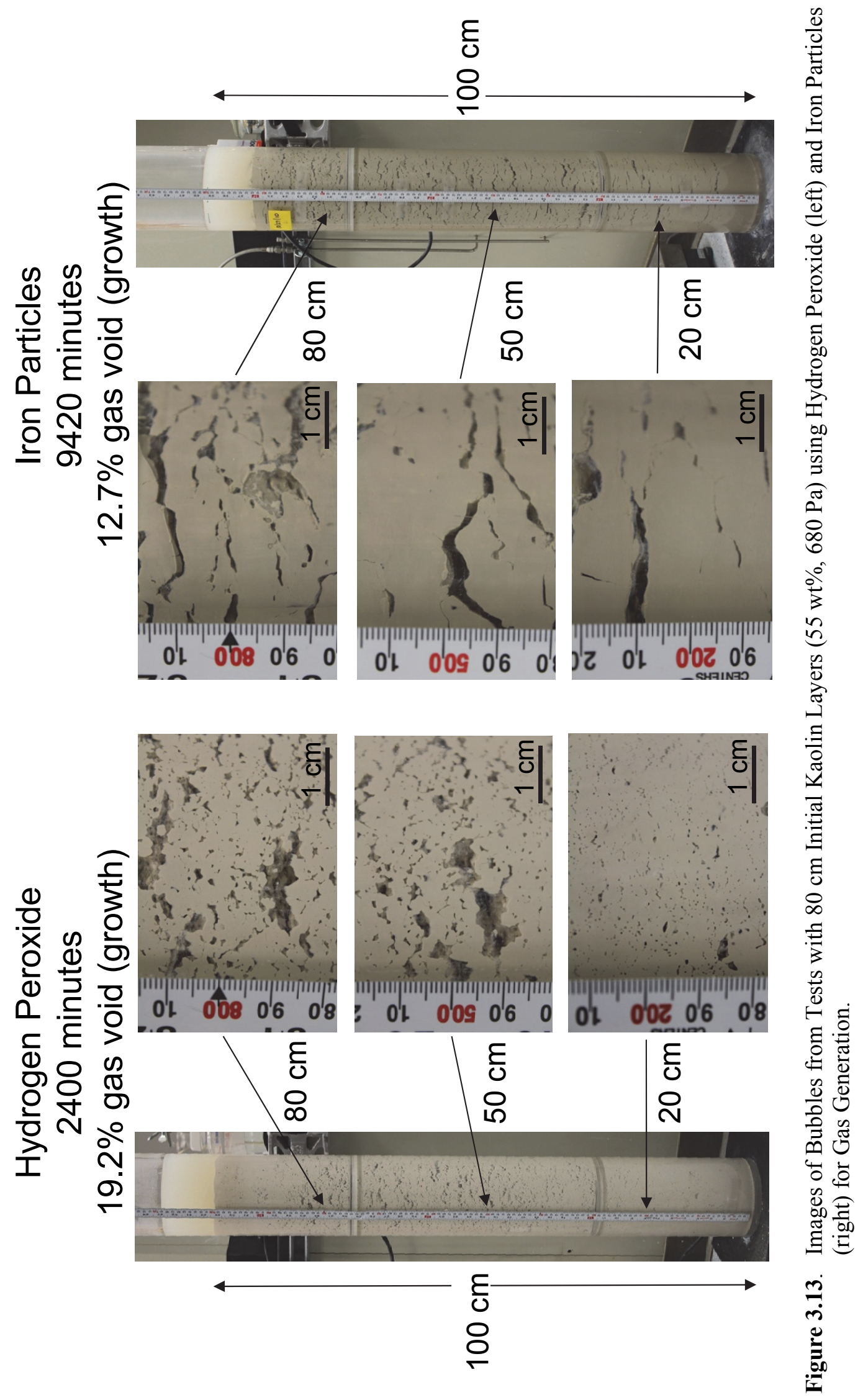




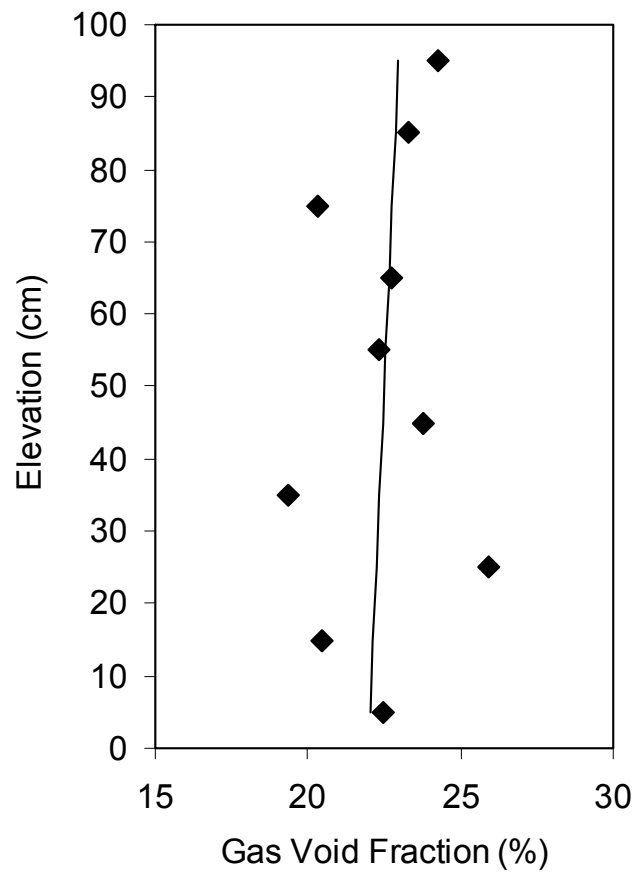

Figure 3.14. Measured Gas Void Fraction as a Function of Elevation at the Conclusion of the $80 \mathrm{~cm}$ Depth Test with $55 \mathrm{wt} \%$ Kaolin Clay. The line shows a linear best fit of the data.

The data for the retained gas for the different initial clay-layer thicknesses can be used with caution to extrapolate to greater simulant depths. Figure 3.16 shows the relationship between the peak values for gas void fraction (growth) given in Figure 3.10 and Figure 3.11 and the bubbly sediment depth at the peak value; the peak gas void fraction versus sediment depth for the large-scale Ketelmeer test is also shown in Figure 3.16. As mentioned previously, the column test results for kaolin show the maximum gas retention decreasing with increasing sediment depth. The two extrapolations shown in Figure 3.16 are from fitting the two larger experiments for both the hydrogen peroxide and iron particles tests. Both extrapolations show decreasing gas retention with the depth of the sediment layer. The extrapolation of the data using iron particles to generate bubbles is fairly close to the results from the large-scale Ketelmeer test. As discussed in Section 1.1, the large-scale Ketelmeer test had biogenic gas generation, used Ketelmeer sediment, and also used a vessel diameter of $3.5 \mathrm{~m}$, which is larger than the $12.7 \mathrm{~cm}$ vessels used with the kaolin clay for the results shown in Figure 3.16. The similar peak gas retention shown in Figure 3.11 for the $12.7 \mathrm{~cm}$ and $58.4 \mathrm{~cm}$ tests suggests that vessel diameter is not a very significant factor, however.

A few tests were conducted using the $12 \mathrm{in.} \mathrm{tall} \mathrm{thin-gap} \mathrm{apparatus} \mathrm{to} \mathrm{observe} \mathrm{bubble} \mathrm{shapes} \mathrm{and} \mathrm{to}$ see whether the formation of channels could be observed. These tests were conducted with 40,50 , and $55 \mathrm{wt} \%$ kaolin clay with a $1 / 8$ in. $(0.328 \mathrm{~cm})$ gasket for the gap. The hydrogen peroxide concentration for these tests was $3 \mathrm{wt} \%$, which is higher than in the previous $12 \mathrm{in}$. and $48 \mathrm{in}$. cylindrical-vessel tests, to ensure plenty of gas generation to observe channels. In general, the bubble shapes were round in the two lower-concentration kaolin simulants and the bubbles were slit-shaped in the $55 \mathrm{wt} \%$ kaolin. This is similar to the images in Figure 1.6 and Figure 3.13. In comparison with these previous images, there was a larger number of smaller bubbles in the thin-gap tests. Figure 3.17 shows images of retained bubbles in the three different strength kaolin slurries. 

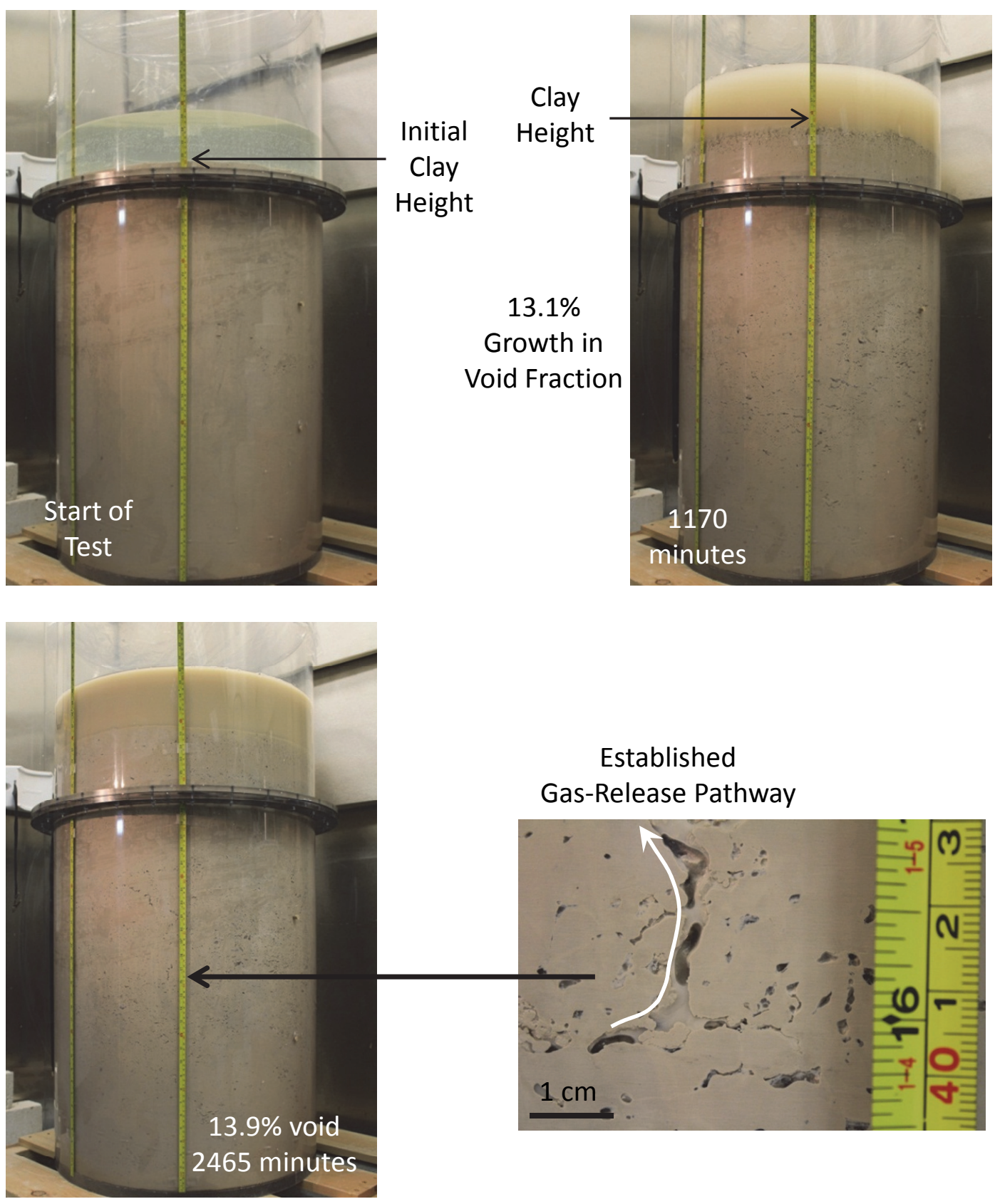

Figure 3.15. Gas Retention and One of the Gas Release Pathways in the Large-Scale Test $(58.4 \mathrm{~cm}$ diameter) with Iron Particles for Gas Generation in 55 wt\% Kaolin Clay (680 Pa) Starting at an Initial Depth of $80 \mathrm{~cm}$ 


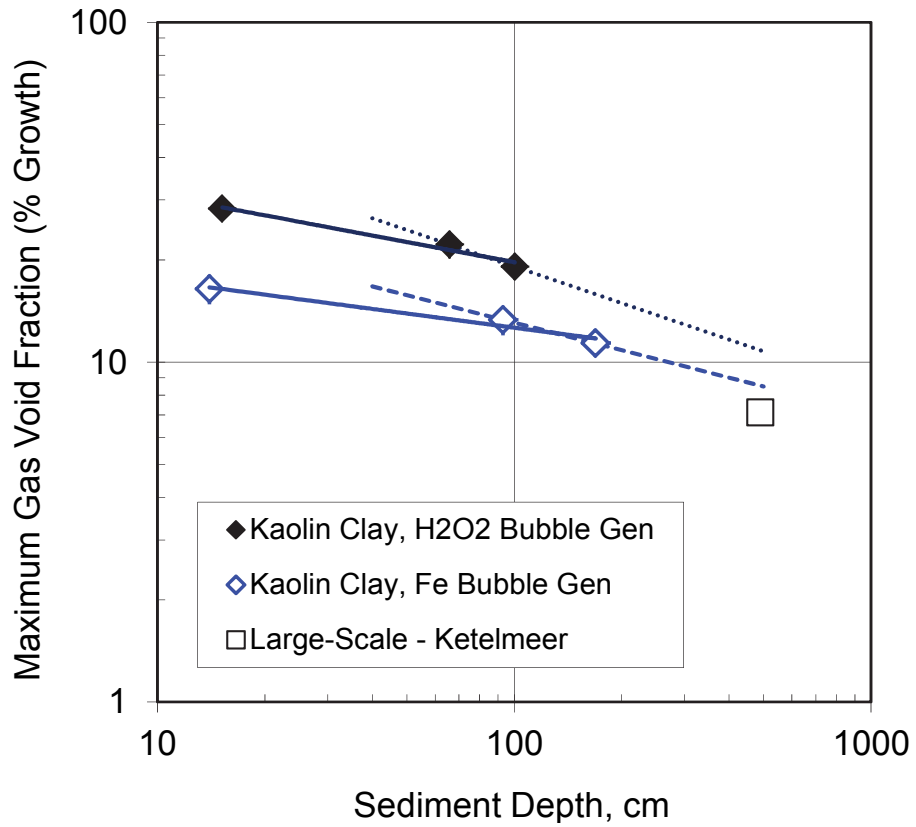

Figure 3.16. Extrapolation to Larger Scale of Maximum Gas Void Fraction Results from Column Tests

\subsection{CT Imaging Results}

CT images showing bubble growth in relatively strong and weak kaolin clay simulants were collected for samples with $55 \mathrm{wt} \%(680 \mathrm{~Pa})$ and $45 \mathrm{wt} \%$ (38 Pa) kaolin. These experiments used the same mixtures of kaolin and hydrogen peroxide as were used in the results reported in Figure 3.6 and Figure 3.7. The initial scan occurred shortly after bubble retention began, and subsequent scans were taken 6,24 , and 48 hours after the beginning of each experiment. Because bubble growth caused internal movement of the sample during imaging, there were some inconsistencies or artifacts when reconstructing the object. In particular, gas- and liquid-filled voids in the center of the cylinder appear elongated or blurred and this is most likely due to movement during scanning. Voids located more toward the outer portion of the cylinder (close to the walls) had fewer motion artifacts and appear sharper. As gas generation slowed with time, there was less internal motion and the images taken after $48 \mathrm{hr}$ of bubble growth were unaffected by the internal movement.

Figure 3.18 shows cross-sections for each scanning time for the two kaolin simulants. In these images, the gas voids are shown as dark objects and the surrounding clay is lighter. As the gas bubbles grow and the void fraction increases, the surface of the clay also rises as seen in the images from left to right. For the $45 \mathrm{wt} \%$ sample, the image at $48 \mathrm{hr}$ shows many bubbles in the bottom of the vessel and comparatively few in the upper half. This was due to a gas-release event that occurred prior to the image at $48 \mathrm{hr}$.

The most notable difference between bubbles in the stronger and weaker kaolin simulants is the size and shape of the retained bubbles. Figure 3.19 shows cross-sections taken at four elevations for the $680 \mathrm{~Pa}$ kaolin, and Figure 3.20 shows an equivalent set of cross-sections for the $38 \mathrm{~Pa}$ kaolin. For the $680 \mathrm{~Pa}$ kaolin, the bubbles are more slit-shaped and these CT images look very similar to the images of bubbles in Figure 3.13 with the same strength kaolin simulant. For the $38 \mathrm{~Pa}$ kaolin, the bubbles are more spherical and appear uniformly distributed. Figure 3.21 shows a more detailed evaluation of the shape of 
an individual bubble in the $680 \mathrm{~Pa}$ kaolin. The images show the 2-D bubble cross-sections from the topto-bottom of a bubble and also from the front-to-back of the bubble. It was hoped that the CT images would allow identification of open channels and potentially water-filled channels, but it was not easy to identify the channels from these reconstructions.

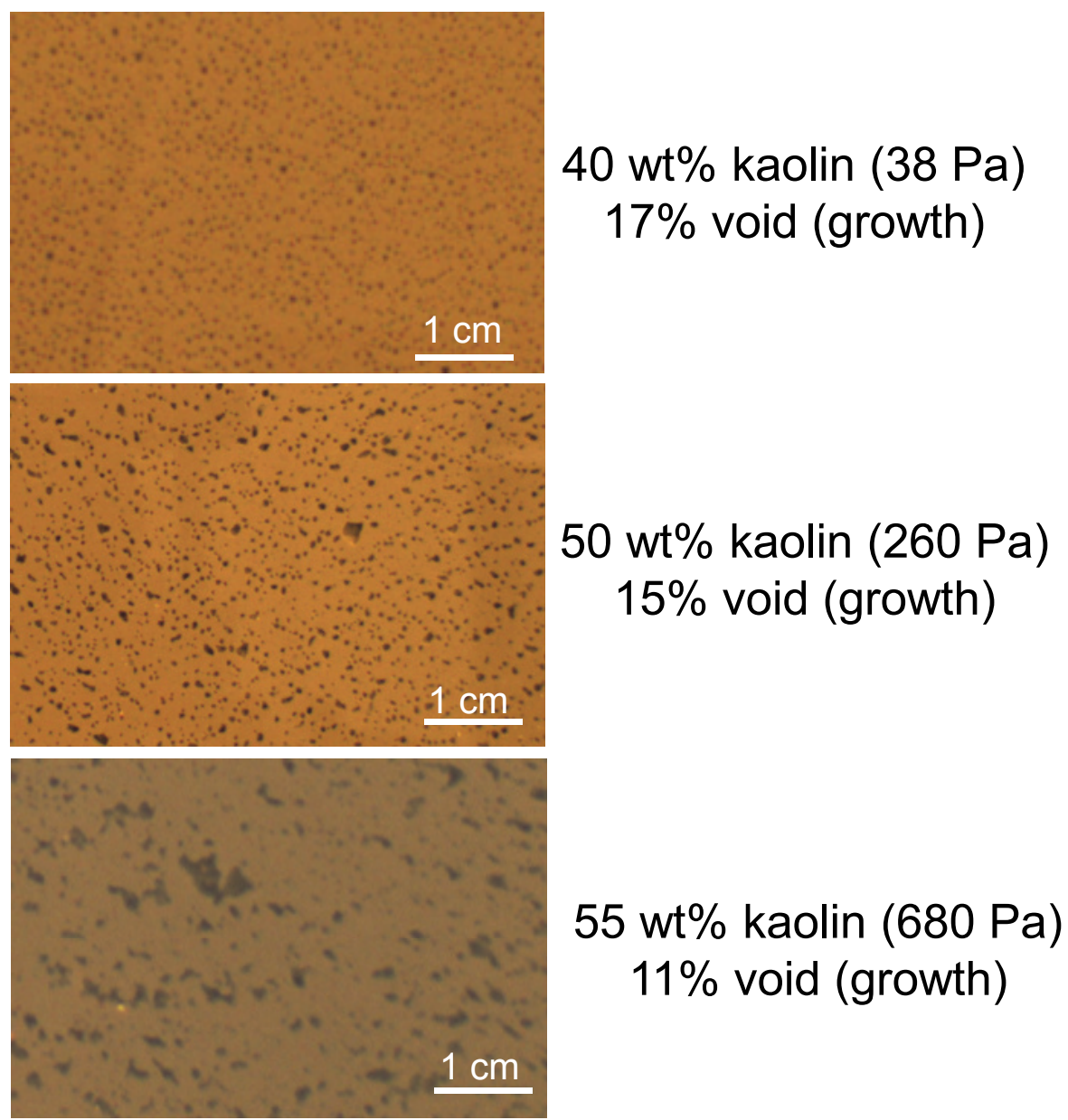

Figure 3.17. Bubbles Retained in the Thin-Gap Apparatus for Different Strength Kaolin Slurries 


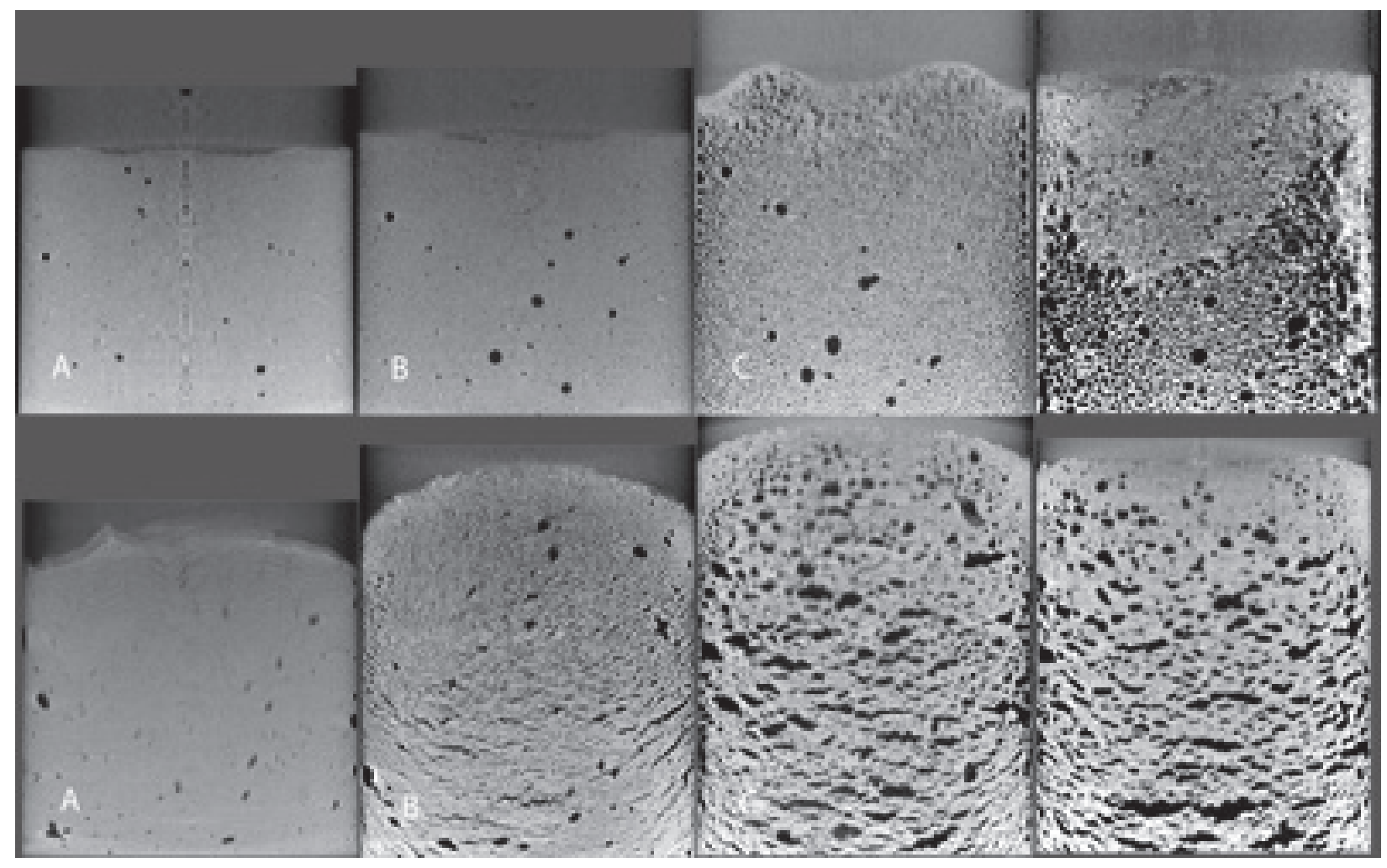

Figure 3.18. Cross-sections of the Weaker $45 \mathrm{wt} \%$ (38 Pa) Kaolin (top) and the Stronger $55 \mathrm{wt} \%$ (680 Pa) Kaolin (bottom) at A) $\sim 0 \mathrm{hr}, \mathrm{B}) 6 \mathrm{hr}, \mathrm{C}) 24 \mathrm{hr}$, and D) $48 \mathrm{hr}$ after the Beginning of Bubble Growth 

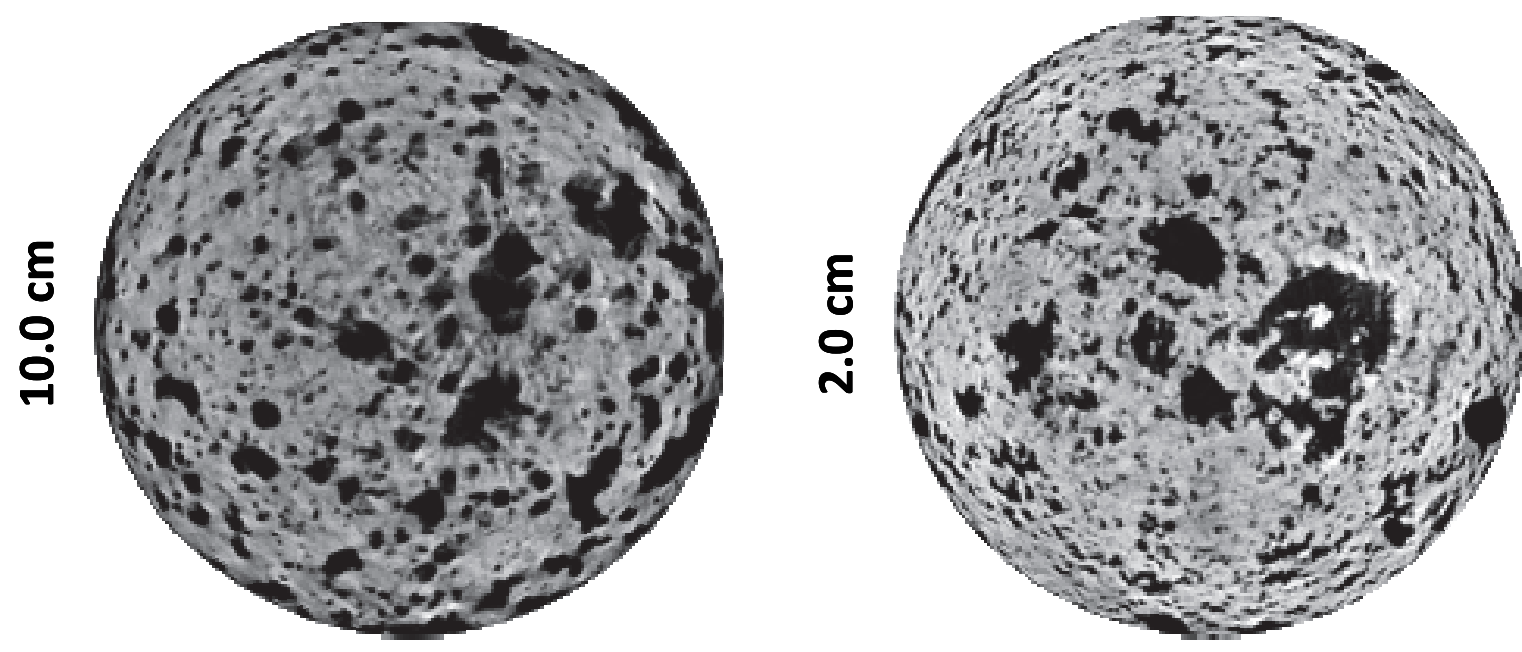

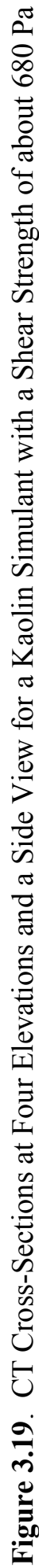



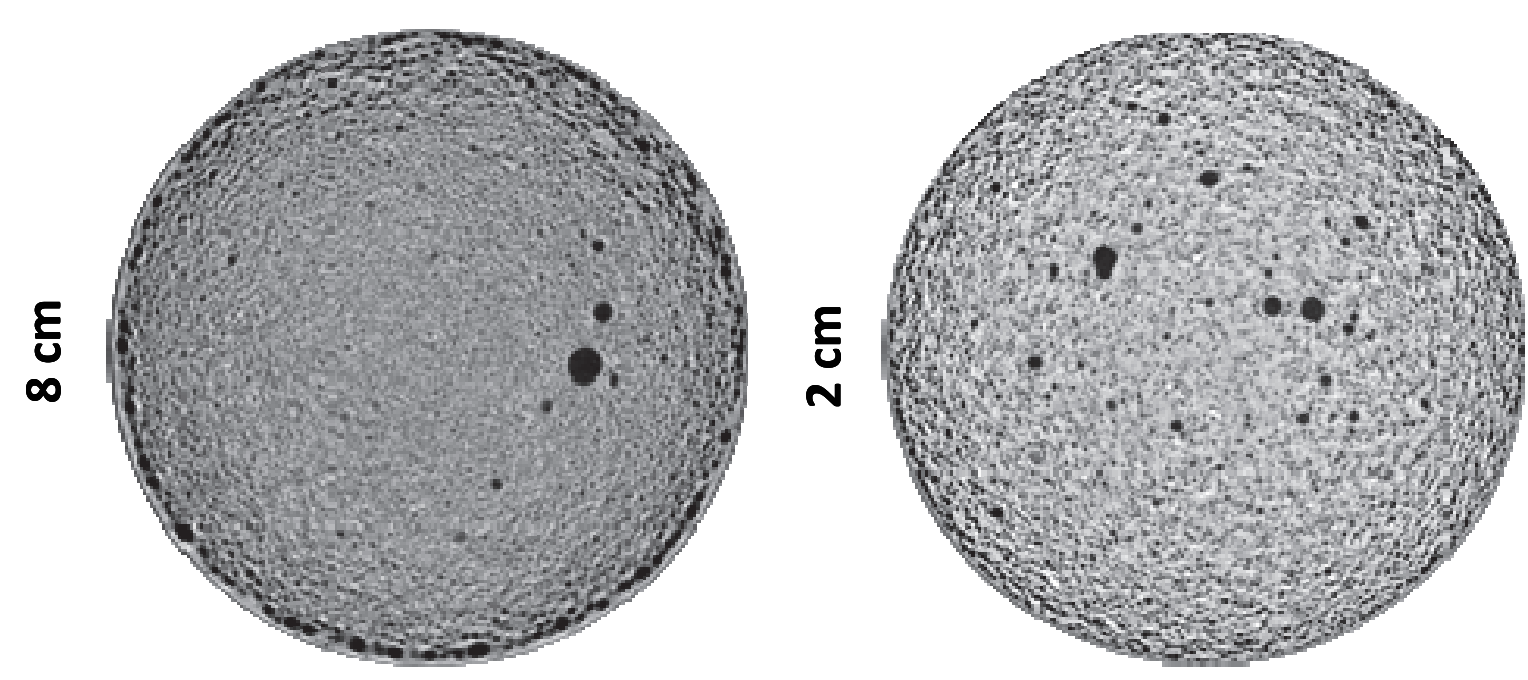

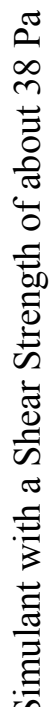
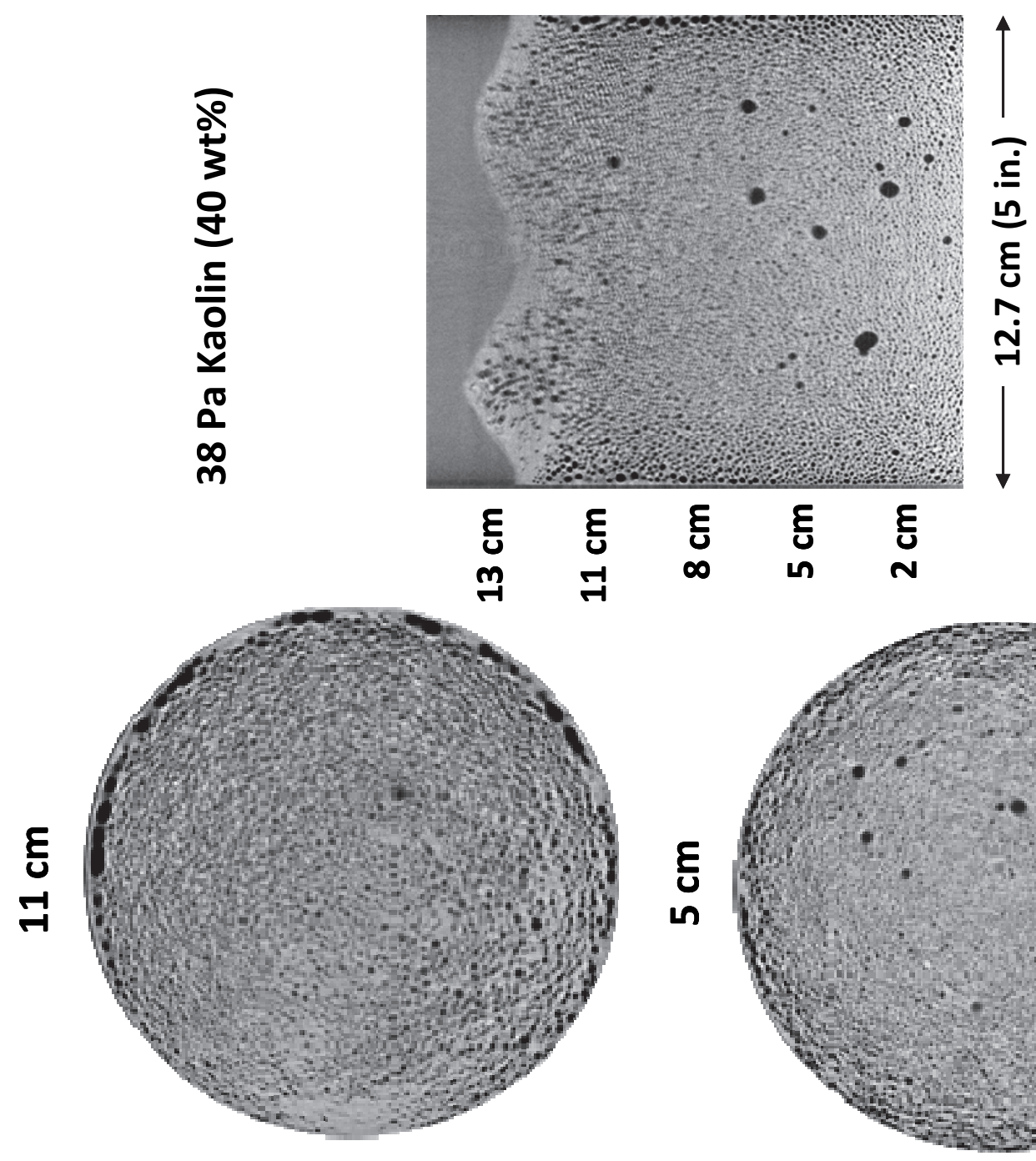

坖
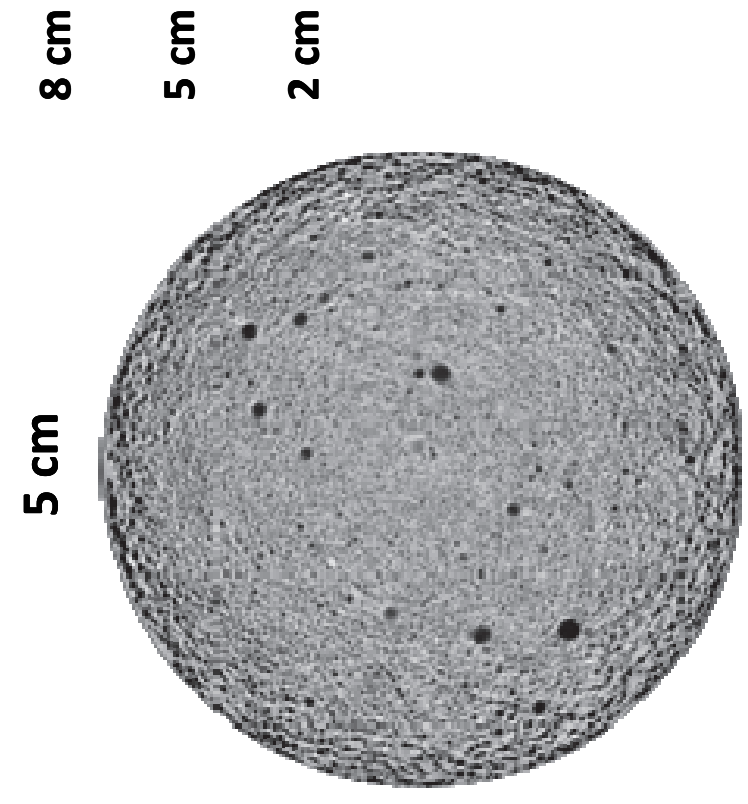

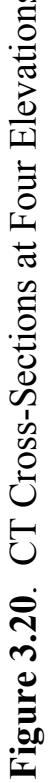




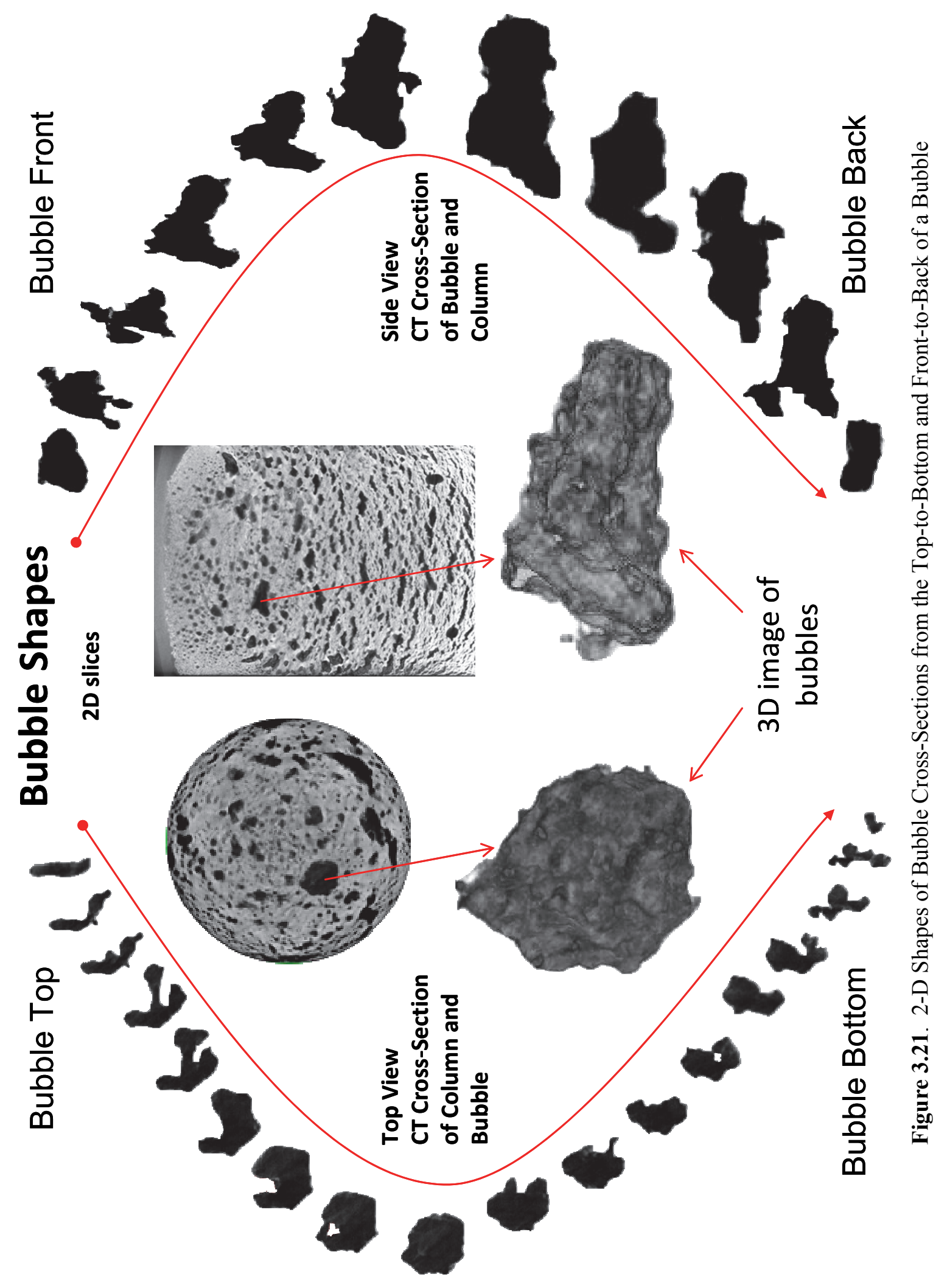





\subsection{Alternate Scenarios and Potential Behavior}

The experiments that have been conducted in this work, and in the previous large-scale test with Ketelmeer sludge (Van Kessel and Van Kesteren 2002), use beds of material that were relatively uniform. In the actual waste tanks at Hanford, the settled waste often has multiple layers in which the individual layers can have varying properties. The gas retention behavior may be quite different when multiple layers are present that have different strengths and/or different gas generation rates. To date, there have been no bubble retention studies that have evaluated the potential behavior of layered systems. In particular, there have been no studies to evaluate whether the presence of one layer might significantly change the overall behavior of an adjacent layer.

Many possible layering scenarios can be postulated, but one particularly simple scenario is a layer of weak material located between layers of strong material above and below the weak material. One possible scenario is that the strong material on the bottom forms cracks and gas release pathways as suggested by the current study, but the adjacent weak layer inhibits the movement of gas from gas release pathways in the lower strong layer to gas release pathways in the upper layer. More specifically, the middle weak layer does not form cracks and gas release pathways so it is unclear how gas will migrate from the lower layer to the upper layer.

Meacham (2010) describes a method of using waste transfers from and to an actual DST, and the expected expansion and compression of any trapped gas due to the changes in hydrostatic head, as an approach for determining whether retained gas is essentially at a maximum value and also the volume fraction of retained gas. To date, there have been no experimental studies demonstrating the response of a layered system to hydrostatic head changes, and the actual behavior of the retained gas may be different from the ideal behavior of a single layer. One possible scenario is again the situation of a weak layer between layers of stronger material. If gas-filled channels exist in the strong material, as suggested by the current study, an increase in hydrostatic head might drive the weak material into these channels. Should this occur, the gas retention behavior and gas releases through the established gas release pathways may be permanently altered in the strong material.

Finally, layers with different gas generation rates may also behave differently from a single layer with a uniform gas generation rate. If a lower layer is generating gas more quickly than an upper layer and begins releasing gas through established gas-release channels, the gas moving through the lower layer may not find a release channel through the upper layer. Exactly what would happen to gas coming from the lower layer is not clear and it may behave differently than expected.

Overall, the understanding of the mechanisms resulting in low gas retention and of the responses of these systems to hydrostatic pressure changes would be improved if testing results were obtained for representative scenarios of layered systems with different strengths and/or gas generation rates. 



\subsection{Conclusions and Recommendations for Future Work}

This report summarizes the results of experiments conducted to evaluate gas retention in strong simulants and to determine the parameters for when relatively low gas retention occurs and whether the low gas retention is similar to that of a previously reported large-scale test. The previous large-scale gasretention test was conducted in a $3.5 \mathrm{~m}$ diameter test vessel with a sediment layer about $5 \mathrm{~m}$ deep. The average retained-gas volume fraction grew over a 25 day period to a peak value of about $7 \%$ and then decreased to about $5 \%$. This is much lower than in previous small-scale tests (see discussion in Section 1.2).

Small-scale tests were conducted with various mixtures of kaolin clay and Min-U-Sil 30 in $12.7 \mathrm{~cm}$ diameter test vessels with gas generation provided either by the decomposition of hydrogen peroxide to form oxygen bubbles or by the corrosion of iron to form hydrogen bubbles. The gas generation rates varied and resulted in peak gas retention that occurred after about 1 to 10 days. The volumes of retained gas and total generated gas were measured over time to determine the retained-gas fraction. Tests were conducted in transparent vessels to allow observations of the bubbles, and the structure of retained bubbles was also characterized in selected experiments using an x-ray microfocus computed tomography (XMT) instrument. These tests were about five-fold larger in diameter and had gas generation rates at least 20 -fold slower than the previous small-scale tests. Tests were also conducted in the $12.7 \mathrm{~cm}$ diameter vessels with initial simulant layer depths that ranged from 0.1 to $1.50 \mathrm{~m}$. In general, for tests with $0.1 \mathrm{~m}$ initial layer depths and with gas generated from hydrogen peroxide, the peak gas retention was about $20-30 \%$. A lower peak gas retention was observed when gas was generated from the iron particles than when it was generated from hydrogen peroxide. The retained bubbles were visibly different between the two methods of gas generation, but experiments to determine the mechanisms that gave different bubble shapes and thus different retention were not conducted. One larger test was conducted with kaolin clay in a $58.4 \mathrm{~cm}$ diameter vessel with gas generated by the corrosion of iron particles.

The most significant results from the current experiments are that progressively lower gas retention occurs in tests with progressively deeper sediment layers and that the method of gas generation also affects the maximum retention. Based on the results of this study, it is plausible that relatively low gas retention could occur in sufficiently deep tank waste in DSTs. The current studies and previous work, however, have not explored how gas retention and release will behave when two or more layers with different properties are present.

The other main conclusion from this study is that there was no apparent role of vessel diameter on bubble retention for the $12.7 \mathrm{~cm}$ and $58.4 \mathrm{~cm}$ diameter vessels used in this study. For tests with layers only $0.1 \mathrm{~m}$ deep, there was no apparent role of simulant strength on the peak retention for strengths between 260 and $1800 \mathrm{~Pa}$. Tests investigating the effect of strength with deeper layers were not conducted.

Current and previous studies have focused on the gas retention behavior in single layers with relatively uniform properties. The gas retention behavior when multiple layers are present that have different strengths and/or different gas generation rates may be quite different. The overall understanding of the mechanisms resulting in low gas retention would be improved if test results were obtained for 
representative scenarios of layered systems. Current and previous experimental studies have also not quantified how accurately gas retention behavior can be determined from measurements when the system pressure is changed through changes in the hydrostatic pressure of an overlying liquid layer. In addition to the general confirmation of expected gas expansion and compression, the gas retention behavior of layered systems may be affected by the interaction of adjacent layers, resulting in uncertainty in interpreting the gas retention behavior. Again, the overall understanding of low gas retention behavior would be improved with testing that demonstrates the behavior of single and multiple gas-retaining layers with changes in hydrostatic pressure. 


\subsection{References}

Bredt PR and SM Tingey. 1996. The Effect of Dilution on the Gas Retention Behavior of

Tank 241-SY-103 Waste. PNNL-10893, Pacific Northwest National Laboratory, Richland, Washington. Accessed October 5, 2010 at http://www.osti.gov/bridge/servlets/purl/192554-

3mYTHU/webviewable/192554.pdf (undated webpage).

Bredt PR, SM Tingey, and EH Shade. 1995. The Effect of Dilution on the Gas Retention Behavior of Tank 241-SY-101 Waste. PNL-10781, Pacific Northwest Laboratory, Richland, Washington. Accessed October 5, 2010 at http://www.osti.gov/bridge/servlets/purl/108207-9sFo4R/webviewable/108207.pdf (undated webpage).

Certa PJ and MN Wells. 2009. River Protection Project System Plan. ORP-11242 Rev 4, U.S. Department of Energy, Office of River Protection, Richland, Washington. Accessed October 5, 2010 at http://www.hanford.gov/orp/uploadfiles/ORP-11242\%20\%20\%5B0909150188\%5D\%5B1\%5D.pdf (undated webpage).

Certa PJ, PA Empey, and MN Wells. 2011. River Protection Project System Plan. ORP-11242 Rev 6, U.S. Department of Energy, Office of River Protection, Richland, Washington. Accessed February 2, 2012 at http://www.hanford.gov/files.cfm/ORP-11242_REV_6_-_[1110050954].pdf (undated webpage).

Chhabra RP. 1993. Bubbles, Drops, and Particles in Non-Newtonian Fluids. CRC Press, Boca Raton, Florida.

Cornelisse JM. 1997. Measurement Report of the Large-Scale Laboratory Experiment on Sediment from Lake Ketel with Artificial Gas Production. Technical Report DM13, Delft Hydraulics, the Netherlands (in Dutch).

Delegard CH and AJ Schmidt. 2009. Uranium Metal Reaction Behavior in Water, Sludge, and Grout Matrices. PNNL-17815, Rev 1, Pacific Northwest National Laboratory, Richland, Washington.

Dullien FAL. 1992. Porous Media: Fluid Transport and Pore Structure. $2^{\text {nd }}$ ed. Academic Press, San Diego, California.

Gauglitz PA, LA Mahoney, DP Mendoza, and MC Miller. 1994. Mechanisms of Gas Bubble Retention. PNL-10120, Pacific Northwest Laboratory, Richland, Washington. Accessed October 5, 2010 at http://www.osti.gov/bridge/servlets/purl/10186009-7disLD/webviewable/10186009.pdf (undated webpage).

Gauglitz PA, SD Rassat, MR Powell, RR Shah, and LA Mahoney. 1995. Gas Bubble Retention and its Effect on Waste Properties: Retention Mechanisms, Viscosity, and Tensile and Shear Strength. PNL-10740, Pacific Northwest Laboratory, Richland, Washington. Accessed October 5, 2010 at http://www.osti.gov/energycitations/servlets/purl/104988-o31YoC/webviewable/104988.pdf (undated webpage).

Gauglitz PA, SD Rassat, PR Bredt, JH Konynenbelt, SM Tingey, and DP Mendoza. 1996. Mechanisms of Gas Bubble Retention and Release: Results for Hanford Waste Tanks 241-S-102 and 241-SY-103 and 
Single-shell Tank Simulants. PNNL-11298, Pacific Northwest National Laboratory, Richland, Washington. Accessed October 5, 2010 at http://www.osti.gov/bridge/servlets/purl/15001164$2 \mathrm{fnImA} /$ native/15001164.pdf (undated webpage).

Gauglitz PA, G Terrones, SJ Muller, MM Denn, and WR Rossen. 2001. Mechanics of Bubbles in Sludges and Slurries: Final Report for U.S. Department of Energy. PNNL-13748, Pacific Northwest National Laboratory, Richland, Washington.

Gauglitz PA, BE Wells, JA Fort, and PA Meyer. 2009. An Approach to Understanding Cohesive Slurry Settling, Mobilization, and Hydrogen Gas Retention in Pulsed Jet Mixed Vessels. PNNL-17707 Rev 0, Pacific Northwest National Laboratory, Richland, Washington. Accessed October 5, 2010 at http://www.pnl.gov/main/publications/external/technical_reports/PNNL-17707.pdf (undated webpage).

Gauglitz PA, WC Buchmiller, JJ Jenks, J Chun, RL Russell, AJ Schmidt, and MM Mastor Jr. 2010. The Disruption of Vessel-spanning Bubbles with Sloped Fins in Flat-Bottom and 2:1 Elliptical-Bottom Vessels. PNNL-19345 Rev 0, Pacific Northwest National Laboratory, Richland, Washington.

Kalender WA. 2000. Computed Tomography: Fundamentals, System Technology, Image Quality, Applications. MDC Werbeagentur GmbH, Munich.

Ketcham RA and WD Carlson. 2001. "Acquisition, Optimization and Interpretation of X-ray Computed Tomographic Imagery: Applications to the Geosciences.” Computers \& Geosciences 27(4):381-400, DOI: 10.1016/S0098-3004(00)00116-3.

McGrail BP, EM Pierce, HT Schaef, EA Rodriguez, JL Steele, AT Owen, and DM Wellman. 2003. Laboratory Testing of Bulk Vitrified and Steam Reformed Low-activity Waste Forms to Support a Preliminary Risk Assessment for an Integrated Disposal Facility. PNNL-14414, Pacific Northwest National Laboratory, Richland, Washington. Accessed October 5, 2010 at http://www.pnl.gov/main/publications/external/technical_reports/PNNL-14414.pdf (undated webpage).

Meacham, JE. 2010. Gas Retention and Release from Hanford High Shear Strength Waste. RPP-RPT-26836, Rev 0, Washington River Protection Services LLC, Richland, Washington.

Rassat SD, PA Gauglitz, PR Bredt, LA Mahoney, SV Forbes, and SM Tingey. 1997. Mechanisms of Gas Bubble Retention and Release: Experimental Results for Hanford Waste Tanks 241-AW-101 and 241-AN-103. PNNL-11642, Pacific Northwest National Laboratory, Richland, Washington. Accessed October 6, 2010 at http://www.osti.gov/bridge/servlets/purl/555249-Leit4z/webviewable/555249.pdf (undated webpage).

Rassat SD, SM Caley, PR Bredt, PA Gauglitz, DE Rinehart, and SV Forbes. 1998. Mechanisms of Gas Bubble Retention and Release: Experimental Results for Hanford Single Shell Waste Tanks 241-A-101, 241-S-106, and 241-U-103. PNNL-11981, Pacific Northwest National Laboratory, Richland, Washington. Accessed October 6, 2010 at http://www.osti.gov/bridge/servlets/purl/665912$\mathrm{BeOyPM/webviewable/665912.pdf} \mathrm{(undated} \mathrm{webpage).}$

Rassat SD, PA Gauglitz, SM Caley, LA Mahoney, and DP Mendoza. 1999. A Discussion of SY-101 Crust Gas Retention and Release Mechanisms. PNNL-12092, Pacific Northwest National Laboratory, 
Richland, Washington. Accessed October 6, 2010 at

http://www.pnl.gov/main/publications/external/technical_reports/PNNL-12092.pdf(undated webpage).

Reardon, EJ. 1995. "Anaerobic Corrosion of Granular Iron: Measurement and Interpretation of Hydrogen Evolution Rates.” Environ. Sci. Technol. 26:2936-2945.

Stewart CW, JM Alzheimer, ME Brewster, G Chen, RE Mendoza, HC Reid, CL Shepard, and G Terrones. 1996. In Situ Rheology and Gas Volume in Hanford Double-shell Waste Tanks. PNL-11296, Pacific Northwest National Laboratory, Richland, Washington.

Van Kessel T. 1998. Bubble Initiation and Bubble Growth in Sediment Layers. Technical Report Z2314, Delft Hydraulics, the Netherlands (in Dutch).

Van Kessel T and WGM van Kesteren. 2002. "Gas Production and Transport in Artificial Sludge Depots.” Waste Management 22(1):19-28, DOI: 10.1016/S0956-053X(01)00021-6.

Verhoeven WJ. 1998. In-Situ Measurements on the Sediment Tank of Delft Hydraulics. Technical Report 96-145/A, GWR, the Netherlands (in Dutch).

Walker DD, CL Crawford, and NE Bibler. 1994. "Radiolytic Bubble Formation and Level Changes in Simulated High-level Waste Salts and Sludges - Application to HLW Storage Tanks." In Proceedings of Waste Management 1994, Vol 1, pp. 393-396. February 27-March 3, 1994, Tucson, Arizona.

Weber RA. 2009. Methodology and Calculations for the Assessment of Waste Groups for the Large Underground Waste Storage Tanks at the Hanford Site. RPP-100006 Rev 8, Washington River Protection Solutions LLC, Richland, Washington.

Wellman DM, JP Icenhower, and AT Owen. 2005. Comparative Analysis of Soluble Phosphate Amendments for the Remediation of Heavy Metal Contaminants: Effect on Sediment Hydraulic Conductivity. PNNL-SA-44734, Pacific Northwest National Laboratory, Richland, Washington.

Wheeler SJ. 1990. "Movement of Large Gas Bubbles in Unsaturated Fine-grained Sediments." Marine Geotechnology 9(2):113-129, DOI: 10.1080/10641199009388234.

Willis WL and MR Ahrendt. 2009. Tank Space Options Report. RPP-7702 Rev 1, Washington River Protection Solutions LLC, Richland, Washington. Accessed October 5, 2010 at http://www.osti.gov/bridge/servlets/purl/963955-8wBmHp/963955.pdf (undated webpage).

Winterwerp JC and WGM van Kesteren. 2004. "Introduction to the Physics of Cohesive Sediment in the Marine Environment." Developments in Sedimentology, Vol 56, Elsevier, New York. 



\section{Appendix}

\section{Approach for Slow Biological Gas Production}





\title{
Appendix
}

\section{Approach for Slow Biological Gas Production}

\author{
FJ Brockman
}

In future bubble retention studies, we propose to generate gas bubbles in a much slower manner than in the PNNL laboratory studies contained in this report. The proposed approach is to use an alternate biogenetic method than the approach used by Van Kessel and Van Kesteren (2002) in which methane was the primary insoluble gas. Since the mid-1970s, it has been well documented that microorganisms can produce gas bubbles in saturated porous media under both field and laboratory conditions. Nitrogen gas $\left(\mathrm{N}_{2}\right)$ is insoluble and can be readily generated, and is the gas we will target to produce biologically in our proposed future column studies, although some carbon dioxide $\left(\mathrm{CO}_{2}\right)$ will also be produced. Nitrogen gas is produced as a metabolic byproduct by a group of bacteria known as nitrate reducers or denitrifiers. The energy-generating metabolism in these bacteria involves extracting electrons from organic compounds (electron donors) and transferring the electrons to nitrate (electron acceptor), forming $\mathrm{N}_{2}$. This process occurs after oxygen (the preferred electron acceptor) becomes depleted.

\section{A.1 Selection of Bacterium and Previous Work}

The bacterium Pseudomonas stutzeri strain KC will be used because it is known to carry the reduction of nitrate to $\mathrm{N}_{2}$ with little or no accumulation of the highly soluble gaseous intermediates nitric oxide (NO) and nitrous oxide $\left(\mathrm{N}_{2} \mathrm{O}\right)$ (Madigan et al., 2000). This bacterium was successfully used to produce extensive gas bubbles in a column study (Williams, 2002). Microbiological aspects of the Williams study were conducted under the mentoring of PNNL microbiologist Fred Brockman. Because the focus of the Williams study was monitoring microbe-induced changes in physical properties via highfrequency acoustic measurements, volumetric measurements of gas production were not made. However, based on acoustic measurements, the first indication of gas bubbles in the Williams column study was 7 days after initiation of the column experiment and most of the observed changes occurred by 30 days. Note that this time frame is approximately the same as the 600 hours for reaching a peak in gas retention in the van Kessel and van Kesteren (2002) studies. In addition, accumulation of gas bubbles was easily observable along the column wall. Thus, previous work demonstrates the proposed approach will successfully produce microbially generated gas bubbles, and that gas production is much slower than the approximately 10 hours for the most recent PNNL tests described in this report.

\section{A.2 Stoichiometry}

Both $\mathrm{CO}_{2}$ and $\mathrm{N}_{2}$ are produced during nitrate reduction. In the absence of ammonium $\left(\mathrm{NH}_{4}\right)$, P. stutzeri carries out both assimilatory nitrate reduction $\left(\mathrm{NO}_{3}\right.$ is converted to ammonia, which is used to synthesize biomass) and dissimilatory nitrate reduction. At high growth rates, approximately $20 \%$ of the electron flow is directed to assimilation and $80 \%$ to dissimilation. Using this fractionation, which is appropriate for a monoculture grown in laboratory nutrient medium, stoichiometric half-reactions were 
determined for nitrate reduction using acetate as the carbon and energy source (Nazaroff and AlvarezCohen, 2001; Rittmann and McCarty, 2001). The half-reactions and the balanced equation are as follows:

Acetate consumption:

$0.125 \mathrm{CH}_{3} \mathrm{COO}^{-}+0.25 \mathrm{H}_{2} \mathrm{O} \rightarrow 0.25 \mathrm{CO}_{2}+0.875 \mathrm{H}^{+}+1.0 \mathrm{e}^{-}$

$80 \%$ electron flow coupled to $\mathrm{N}_{2}$ production:

$0.16 \mathrm{NO}_{3}^{-}+0.96 \mathrm{H}^{+}+0.8 \mathrm{e}^{-} \rightarrow 0.08 \mathrm{~N}_{2}+0.48 \mathrm{H}_{2} 0$

$20 \%$ electron flow coupled to biomass synthesis:

$0.036 \mathrm{CO}_{2}+0.007 \mathrm{NO}_{3}{ }^{-}+0.207 \mathrm{H}^{+}+0.2 \mathrm{e}^{-} \rightarrow 0.007 \mathrm{C}_{5} \mathrm{H}_{7} \mathrm{O}_{2} \mathrm{~N}+0.079 \mathrm{H}_{2} 0$

Balanced equation:

$0.125 \mathrm{CH}_{3} \mathrm{COO}^{-}+0.167 \mathrm{NO}_{3}^{-}+0.292 \mathrm{H}^{+} \rightarrow 0.007 \mathrm{C}_{5} \mathrm{H}_{7} \mathrm{O}_{2} \mathrm{~N}+0.08 \mathrm{~N}_{2}+0.309 \mathrm{H}_{2} 0+0.214 \mathrm{CO}_{2}$

The balanced equation can be applied to estimate volumetric gas production in the Williams study. The balanced equation shows that $27 \%$ of the total gas produced is $\mathrm{N}_{2}$, with the remainder being the highly soluble $\mathrm{CO}_{2}$. Considering the above stoichiometry (note that $96 \%$ of the nitrate is converted to $\mathrm{N}_{2}$ when $80 \%$ of the electron flow is dissimilatory), and the pore volume $\left(276 \mathrm{~cm}^{3}\right)$ and concentrations of acetate and nitrate (36.6 mM and $23.5 \mathrm{mM}$ respectively) used in the Williams column study, $70 \mathrm{~cm}^{3}$ of $\mathrm{N}_{2}$ would have been produced at standard pressure. Assuming all $\mathrm{CO}_{2}$ was soluble and all $\mathrm{N}_{2}$ was insoluble, $70 \mathrm{~cm}^{3}$ of $\mathrm{N}_{2}$ is equivalent to $25 \%$ of the porous media bed volume.

The Williams study also used the most probable number (MPN) enrichment method to estimate the total number of cells in the column at the end of the experiment. The mean population of cells was $1.5 \times 10^{8}$ cells per gram wet weight, which represented at least one order of magnitude of growth (compared to the population assumed to have attached in the column during inoculation) and was $70 \%$ of the expected growth based on the full utilization of nitrate and the balanced equation. The MPN method is known to underestimate biomass by as much as a factor of two, so the actual value was probably much closer to $100 \%$. This calculation demonstrated that the yield of biomass fell closely in line with the balanced equation, and thus the estimated $\mathrm{N}_{2}$ production in the experiment was also likely to be in accordance with the balanced equation.

\section{A.3 Experimental Design}

\section{A.3.1 Adapting Bacteria to Required Nutrient Concentrations}

One of the objectives of future strong-sludge gas retention experiments is to use microbial metabolism to slowly produce insoluble $\mathrm{N}_{2}$ gas. The target for a gas retention experiment is to produce 1 unit volume of insoluble $\mathrm{N}_{2}$ from the same unit volume of starting slurry containing solids, bacteria, and nutrients dissolved in water. This amount of gas is typically sufficient to determine the maximum gas retention for a slurry, particularly for slurries and conditions that give a relatively low maximum gas retention of about $10 \mathrm{vol} \%$ retained gas. To achieve this target, 1 liter of slurry must produce 44.63 millimoles of $\mathrm{N}_{2}$ gas (equivalent to 1 liter $\mathrm{N}_{2}$ gas). Using the $95.8 \%$ conversion of nitrate to $\mathrm{N}_{2}$, 93.20 millimoles of nitrate ( $7.92 \mathrm{~g}$ sodium nitrate) must be consumed per liter of slurry. This amount of nitrate consumption requires 69.76 millimoles of acetate ( $5.72 \mathrm{~g}$ sodium acetate). To account for possible deviations from the balanced stoichiometric equation, to make sure nitrate is not limiting, and to account 
for oxygen in the system (see below) that will require acetate consumption prior to the coupling of acetate to nitrate reduction, the concentrations of acetate and nitrate should be increased by $25 \%$ and $5 \%$, respectively. Thus, to produce the target of 1 liter $\mathrm{N}_{2}$, we need to supply 87 millimoles acetate and 98 millimoles nitrate per liter of slurry.

No literature is available on whether these concentrations are inhibitory or toxic to $P$. stutzeri strain KC. However, these concentrations are typically inhibitory and/or toxic in other bacteria. While lower concentrations could be used combined with periodic resupply of nutrients, this requires pumping and a major and time-consuming modification of our test system, and has therefore been ruled out. Another approach would be to use lower concentrations and continuously supply nutrients by diffusion across a membrane at the bottom of the column or column annulus. There are numerous reasons this approach is untenable, and this approach was likewise ruled out.

Therefore, our strategy is to conduct solution-only batch tests at a variety of concentrations ranging between $36.6 \mathrm{mM}$ acetate and $23.5 \mathrm{mM}$ nitrate in standard Medium D denitrifying medium (Tatara et al., 1993) and denitrifying medium containing the required $87 \mathrm{mM}$ acetate and $98 \mathrm{mM}$ nitrate, to determine the degree to which inhibition or toxicity occurs at each concentration. A moderate inhibition of growth resulting in an acceptable decrease in the rate of bubble production is acceptable, but severe inhibition or toxicity will result in the experiments proceeding too slowly or to an ineffective endpoint. If severe inhibition or toxicity occurs at $87 \mathrm{mM}$ acetate and $98 \mathrm{mM}$ nitrate, we will adapt $P$. stutzeri strain $\mathrm{KC}$ to this concentration over time by growing cultures serially in medium with gradually higher concentrations of nutrients. Reaching $50 \%$ of the $87 \mathrm{mM}$ acetate and $98 \mathrm{mM}$ nitrate target is highly likely, and $75 \%$ or better is possible. Even if we were only able to reach $50 \%$ of the target concentrations, then 0.5 liter (rather than 1 liter) $\mathrm{N}_{2}$ would be produced per liter of slurry, which would still enable tests to reach up to $30 \%$ gas void fraction should retention this high occur.

\section{A.3.2 Growth of Bacteria and Inoculation of Columns}

P. stutzeri strain KC can be grown with either oxygen or nitrate as the electron acceptor. For ease of processing and inoculating large volumes of cells, initial cell cultures will be inoculated into sterile Medium D containing acetate and nitrate and grown with an aerobic headspace and shaking in 10\% tryptic soy broth to stationary phase. Cells will be centrifuged and washed under sterile conditions to remove nutrients, and resuspended in an appropriate volume of sterile Medium D containing acetate and nitrate. In any given experiment, the volume of medium to be used for resuspension will be calculated based upon the desired solid:liquid ratio of the slurry and a starting concentration of $1 \times 10^{7}$ cells per gram of slurry. Solids will be autoclaved and the slurry prepared under sterile conditions.

The cell suspension and solids will be mixed into a slurry and loaded into columns under aerobic conditions according to the protocol in our most recent tests, with the exception that the columns and loading procedure will be conducted in a manner that excludes entry of microbial contaminants that could compete with $P$. stutzeri strain KC. To further exclude microbial contaminants and greatly minimize any diffusion of oxygen into the column over the course of the experiment, the column headspace will be flushed with filter-sterile nitrogen or argon gas (through a toggled fitting added to the column cap), $\mathrm{CO}_{2}$ sparged filter-sterile water will then be pumped into the column headspace through the same fitting, and a 0.2 micron pore size filter will be placed in the poly tubing where it enters the column headspace. 
Given the volumes of slurry being handled, it is impractical to exclude oxygen during slurry preparation and column loading. However, before $P$. stutzeri strain $\mathrm{KC}$ begins using nitrate, it will remove the oxygen initially entrained in the column slurry. The molar amount of oxygen entrained in the column will be at most a few $\%$ of the molar amount of nitrate, having minimal impact on acetate consumption and a minimal increase in the lag time before significant $\mathrm{N}_{2}$ gas generation occurs.

\section{A.3.3 Scoping Tests}

Scoping tests will be conducted with a microbiologist to perfect the sterility protocols. Scoping tests will also determine the kinetics of gas displacement in the system. Kinetics can be sped up or slowed down to meet experimental objectives by adjusting the concentration of cells inoculated per gram of slurry.

\section{A.4 References}

Madigan MT, JM Martinko, and J Parker. 2000. "Biochemistry of Dissimilative Nitrate Reduction," Chapter 15 in Brock Biology of Microorganisms, DM Sylvia, JJ Fuhrmann, PG Hartel, and DA Zuberer (Editors), Prentice-Hall, Upper Saddle River, New Jersey.

Nazaroff WW and L Alvarez-Cohen. 2001. "Transformation Processes," Chapter 3 in Environmental Engineering Science, John Wiley and Sons, New York, New York.

Rittmann BE and PL McCarty. 2001. "Stoichiometry and Bacterial Energetics," Chapter 2 in Environmental Biotechnology: Principles and Applications, McGraw-Hill, New York, New York.

Tatara GM, MJ Dybas, and CS Criddle. 1993. "Effects of Medium and Trace Minerals on Kinetics of Carbon Tetrachloride Transformation by Pseudomonas sp. Strain KC." Applied and Environmental Microbiology 59(7):2126-2131.

Van Kessel T and WGM van Kesteren. 2002. "Gas Production and Transport in Artificial Sludge Depots.” Waste Management 22(1):19-28, DOI: 10.1016/S0956-053X(01)00021-6.

Williams KH. 2002. "Monitoring Microbe-Induced Physical Property Changes Using High-Frequency Acoustic Waveform Data: Toward the Development of a Microbial Megascope." Master's thesis, LBNL-50692. Ernest Orlando Lawrence Berkeley National Laboratory, Berkeley, California. 


\section{Distribution}

No. of

Copies

\section{OFFSITE}

N Machara

EM-31

US Department of Energy

20400 Century Blvd

Germantown, MD 20874

P Mallick

EM-31

US Department of Energy

20400 Century Blvd

Germantown, MD 20874

SL Marra

Savannah River National Laboratory

Savannah River Site

Aiken, SC 29808

S Schneider

EM-31

US Department of Energy

20400 Century Blvd

Germantown, MD 20874

JH Scogin

Savannah River National Laboratory

Savannah River Site

Aiken, SC 29808
No. of

Copies

ONSITE

3 DOE Office of River Protection

TW Fletcher, H6-60

SH Pfaff H6-60

JS Shuen H6-60

3 Washington River Protection Solutions

WB Barton $\quad$ S7-90

NW Kirch R2-58

JE Meacham R2-58

14 Pacific Northwest National Laboratory

FJ Brockman J4-16

WC Buchmiller K6-24

PA Gauglitz (5) K7-15

LA Mahoney K7-15

TE Michener K7-15

AT Owen K6-81

RA Peterson P7-22

SD Rassat K6-28

BE Wells K7-15

Project Records (MG Champion) K3-52 




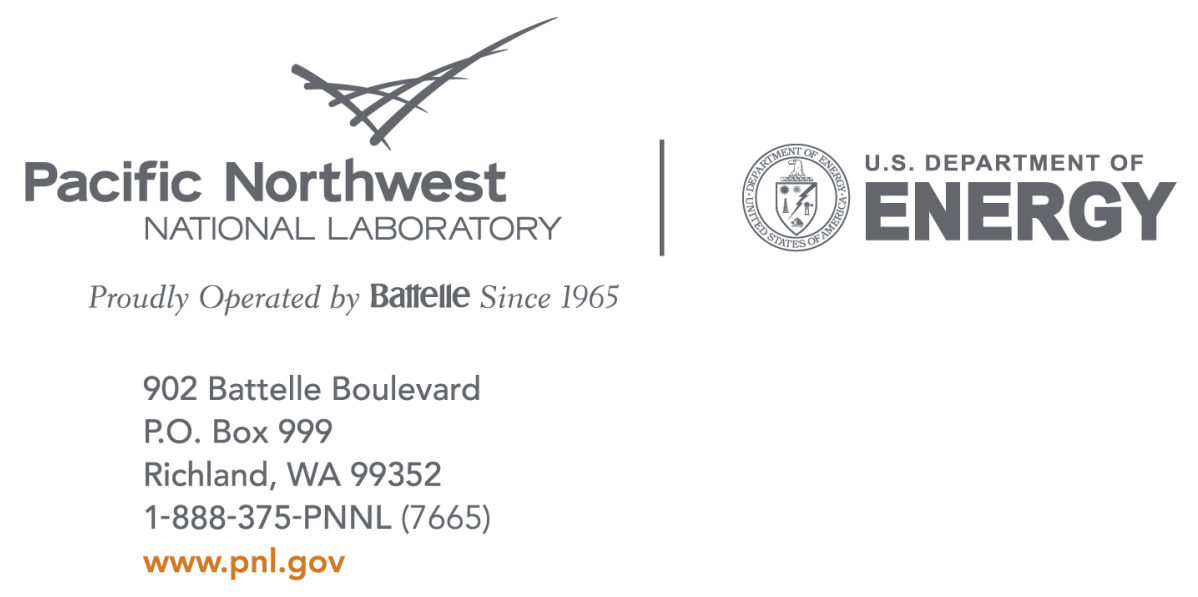

